\title{
Indexação de Dados em Domínios Métricos Generalizáveis 1
}

\author{
Ives Renê Venturini Pola \\ ives@icmc.usp.br \\ Orientador: \\ Prof. Dr. Caetano Traina Júnior \\ caetano@icmc.usp.br
}

Dissertação de mestrado apresentada ao Instituto de Ciências Matemáticas e de Computação - ICMC/USP, como parte dos requisitos para a obtenção do título de Mestre em Ciências de Computação e Matemática Computacional

USP - São Carlos

Maio de 2005

\footnotetext{
${ }^{1}$ Este trabalho tem o apoio financeiro do CNPq (Conselho Nacional de Desenvolvimento Científico e Tecnológico).
} 
Indexação de Dados em Domínios Métricos Generalizáveis 
"Dedica-te ao trabalho em que te sustentes, sem desprezar a pausa de repouso ou o entretenimento em que te restaurem as energias."

(Emmanuel, em Tensão Emocional) 
Dedico este trabalho aos meus pais, Izes e Osmar, que sempre me motivaram e apoiaram em todas as minhas decisões, à minha irmã Isis, que mesmo longe tentou caminhar ao meu lado e ao meu orientador e amigo Caetano, que sempre me ajudou a resolver os problemas nas horas mais difíceis.

Ives Renê Venturini Pola 


\section{Agradecimentos}

Agradeço aos meus pais, pelo amor, educação, carinho e atenção dados a mim, sempre que eu precisei. À minha irmã, pelo carinho e apoio, mesmo a distância.

Ao meu orientador e amigo, Prof. Dr. Caetano Traina Júnior, sempre paciente e motivador, pela confiança e apoio que sempre demonstrou a mim.

À Prof. Dra. Agma Juci Machado Traina, pela ajuda e aconselhamento, além da tranquilidade que sempre me passou.

Aos meus amigos de laboratório: Odnei, Humberto, Enzo, Camilla, Andre, Luis M., Marcela, Monica, Marcos, Adriano e Tiago.

À minha namorada Fernanda Paula Barbosa, que com todo seu amor me fortalece e me dá um sentido novo na vida. 
Lista de Figuras

$\begin{array}{lll}\text { Lista de Tabelas } & \text { v }\end{array}$

Lista de Abreviaturas vi

Lista de Símbolos vii

Resumo viii

Abstract ix

\begin{tabular}{lll}
\hline & Introdução & $\mathbf{1}$
\end{tabular}

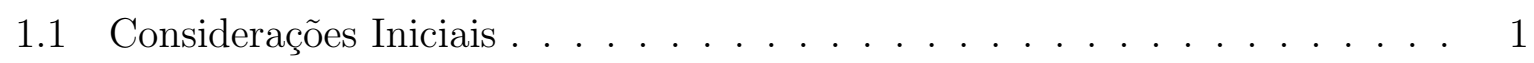

1.2 Histórico . . . . . . . . . . . . . . . . . . . . . . . . . . . . 2

1.3 Métodos de Acesso . . . . . . . . . . . . . . . . . . . . . . 4

1.4 Objetivos $\ldots \ldots \ldots \ldots \ldots \ldots \ldots \ldots$

1.5 Organização do documento . . . . . . . . . . . . . . . 6

2 Conceitos Preliminares $\quad 8$

2.1 Introdução . . . . . . . . . . . . . . . . . . . . . . . . . . . . . . . 8

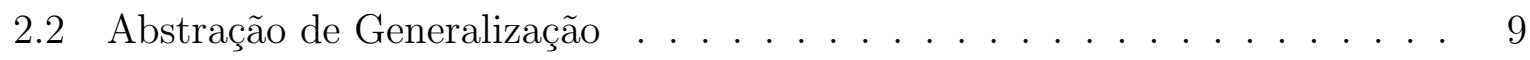

2.3 Espaço Métrico . . . . . . . . . . . . . . . . . . . . . . . . . . . . . . . 10

2.4 Consultas por Similaridade . . . . . . . . . . . . . . . . . . . . . 12

2.5 Aplicações . . . . . . . . . . . . . . . . . . . . . . . . . . . . . . 14

2.6 Conclusão $\ldots \ldots \ldots \ldots \ldots$

3 Recuperação Baseada em Conteúdo 16

3.1 Introdução . . . . . . . . . . . . . . . . . . . . . . . 16

3.2 Extratores de Características . . . . . . . . . . . . . . . . . . . . . . . . . . . 19

3.2 .1 Atributos visuais . . . . . . . . . . . . . . . . . . 20

3.3 Métodos de Acesso Métricos . . . . . . . . . . . . . . . . . . . . . . 24 


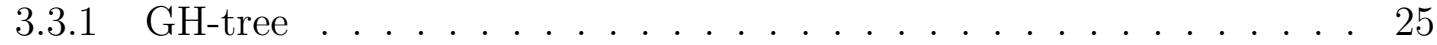

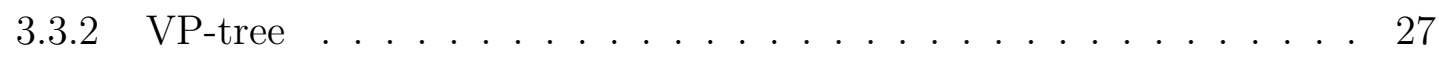

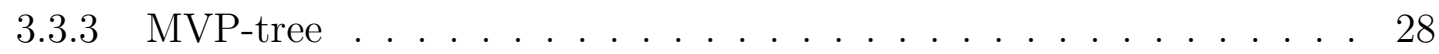

3.3 .4 MM-tree . . . . . . . . . . . . . . . . . . . . . . . . . . . . 29

$3.3 .5 \quad$ M-tree . . . . . . . . . . . . . . . . . 33

3.3 .6 Slim-tree . . . . . . . . . . . . . . . . . . . . . . . 36

$3.3 .7 \quad$ Família $O M N I \ldots \ldots \ldots$. . . . . . . . . . . . . . . . 41

3.4 Análise da recuperação de dados . . . . . . . . . . . . . . . . . . . 44

$3.4 .1 \quad$ Precision and Recall . . . . . . . . . . . . . . . . . 45

3.5 Conclusão . . . . . . . . . . . . . . . . . . . . 46

4 Domínio Métrico Generalizável 48

4.1 Introdução . . . . . . . . . . . . . . . . . . . . . . . . . 48

4.2 Motivação $\ldots \ldots \ldots \ldots$

4.3 O Domínio Métrico Generalizável . . . . . . . . . . . . . . . . . . . 50

$4.3 .1 \quad$ Múltiplas Características . . . . . . . . . . . . . . . . . . 52

4.3 .2 Múltiplas Funções de Distância . . . . . . . . . . . . . . . 54

4.3 .3 Função de Distância Adaptativa . . . . . . . . . . . . . . . . 55

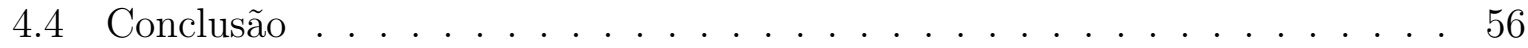

$\begin{array}{lll}5 & \text { Experimentos e Resultados } & 58\end{array}$

5.1 Introdução $\ldots \ldots \ldots \ldots \ldots \ldots \ldots \ldots \ldots \ldots$

5.2 Base de Dados e Métricas Utilizadas $\ldots \ldots \ldots \ldots$. . . . . . . 58

5.3 Gráficos Precision and Recall . . . . . . . . . . . . . . . . . 60

5.4 Medidas de Desempenho e Escalabilidade . . . . . . . . . . . . . . . 62

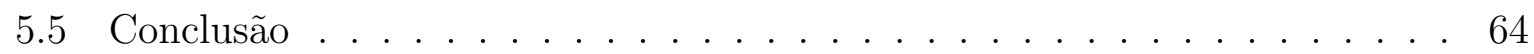

\begin{tabular}{lll}
\hline & Conclusão & 67
\end{tabular}

6.1 Propostas de Trabalhos Futuros $\ldots \ldots \ldots \ldots$ 


\section{Lista de Figuras}

2.1 Exemplo de abstração de generalização. . . . . . . . . . . . . . . . . . . . . 9

$2.2 \quad$ Formas geométricas geradas de acordo com a métrica $L_{p}$ utilizada. . . . . . 12

2.3 Exemplo de consulta por abrangência. . . . . . . . . . . . . . . . . . 13

$2.4 \quad$ Exemplo de consulta por vizinhos mais próximos, $\mathrm{k}=4 . \quad$. . . . . . . . . . 13

3.1 Utilização da desigualdade triangular para podar cálculos de distância. . 19

3.2 Exemplo de matrizes de co-ocorrência . . . . . . . . . . . . . . . . . 22

3.3 Decomposição do espaço na GH-tree . . . . . . . . . . . . . . . . . 26

3.4 Decomposição do espaço na VP-tree. . . . . . . . . . . . . . . . . 27

3.5 Exemplo de uma mvp-tree binária em $\left(\mathbf{R}^{2}, L_{2}\right)$. . . . . . . . . . . . . 30

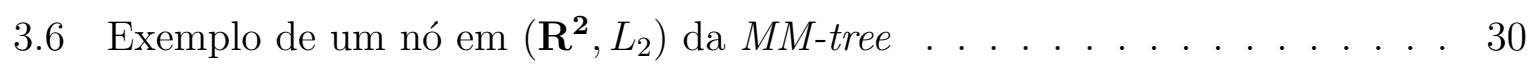

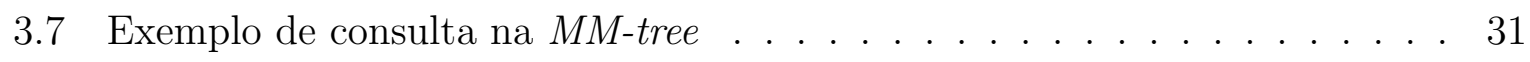

3.8 Balanceamento exaustivo na $M$ M-tree. . . . . . . . . . . . . . . . . . . . . 32

3.9 Particionamento em $\left(\mathbf{R}^{\mathbf{2}}, L_{2}\right)$ de um nó na M-tree. Figura tirada de [28] . . 34

3.10 Exemplo estrutural da Slim-tree indexando palavras usando uma métrica

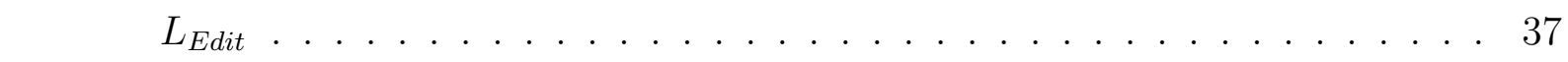

3.11 Exemplo de particionamento na Slim-tree usando o algoritmo $M S T$. . . . 38

3.12 Exemplo de duas árvores indexando o mesmo conjunto de dados, com diferente número de nós e absolute fat-factors . . . . . . . . . . . . . . . . . . 39

3.13 Exemplo de aplicação do algoritmo Slim-down . . . . . . . . . . . . . . 40

3.14 Exemplo de utilização de múltiplos representantes globais em consultas. . . 42

3.15 Exemplo de escolha dos omni-foci. . . . . . . . . . . . . . . . 42

3.16 Utilização de múltiplos representantes globais com a Slim-tree. . . . . . . . 44

3.17 Exemplo de um gráfico Precision and Recall . . . . . . . . . . . . . . . . . 45

3.18 Conjuntos de resultados possíveis. . . . . . . . . . . . . . . . 46

4.1 Exemplo de generalização em imagens. . . . . . . . . . . . . . . . . . 51

4.2 Classes e Sub-classes . . . . . . . . . . . . . . . . . . . . . . . . . . 51

4.3 Exemplo de projeção de características. . . . . . . . . . . . . . . . . 52

4.4 Exemplo de abrangência de funções de distância usando a família $L_{p}$. . . 55 
5.1 Classificação das imagens utilizadas por cortes e orgãos . . . . . . . . . . . 59

5.2 hierarquia $\ldots \ldots \ldots \ldots \ldots \ldots \ldots \ldots$

5.3 Gráficos Precision and Recall para as diferentes classes de imagens. . . . . 61

5.4 Gráficos de desempenho para consultas do tipo KNNQ(a,c,e) e RQ(b,d,f). . 63

5.5 Gráficos de escalabilidade para consultas do tipo KNNQ(a,c,e) e RQ(b,d,f). 65 


\section{Lista de Tabelas}

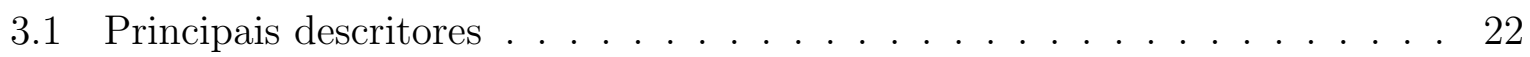

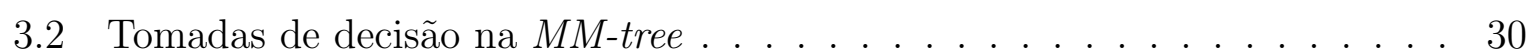

3.3 Condições de intersecções em consultas na MM-tree . . . . . . . . . . . . . 31

$5.1 \quad$ Associação de uma métrica a cada classe de imagem. . . . . . . . . . . . . 59 


\section{Lista de Abreviaturas}

SGBD Sistema Gerenciador de Bases de Dados.

MA Método de acesso

MAM Método de acesso métrico

DMG Domínio Métrico Generalizável

GMAM Método de Acesso Métrico Generalizado

SQL Structured Query Language

RM Ressonância Magnética

TC Tomografia Computadorizada

FDA Funçao de Distância Adaptativa 


\section{Lista de Símbolos}

$\begin{array}{ll}\mathbb{M}<\mathbb{S}, d> & \text { Domínio métrico } \\ \mathbb{S} & \text { Domínio de objetos que seguem propriedades específicas } \\ S & \text { Instância de } \mathbb{S} \text {, armazenado na base de dados, } S \subseteq \mathbb{S} \text {. } \\ d: \mathbb{S} \times \mathbb{S} \rightarrow \mathbb{R}^{+} & \text {Função de distância } \\ s_{i} & \text { Objeto do domínio, } s_{i} \in S \\ E & \text { Dimensão de um domínio vetorial } \\ a=\left\{a_{1}, a_{2}, \ldots, a_{E}\right\} & \text { Elemento de um espaço vetorial } E \text {-dimensional } \\ a_{i} & \text { Valor do elemento a na dimensão } i \\ K N N Q & \text { Consulta aos } k \text { vizinhos mais próximos } \\ k & \text { Número de vizinhos em uma consulta kNNq } \\ R Q & \text { Consulta por abrangência }\end{array}$

Convenção de formatação:

Itálico: Foi utilizado para indicar palavras provenientes de língua estrangeira.

Negrito: Foi utilizado na definição de termos e na enfatização de palavras. 
POLA, I. R. V. Indexação de Dados em Dominios Métricos Generalizáveis São Carlos, 2005. Monografia de Conclusão de Mestrado - Instituto de Ciências Matemáticas e de Computação - ICMC, USP.

\section{RESUMO}

Os sistemas Gerenciadores de Bases de Dados (SGBDs) foram desenvolvidos para manipular domínios de dados numéricos e/ou pequenas seqüencias de caracteres (palavras) e não foram projetados prevendo a manipulação de dados complexos, como por exemplo dados multimídia. Os operadores em domínios de dados que requisitam a relação de ordem têm pouca utilidade para manipular operações que envolvem dados complexos. Uma classe de operadores que se adequa melhor para manipular esses dados são os operadores por similaridade: consulta por abrangência ("range queries") e consulta de vizinhos mais próximos ("k-nearest neighbor queries"). Embora muitos resultados já tenham sido obtidos na elaboração de algoritmos de busca por similaridade, todos eles consideram uma única função para a medida de similaridade, que deve ser universalmente aplicável a todos os pares de elementos do conjunto de dados. Este projeto propõe explorar a possibilidade de trabalhar com estruturas de dados concebidas dentro dos conceitos de dados em domínios métricos, mas que admitam o uso de uma função de distância adaptável, ou seja, que mude para determinados grupos de objetos, dependendo de algumas características universais, e assim permitindo acomodar características que sejam particulares a algumas classes de imagens e não de todo o conjunto delas. Isso irá permitir reduzir o conjunto de características úteis de cada elemento do conjunto de dados individualmente, baseando-se nos valores obtidos para uma ou algumas poucas características a serem extraídas em primeiro lugar. A partir desses valores, poder-se-á então decidir quais outras características são importantes para esse elemento de dado em particular. 


\begin{abstract}
The DBMS were developed to manipulate data in numeric domains and short strings, not considering the manipulation of complex data, like multimidia data. The operators em data domain which requests for the total order property have no use to handle complex data. An operator class that fit well to handle this type of data are the similarity operators: range query and nearest neighbor query. Although many results have been shown in research to answer similarity queries, all use only one distance function to measure the similarity, which must be applicable to all pairs of elements of the set. The goal of this work is to explore the possibility of deal with complex data in metric domains, that uses a suitable distance function, that changes its behavior for certain groups of data, depending of some universal features, allowing them to use specific features of some classes of data, not shared for the entire set. This flexibility will allow to reduce the set of useful features of each element in the set individually, relying in the values obtainded for one or few features extracted in first place. This values will guide the others important features to extract from data.
\end{abstract}




\section{Capítulo \\ 1 \\ Introdução}

\subsection{Considerações Iniciais}

Um dos principais suportes com o qual um sistema gerenciador de bases de dados conta para agilizar as operações de busca é o sistema de índices criado por seus métodos de acesso. Então, o projeto de métodos de acesso eficientes tem sido muito pesquisado na área de bases de dados. Além disso, o volume de dados armazenado vem crescendo muito e tais dados se tornando mais complexos, necessitando maior custo computacional e ocupando mais espaço nos SGBDs. Algumas aplicações que exemplificam tal fato são: dados multimídia (imagem, vídeo, audio, textos longos), séries temporais, dados de telemetria, informações geográficas, seqüencias de proteínas e DNA (Ácido Desoxirribonucléico).

A técnica utilizada para recuperar, de modo eficiente, dados armazenados em bases de dados é a utilização de Métodos de Acesso (MA), também conhecidos como estruturas de indexação. Foram desenvolvidos ótimos métodos para dados simples, mas continuamente novas aplicações lidam com tipos de dados mais complexos, e nem sempre estes podem ser indexados pelos métodos existentes pois estes não provém o tipo de consulta desejado ou o desempenho não é aceitável. Portanto são necessárias novas estruturas de indexação voltadas para tipos de dados complexos.

Os SGBDs tradicionais indexam domínios de dados que têm relação de ordem total entre os seus elementos, como os números e pequenos textos. Isto permite a estes sistemas fornecer um suporte eficiente a consultas por igualdade e por abrangência, onde usualmente utilizam métodos de acesso tais como as árvores $B$-trees [29] e suas variantes. No entanto, quando os elementos do domínio de dados não possuem relação de ordem total, como a maioria dos dados complexos, esses métodos não podem ser utilizados. Por exemplo, não se pode definir que uma imagem está à esquerda ou vem antes de outra. Assim, novos MA foram desenvolvidos para suportar consultas sobre tais dados.

Consultas em um domínio de dados complexo são por natureza diferentes das que 
se fazem em domínios de dados tradicionais. Em domínios complexos faz mais sentido realizarem-se consultas por similaridade de objetos. As consultas por similaridade retornam usualmente a identificação dos objetos mais semelhantes ao objeto de referência da consulta. Além disso, como as operações de comparação em dados complexos são usualmente muito caras, em geral extraem-se características que descrevam adequadamente cada objeto.

As operações de comparação entre objetos complexos são feitas através de comparações nas características extraídas dos objetos. A extração de características é feita utilizandose procedimentos automáticos para a geração de medidas, em geral representadas como valores numéricos [76]. Exemplos em um domínio de imagens são histogramas, medidas de textura, descritores de forma e outras medidas específicas dos domínios de aplicação de imagens. Usualmente, cada característica extraída é quantitativa, representada como um valor numérico ou uma coleção deles. Cada elemento do conjunto pode ser visto como um elemento de um conjunto de um domínio de dados espacial, no qual cada característica corresponde a uma dimensão desse espaço. Através dessa perspectiva, um conjunto de dados multimídia pode ser visto como um conjunto de dados de um domínio espacial, e estruturas de indexação espacial podem ser utilizadas para indexar o conjunto, agilizando a obtenção de consultas de seleção nesse conjunto. Em aplicações envolvendo imagens médicas, por exemplo, consultas por exames semelhantes a um determinado exame pode ser interessante para auxiliar o diagnóstico, baseando-se em casos semelhantes, facilitando a identificação de patologias.

\subsection{Histórico}

É comum o uso de estruturas para localização/recuperação de dados, e desde o princípio da era da informática buscam-se meios eficientes para realizar esta tarefa, tendo sido desenvolvidas estruturas muito boas. Uma primeira abordagem para resolver o problema de busca em um conjunto de dados pode envolver a criação de um arquivo onde os dados estão dispostos seqüencialmente, o que é suficiente quando se manipulam pequenas quantidades de informações. Mas, quando lida-se com grandes quantidades de informações, este tipo de organização leva a consultas muito demoradas. Supondo que o item a ser procurado não exista, então o algoritmo deve percorrer todo o arquivo para descobrir isso.

Assim sendo, é necessária a criação de estruturas especialmente desenvolvidas para localizar os objetos armazenados. Como já mencionado, inicialmente houve a criação de estruturas para indexar objetos simples, como números e caracteres, ou seja, domínios de dados que possuam a relação de ordem total entre os elementos. Estruturas para esses domínios possuem um ótimo desempenho e uma complexidade pequena, sendo por isso muito utilizadas. Mas o problema deste tipo de indexação está no tipo de objeto suportado pela estrutura, uma vez que nem sempre o objeto a ser indexado é um simples número, mas uma coleção destes. Coleções de números não apresentam a propriedade de 
relação de ordem total. Para coleções de números em que todo elemento de dado tiver o mesmo número de elementos (dimensão), criaram-se as estruturas de indexação ditas pontuais. Desta vez o problema se situa no grau de complexidade que estas estruturas podem chegar ao se tratar certos tipos de objetos, quando ainda conseguem suportar sua indexação. Para melhorar o desempenho e aceitar mais tipos de objetos desenvolveram-se estruturas para indexar dados espaciais, onde se utilizam estruturas geométricas multidimensionais (hipercircunferências, hiper-retângulos, hipercubos etc.) para indexar os objetos [36].

Infelizmente, a grande maioria dos métodos de acesso espaciais foi desenvolvida para operar eficientemente em espaços de relativamente baixa dimensionalidade [52]. E é fato amplamente reconhecido que a maioria dos métodos de indexação espaciais se tornam muito ineficientes para dimensões maiores do que 10 ou 20 [3]. Por outro lado, um vetor de características de imagens, dependendo dos métodos extratores de características utilizados, pode facilmente ultrapassar uma ou duas ordens de grandeza esses valores. Devido a isso, tem havido bastante interesse e trabalhos dedicados a reduzir a dimensionalidade desses conjuntos de dados [1].

Todos os trabalhos de redução de dimensionalidade de que temos conhecimento apoiam-se em técnicas de processamento numérico ou redes neurais e quase todos reduzem a dimensionalidade do conjunto de dados como um todo [64] [63] [82] [51] [22]. Essa redução global da dimensionalidade de todo o conjunto é um requisito para a indexação em uma estrutura única de dados - todos os elementos do conjunto de dados devem ser acessíveis utilizando-se a mesma "chave" de indexação.

Métodos de acesso espaciais podem ser usados para se realizarem buscas por similaridade, pois muitas das características extraídas dos elementos do domínio de dados, por exemplo de imagens, podem ser indexadas por tais métodos [39] [71] [21]. O ponto é que tais características atingem facilmente uma dimensão alta, a ponto de degradar violentamente o desempenho destes métodos em buscas por similaridade. Tal deficiência é conhecida como a "maldição da dimensionalidade" (dimensionality curse). Assim sendo, métodos de acesso especializados foram propostos para lidar com altas dimensões de dados, como as árvores $X$-tree [7], SR-tree [49] e TV-tree [59], ainda assim sendo limitadas pelo espaço onde são concebidas.

Estas estruturas são otimizadas para responder a consultas dentro do domínio de dados espaciais. No entanto, em domínios de dados mais complexos, como os dados multimídia, os dados não possuem relação de ordem total e tampouco é possível gerar vetores de características onde todos os objetos complexos gerem vetores sempre com a mesma dimensão $E$. Nestes domínios, a similaridade entre os elementos é o fator mais importante. Portanto, os métodos de acesso métrico são ideais para responderem este tipo de consulta, uma vez que são construídas diretamente sobre medidas de similaridade entre os objetos e possuem mecanismos matemáticos para realizar podas com base nas distâncias. 
Porém, estruturas de indexação concebidas no espaço métrico, onde se utilizam de uma função de distância métrica que mede a dissimilaridade entre os elementos do domínio, são mais naturais para estes domínios. Além disso, tais estruturas utilizam axiomas métricos que podem reduzir o número de cálculos de distância em operações na estrutura, bem como inserção ou buscas, uma vez que estes cálculos são altamente custosos computacionalmente.

\subsection{Métodos de Acesso}

Um Método de Acesso (MA) é um dos principais recursos dos SGBDs para um maior desempenho na recuperação dos dados armazenados. O conceito fundamental que embasa um MA é o uso de determinadas propriedades existentes nos objetos indexados. Através dessas propriedades é possível descartar um subconjunto dos dados sem compará-los entre si, utilizando somente a comparação entre um dos objetos indexados e o objeto de referência para a consulta. Por exemplo, considere dados numéricos mantidos de maneira ordenada: neste caso a propriedade utilizada é a relação de ordem total entre os números (o número 5 é menor que 7, que por sua vez é menor que 10). Neste caso qualquer número de referência separa um subconjunto em duas partes: os que são menores e os que são maiores que a referência. Quando se deseja procurar por um determinado número de referência, compará-lo com qualquer número indexado permite descartar uma das partes que o número indexado define.

Uma classe de métodos de acesso muito comum, baseada numa estrutura hierárquica, é chamada de árvore, adotando um processo recursivo para a indexação dos dados. Nesta classe os objetos são divididos em blocos, geralmente chamados de nós, onde para cada nó é escolhido um ou mais objetos, chamados de objetos representantes (ou apenas representantes do nó) que podem ser utilizados para representar todos os objetos hierarquicamente abaixo daquele nó. Os nós que armazenam os objetos originais são chamados de nós folhas, embora em algumas árvores estáticas nem todos os objetos estejam nas folhas. Os objetos representantes são por sua vez agrupados em outros nós, chamados de nós internos da árvore. De cada nó interno é escolhido também um representante, criando-se um novo nível (ou camada) de nós internos, e assim sucessivamente novos níveis vão sendo acrescentados, até que em um determinado nível apenas um nó seja necessário. Este nó é então chamado de nó raiz e o processo termina. Quando for necessário realizar uma consulta nesta estrutura, compara-se o objeto de busca com os objetos representantes da raiz, e com isso determinam-se as subárvores que precisam ser avaliadas para prosseguir com o processo de consulta.

Note-se que se for possível estabelecer uma relação de ordem total entre os objetos, através da propriedade adotada para a comparação entre pares de objetos, apenas uma subárvore precisa ser avaliada em cada nível nas buscas. Caso a propriedade estabeleça uma relação de ordem parcial, então pode ser necessário avaliar mais de uma subárvore em 
cada nível. Por exemplo, a relação de ordem numérica em domínios numéricos ou a relação de ordem lexicográfica em domínios de cadeias de caracteres são relações de ordem total e, portanto, árvores criadas usando essas propriedades são consultadas avaliando apenas um nó em cada nível da estrutura. Já árvores construídas usando como propriedade a relação de ordem entre cada uma das coordenadas de um domínio espacial não é uma relação de ordem total, portanto pode ser necessário avaliar mais do que uma subárvore em cada nível da estrutura.

Existem diversas variações possíveis para a criação de árvores. Por exemplo, quando se escolhe um objeto para ser o representante de um nó, esse objeto pode ser mantido no nó onde ele já estava ou não. Caso ele seja mantido no nó original, todos os objetos indexados estarão nas folhas, caso contrário a recuperação de todos os objetos obriga a busca por todos os nós da árvore. A altura de um nó é o número de níveis que o separa do nó raiz. As árvores que possuem todas subárvores de cada nó sempre com a mesma altura são ditas balanceadas, caso contrário são chamadas de desbalanceadas.

Caso a altura de uma árvore seja grande, são necessários mais acessos a disco para percorrê-la, sendo então muito importante mantê-la o menos profunda possível. Uma árvore desbalanceada leva a diferentes quantidades de acessos a disco, dependendo de quais subárvores precisem ser avaliadas em cada consulta. Quando se permite que uma árvore seja desbalanceada, é possível que o desbalanceamento degenere completamente a árvore, pois em geral não se tem controle sobre como, ou quanto, a árvore fica desbalanceada. Quando existe um controle sobre o grau de desbalanceamento permitido, evita-se que a árvore degenere e esta pode ser empregada. Um exemplo de árvore não balanceada mas que mantém um grau de controle sobre o desbalanceamento admitido é a árvore AVL. No entanto, como essa é uma árvore para uso em memória principal e não em disco, ela não é utilizada em SGBDR. Assim, apenas árvores balanceadas têm sido amplamente empregadas em SGBDs.

Armazenar os nós em registros em disco é importante, pois permite a persistência e o suporte a um grande número de objetos, porém o acesso aos registros torna-se mais lento, obrigando os MA a tentar reduzir ao máximo o número de acessos a disco para responder cada consulta. Quando utilizadas como MA em SGBDRs, os nós são armazenados como registros em disco e como os objetos podem ter tamanhos diferentes, a capacidade de cada nó também varia.

\subsection{Objetivos}

Usualmente, árvores métricas indexam dados complexos, a partir das características extraídas dos dados a serem indexados. A extração de características é feita utilizando-se procedimentos automáticos para a geração de medidas, em geral representadas como valores numéricos. Exemplos em um domínio de imagens são histogramas, medidas de textura, descritores de forma e outras medidas específicas dos domínios de aplicação de 
imagens.

Acontece que, em domínios de dados complexos, é um problema definir a dissimilaridade entre os elementos do domínio, pois esta definição deve corresponder o mais próximo possível da percepção desejada. Até então, algoritmos de consulta por similaridade consideram apenas uma única função de medida de similaridade, que deve ser universalmente aplicável a todos os elementos do conjunto de dados. Isto inibe a possibilidade de aplicar algoritmos que discriminem melhor elementos específicos do conjunto, sendo necessário o uso de um outro MA para estes elementos específicos, acarretando ineficiência e propensão a erros oriundos de falsos positivos e falsos negativos das próprias estruturas.

Assim, o objetivo deste trabalho foi o desenvolvimento de uma técnica de indexação que possa utilizar mais de uma função de distância para indexar dados que estão em "um domínio métrico generalizável", sendo que este termo se refere a uma ampliação do conceito de domínios métricos, onde mais de uma função de distância pode estar definida, onde nem todas são aplicáveis a todos os elementos do conjunto.

Isso torna possível indexar conjuntos de imagens agrupados hierarquicamente, seguindo a abstração de generalização. Essa abstração, oriunda do paradigma de orientação a objetos para a modelagem de dados, estabelece que todo objeto de determinado tipo pode ser especializado em um ou mais subtipos, recursivamente, criando uma hierarquia de tipos. Nesta hierarquia, um objeto que seja de determinado subtipo é também de todos os subtipos hierarquicamente superiores. Por exemplo, um objeto de subtipo "carpinteiro" é também do subtipo "profissional", que é do tipo "pessoa".

Imagens de um determinado tipo podem apresentar características que a fazem ser de determinado subtipo, e assim também recursivamente, podendo ser especializadas. Sempre que ocorra uma especialização, características específicas são agregadas no vetor de características. Como as características específicas não ocorrem no vetor de características mais genéricas, para levar em conta as características específicas, a função de distância deve ser diferente para cada subtipo. Pormenorizando, este trabalho propõe um conceito que aplicado a um MAM, possibilita este levar em conta a possibilidade das imagens em um conjunto de dados estarem organizadas em uma abstração de generalização, possibilitando assim trabalhar com múltiplas funções de distância, admitindo que as imagens estejam em um "domínio métrico generalizável".

\subsection{Organização do documento}

Este documento apresenta a seguinte organização:

- No capítulo 2 são apresentadas as definições de espaço métrico e funções de distância métricas. São apresentados os dois tipos mais comuns de consultas por similaridade, com exemplos de aplicações;

- No capítulo 3 discorre-se sobre as principais técnicas de extração de características relatadas na literatura e são apresentadas as definições e exemplos dos principais 
métodos de acesso para dados em domínios métricos. Também são apresentadas técnicas de validação de tais métodos de acesso no aspecto qualitativo;

- No capítulo 4 é descrito o conceito proposto neste trabalho.

- No capítulo5 são mostrados os experimentos realizados e os resultados alcançados.

- No capítulo 6 é apresentada a conclusão e são apresentados os trabalhos futuros.

- E, finalmente são apresentadas as Referências Bibliográficas. 


\section{Capítulo \\ 2 \\ Conceitos Preliminares}

\subsection{Introdução}

Os SGBDs tradicionais suportam consultas onde a propriedade de relação de ordem total é utilizada como mecanismo de busca e comparação no método de acesso. Exemplo disto é quando um atributo chave de uma tabela é indexado e este é do tipo numérico, onde a partir de um número de entrada, navega-se na estrutura comparando os números indexados por igualdade. Porém, em aplicações em domínios de dados complexos, as operações dependentes da relação de ordem total não são aplicáveis, pois os objetos complexos não são ordenáveis. Mesmo as operações de igualdade são de pouca utilidade, uma vez que a probabilidade de dois objetos indexados serem iguais é muito pequena [30].

Assim, as comparações por similaridade são mais naturais nestes domínios e é o fator mais importante nas consultas. Por exemplo, em aplicações médicas, consultas como "encontre as cinco tomografias mais parecidas com esta" podem ser úteis ao diagnóstico de patologias. Tais consultas são conhecidas como Consultas Baseadas em Conteúdo (Content Based Queries) e são usualmente implementadas por métodos de acesso métricos. A semelhança entre dois objetos é determinada por uma função de distância métrica, comparando-se os objetos diretamente ou comparando as características extraídas dos mesmos.

Como este trabalho propõe indexar conjuntos de imagens que podem ser agrupados hierarquicamente de acordo com suas características, seguindo a abstração de generalização, este capítulo apresenta alguns conceitos sobre esta abstração, além de definições sobre o espaço métrico, sobre consultas por similaridade e exemplos de aplicações que as utilizam. 


\subsection{Abstração de Generalização}

A abstração de informações é uma maneira de representar as situações do mundo real em um modelo de dados. Abstrair significa representar apenas o que é importante para caracterizar e delimitar as propriedades, regras e comportamentos da informação em questão. Assim, modelos de dados são constituídos por abstrações semanticamente integradas [9].

A abstração de generalização é definida como sendo o fato de que um tipo de objeto pode abstrair o comportamento e o significado de outros tipos de objetos mais específicos. De maneira inversa, um tipo de objeto pode acrescentar detalhes a um outro tipo já definido, especializando-o, porém preservando informações herdadas pelo tipo de objeto mais genérico. Um ótimo trabalho sobre o assunto pode ser visto em [37].

O modelo de dados mais difundido e utilizado, o Modelo Entidade-Relacionamento Estendido (ME-RX), especifica alguns critérios para uma especialização, dando mais poder à modelagem. Considere uma especialização $X=\left\{s_{1}, s_{2}, \ldots, s_{n}\right\}$, onde $s_{i}$ é uma subclasse e qualquer $s_{i}$ possui a mesma superclasse $G$. Uma especialização $X$ é total sempre que $\left(U_{i=1}^{n} s_{i}\right)=G$, caso contrário ela é dita parcial. Além disso, é definida como mutuamente exclusiva sempre que $s_{i} \cap s_{j}=\emptyset$ para todo $i \neq j$, caso contrário é dita como sobreponível.

Um exemplo da abstração de generalização e sua notação pode ser vista na Figura 2.1. As entidades são indicadas por retângulos, e os atributos por círculos ligados às entidades aos quais são pertencentes. Toda especialização/generalização deve ter um atributo que define qual subclasse cada entrada irá pertencer. Na figura, este atributo é o atributo "tipo", que define qual(is) subtipo(s) uma entidade pode participar. Assim, na figura temos um tipo de entidade genérica "Pessoa" especializada em "Aluno", "Professor" e "Funcionário". Neste exemplo a especialização é total, indicada pela seta na entidade pessoa. Isto força que todo objeto do tipo pessoa deve ser necessariamente de no mínimo um subtipo. É também sobreponível, indicada pela ausência de arcos cortando as especializações, onde por exemplo, indica que pode haver uma ocorrência do tipo pessoa que seja aluno e funcionário ao mesmo tempo.

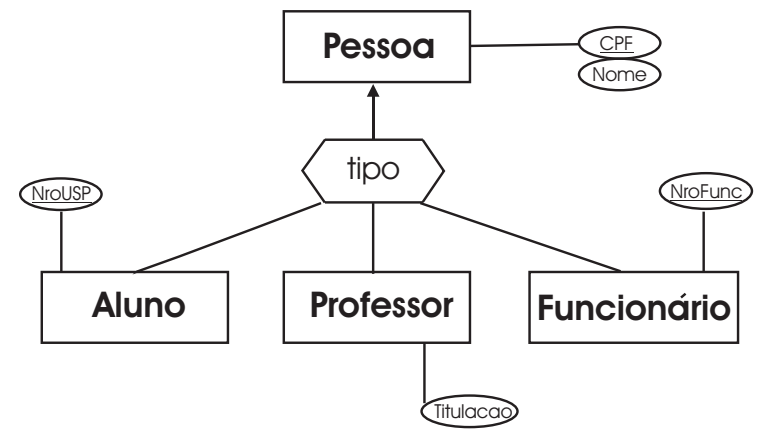

Figura 2.1: Exemplo de abstração de generalização. 


\subsection{Espaço Métrico}

Um espaço métrico é definido por $\mathbb{M}=<\mathbb{S}, d>$, onde $\mathbb{S}$ é um domínio de objetos possíveis, e $d$ é a função de distância, definida para os elementos imersos em $\mathbb{S}$. A função $d: \mathbb{S} x$ $\mathbb{S} \rightarrow \mathbb{R}^{+}$indica a distância entre dois objetos do domínio, onde quanto menor esta distância mais semelhantes eles são e vice-versa. O par $\langle\mathbb{S}, d\rangle$ é chamado um domínio métrico sempre que a função $d()$ atender às seguintes três propriedades:

1. Simetria: $d\left(s_{1}, s_{2}\right)=d\left(s_{2}, s_{1}\right)$;

2. Não negatividade: $0<d\left(s_{1}, s_{2}\right)<\infty$, para $s_{1} \neq s_{2}$ e $d\left(s_{1}, s_{1}\right)=0$;

3. Desigualdade triangular: $\left.d\left(s_{1}, s_{2}\right) \leq d\left(s_{1}, s_{3}\right)+d\left(s_{3}, s_{2}\right)\right)$.

onde $s_{1}, s_{2}, s_{3} \in \mathbb{S}$.

É importante lembrar que o espaço vetorial pode ser visto como um espaço métrico se uma função de distância métrica for definida para este domínio. Assim, o espaço métrico é capaz de englobar espaços vetoriais, bem como espaços adimensionais, desde que seja definida uma função de distância métrica.

Muitas classes de funções de distância possibilitam que seu comportamento se torne mais restritivo, dependendo de um certo parâmetro ou regra associada.

\section{Funções de distância quadráticas}

Consultas por similaridade podem ser adaptadas ao usuário utilizando-se funções de distância quadráticas [40], que podem formar consultas com raio de abrangência elipsóide, cuja forma será definida por uma matriz de similaridade $A \in \Upsilon$ definida, onde $\Upsilon$ é o espaço de todas matrizes simétricas positivas possíveis.

Por exemplo, ao indexar imagens baseando-se em histogramas de cores, o usuário pode especificar uma matriz de similaridade A. A similaridade entre dois destes histogramas então poderá ser avaliada multiplicando a diferença entre cada par de bins dos histogramas pela similaridade entre as respectivas cores. Isto leva à função de distância quadrática definida na equação 2.1 .

$$
d_{q f}[A]\left(s_{1}, s_{2}\right)=\sqrt{\left.\left(s_{1}-s_{2}\right)^{T} A\left(s_{1}-s_{2}\right)\right)}=\sqrt{\sum_{i} \sum_{j} a_{i j}\left(s_{1 i}-s_{2 i}\right)\left(s_{1 j}-s_{2 j}\right)}
$$

onde o elemento $a_{i j}$ de $A$ é a similaridade entre as cores $i$ e $j$.

\section{Família de Levenshtein}

As métricas de Levenshtein [56], conhecida como $L_{E d i t}$, são comumente utilizadas para avaliar a similaridade entre strings. Essencialmente, o parâmetro nesta família de funções 
consiste na existência ou não de pesos associados às posições nas strings. A versão sem pesos simplesmente retorna o número mínimo de operações de edições (inserções, remoções e substituições de caracteres) necessárias para transformar um cadeia de caracteres $c_{1}$ numa outra cadeia $c_{2}$. Uma característica desta métrica é que a distância mínima é zero e a máxima pode ser o tamanho da maior palavra do domínio. Porém, essa distância máxima em muitas línguas e dicionários reais dificilmente representa um valor grande. Nesse sentido, a discriminação tende a ser pequena. A versão com pesos associa a cada operação atômica de edição um peso (ou custo), tornando assim a função mais restritiva.

Outras aplicações demandam buscas por subpalavras, como no caso de bases de seqüências genômicas. Porém nesse caso, a aplicação da $L_{E d i t}$ é limitada, possibilitando o uso de outros tipos de funções mais adequadas a este domínio, como por exemplo a apresentada em [47].

\section{Família de Minkowski}

As métricas de Minkowski [84], conhecida como $L_{p}$, é usualmente empregada em espaços vetoriais. O espaço vetorial caracteriza-se por seus dados poderem serem vistos como pontos em um espaço de dimensão $E$. Por exemplo, se as características visuais de imagens forem representadas por vetores numéricos de $E$ posições, estas características terão dimensões fixas para todos os elementos do domínio, podendo então ser indexadas por árvores métricas, se uma função de distância métrica (ou apenas métrica) estiver associada ao domínio. Deste modo, é possível utilizar distâncias geométricas da família $L_{p}$ para comparar estes dados de dimensão fixa.

Suponha que $a=\left\{a_{1}, a_{2}, \ldots, a_{E}\right\}$ e $b=\left\{b_{1}, b_{2}, \ldots, b_{E}\right\}$ sejam dois vetores de dimensão $E$. A família de distâncias $L_{p}$ é definida como:

$$
L_{p}(a, b)=\left(\sum_{i=1}^{E}\left|a_{i}-b_{i}\right|^{p}\right)^{1 / p}
$$

Alguns bem conhecidos membros da família $L_{P}$ são as seguintes métricas:

$\star L_{1}(a, b)($ City-Block $): \sum_{i=1}^{E}\left|a_{i}-b_{i}\right|$

$\star L_{2}(a, b)($ Euclidean $):\left(\sum_{i=1}^{E}\left|a_{i}-b_{i}\right|^{2}\right)^{1 / 2}$

$\star L_{\infty}(a, b)$ (Chebyshev): $\max _{i=1}^{E}\left|a_{i}-b_{i}\right|$

A métrica $L_{1}$, também conhecida como distância entre quarteirões ou Manhattan, corresponde ao somatório do módulo das diferenças entre as coordenadas. Nesse caso, o conjunto de pontos a mesma distância $r$ de um centro forma um losango. A métrica $L_{2}$, mais conhecida como distância euclidiana, corresponde à função usual para distância entre vetores. O conjunto de pontos de mesma distância de um centro para $L_{2}$ forma uma 
circunferência. Calculando-se o limite da equação (2.1) quando $p$ tende ao infinito, obtémse a métrica $L_{\infty}$, também conhecida como Chebychev, na qual o conjunto de pontos com mesma distância e um centro forma um quadrado.
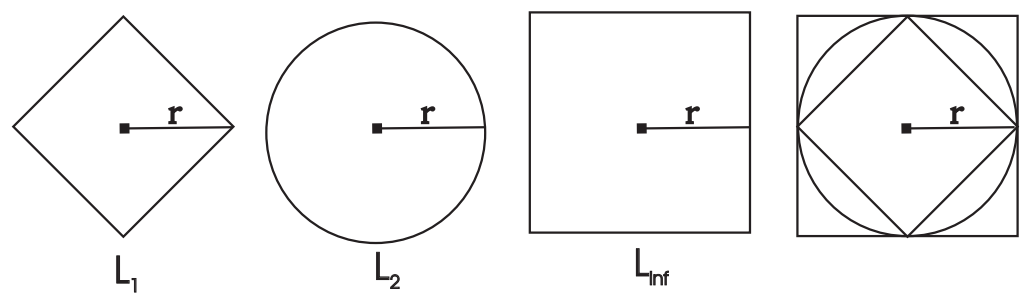

Figura 2.2: Formas geométricas geradas de acordo com a métrica $L_{p}$ utilizada.

A figura 2.2 apresenta as formas geométricas geradas pelas funções $L_{1}, L_{2}$ e $L_{\infty}$ para um espaço bidimensional. Uma generalização para um espaço $E$-dimensional fará com que a função $L_{1}$ gere um hiper-losango de dimensão $E$ e $L_{2}$ gere uma hiper-esfera de dimensão $E$, e assim por diante. Na figura, a sobreposição das representações geométricas das funções sugere que diferentes métricas englobam subespaços diferentes.

\subsection{Consultas por Similaridade}

Consultas por similaridade devem ser feitas sobre objetos em um espaço métrico, pois requerem a existência de uma função de distância métrica. As consultas por similaridade mais comuns são as consultas por abrangência (range queries) e consultas pelos $k$ vizinhos mais próximos (k-nearest neighbor queries). Existem variações destas, porém a incidência é pequena. Estas duas consultas são detalhadas a seguir. Observe que a desigualdade triangular pode ser usada para evitar que cálculos de distância desnecessários sejam feitos nestas consultas, como indicado na seção 3.1, vantagem alcançada pelos MAM sobre outras estruturas espaciais.

Seja um subconjunto $S \subseteq \mathbb{S}$ representando um conjunto de objetos nos quais as consultas são efetuadas. As consultas a seguir são efetuadas sobre a instância $S$ e retornam resultados $s_{i} \in \mathbb{S}$. Note-se que o centro das consultas não necessariamente precisa estar contido em $S$, mas sim em $\mathbb{S}$.

1. Consulta por abrangência (range query): Este tipo de consulta recebe como entrada um objeto de referência $s_{q}$ e um raio de cobertura $r_{q}$. A resposta deve incluir todos os objetos $s_{j}$ que estão a uma distância menor ou igual a $r_{q}$ de $s_{q}$. Formalmente:

$$
R q\left(s_{q}, r_{q}\right)=\left\{s_{j} \mid d\left(s_{j}, s_{q}\right) \leq r_{q}\right\}, s_{q} \in \mathbb{S}, s_{j} \in S
$$




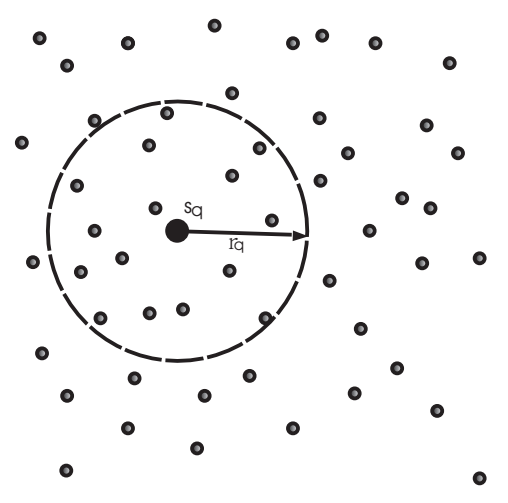

Figura 2.3: Exemplo de consulta por abrangência.

A figura 2.3 exemplifica uma consulta deste tipo num espaço bidimensional com a função de distância euclidiana $L_{2}$ (veja seção 2.3). Os objetos contidos pelo raio de cobertura $r_{q}$ são a resposta.

2. Consulta aos k vizinhos mais próximos ( $k$ nearest neighbor query): Este tipo de consulta recebe um objeto de referência $s_{q}$ e o número $k$ de vizinhos mais próximos que deseja recuperar. Formalmente:

$$
K N N q\left(s_{q}, k\right)=A=\left\{s_{j}\left|s_{j} \in S, \forall s_{i} \in\{S-A\}, d\left(s_{q}, s_{i}\right) \geq d\left(s_{q}, s_{j}\right),\right| A \mid=k\right\}
$$

A figura 2.4 exemplifica uma consulta deste tipo num espaço bidimensional com a função de distância euclidiana $L_{2}$ novamente. Na figura, a consulta teve como entrada um objeto de consulta $s_{q}$ e o valor de $k$ igual a 4 . Apenas os objetos ligados por traços (os mais próximos) compõem a resposta. Para tal resposta, $s_{q}$ não está indexado na árvore, senão tal resultado seria atingido se $\mathrm{k}=5$.

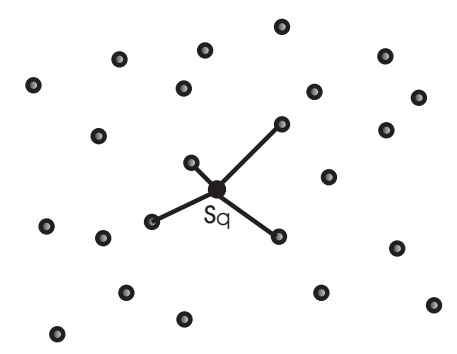

Figura 2.4: Exemplo de consulta por vizinhos mais próximos, k=4.

Um detalhe que deve ser tratado na implementação deste algoritmo é o tratamento de empates. Suponha que seja definida uma consulta pelos dois vizinhos mais próximos a partir de um objeto central de consulta, mas no entanto existem três objetos igualmente distantes do objeto central e eles são os mais próximos a 
ele. Nesse caso deve ser dada a quem utiliza a estrutura de indexação uma opção de escolha se o desempate deve ser feito ou deve-se retornar mais vizinhos do que o número pedido.

\subsection{Aplicações}

Aplicações que manipulam dados complexos (como dados multimídia) devem fornecer mecanismos para responder a consultas por similaridade, vistas na seção anterior. A similaridade entre os objetos, definida por alguma função de distância métrica, vem sendo um desafio na questão de avaliar se esta é bem definida e apropriada para o domínio de dados em questão. A seguir são mostradas algumas aplicações que manipulam tipos de dados complexos e utilizam consultas por similaridade.

Tipos de dados como imagens, vídeo, áudio e textos são considerados dados multimídia e formam bases de dados multimídia [65]. Em aplicações tradicionais, é comum a inclusão de descrições textuais ou palavras chaves associadas a estes tipos de dados para posterior consulta, mas isso leva a erros oriundos da interpretação individual de cada usuário ao inserir dados, além do fato de que outras características podem ser perdidas sem serem percebidas. Assim, um método automático deve extrair características dos dados para posterior consulta por similaridade [30]. Uma função de distância métrica específica deve ser definida para avaliar a similaridade a partir destas características extraídas em primeiro lugar. Por exemplo, para o domínio de imagens [24] [32], atributos tais como forma, textura e cor, entre outros, são extraídos das imagens para a composição de vetores de características e uma função de distância métrica deve ser definida para avaliar estas características. Assim, consultas do tipo "recupere cinco imagens mais parecidas com a imagem $A$ " são realizadas de modo que o método de acesso verifique quais são as cinco imagens da base de dados que possuem o menor valor de distância em relação ao vetor de características da imagem de consulta $(A)$ e as incluam no conjunto resposta. Se a seletividade da consulta for pequena, o que normalmente é, um índice feito utilizando um método de acesso métrico agiliza e muito este processo, não precisando verificar toda a base de dados seqüencialmente para responder a tal consulta (sequencial scan), a menos que não haja um índice criado [31].

Seqüências de DNA podem ser interpretadas como fragmentos de texto e formam bases de dados genéticas uma vez que as quatro bases nitrogenadas que as seqüências de DNA possuem podem ser representadas pelas letras A, G, C e T [43]. Consultas submetidas a estas aplicações demandam buscas por ocorrências de uma seqüencia de letras em outra seqüencia maior, normalmente para a detecção de anomalias genéticas. Neste caso, a aplicação da função de distância $L_{E d i t}$ se torna inviável, tornando necessário o uso de outros tipos de funções, como por exemplo a apresentada em [47].

Bases de séries temporais podem ser quaisquer coleções de dados feita seqüencial-

mente no tempo. Consultas buscam por padrões similares ao longo de uma coleção de 
seqüências. Alguns exemplos são variações do preço de ações no mercado financeiro ou quantidade de água pluvial em relação ao tempo em um determinado local [51]. Para a comparação das séries temporais, características são extraídas e a função de distância Euclidiana $L_{2}$ pode ser utilizada [51], porém melhores resultados vem sendo conseguidos utilizando-se as chamadas warp distances [34] [50].

Algumas outras aplicações, como por exemplo reconhecimento de fala, onde buscam-se padrões vocais similares (freqüentemente através de transformadas de Fourier) de uma base de padrões vocais; compactação de vídeo, onde a busca recai em encontrar blocos de imagens de um quadro anterior que são similares a blocos em um novo quadro para gerar vetores de movimento em compressões de vídeos $M P E G$; detecção de cópias, onde plágios podem ser detectados buscando sentenças similares em um grande repositório de documentos.

Assim, como visto, existem muitas aplicações de consultas por similaridade em dados complexos. Mas, é evidente para estas aplicações que uma gama maior de funções de distância aplicável ao mesmo conjunto de dados é necessária, para flexibilizar o grau de discriminação de acordo com os tipos de dados indexados.

\subsection{Conclusão}

A crescente necessidade de armazenamento e manipulação de dados complexos trouxe consigo a necessidade destes responderem a consultas por similaridades baseadas no conteúdo dos dados. Entre os diversos tipos de consultas por similaridade, as mais utilizadas são as por abrangência e aos $k$-vizinhos mais próximos. Muitas aplicações necessitam do suporte a estas consultas de modo eficiente, como é o caso de bases de dados multimídia, genéticas e de séries temporais.

O espaço métrico é ideal para abordar as consultas por similaridade, pois estas são operações naturais a dados imersos em tal espaço, além dos axiomas métricos que são usados como mecanismos para a poda de cálculos de distância desnecessários. Baseando-se em uma função de distância métrica e em suas propriedades, é possível elaborar técnicas de indexação eficientes, capazes de responder a essas consultas em tempo adequado. Porém, a definição de uma função de distância adequada não é uma tarefa simples e esta é específica para cada domínio de dados, sendo que ela também define o grau de discriminação dos elementos do domínio.

Métodos de Acesso Métricos são muito utilizados para responder a consultas por similaridade, onde indexam os objetos em função da dissimilaridade entre eles, medida esta baseada nas características dos objetos indexados, onde tais características usualmente são extraídas por extratores específicos para cada classe de objeto complexo. Assim, os MAM não utilizam posições espaciais para indexar os dados, utilizam apenas as distâncias relativas entre eles. O próximo capítulo detalhará alguns MAM encontrados na literatura, além de extratores de características específicos para imagens. 


\section{Capítulo \\ 3 \\ Recuperação Baseada em Conteúdo}

\subsection{Introdução}

Nos últimos anos, o número de imagens em meio digital cresceu de maneira considerável, da mesma forma que o custo de processamento e armazenamento das mesmas decresceram. A facilidade de distribuição proporcionada pela popularização da Internet e o aumento do poder computacional contribuíram decididamente para este quadro.

Diversas são as áreas que contribuem para a geração de imagens digitais. Dentre as principais destacam-se as áreas de entretenimento, bibliotecas digitais e educação, aplicações médicas e criminalísticas. Em todos os casos, busca-se armazenar grande quantidade imagens de forma segura e compacta e, freqüentemente, realizar consultas, visando a recuperação de itens relevantes dentro do banco de imagens estabelecido.

Tradicionalmente, as imagens de uma base são catalogadas utilizando-se informação textual. Neste caso, a recuperação é realizada através de comandos interpretados pelo sistema de gerenciamento do banco de dados (por exemplo, comandos $S Q L$ ). Embora prática e simples, esta abordagem apresenta determinadas limitações. Uma delas consiste no fato de que se é praticamente inviável fazer anotações manuais para todas as imagens do banco, considerando uma aplicação de grande porte. Além disso, a essência semântica do conteúdo visual das imagens, principalmente aquelas que possuem mais detalhes, dificultam a descrição textual das mesmas [11, 87]. Diferentes pessoas, por exemplo, podem fornecer descrições diferentes para a mesma imagem, causando ambigüidades e gerando resultados pouco precisos para uma operação de consulta.

Dentro deste contexto, surgiu a necessidade de se estender as técnicas tradicionais de recuperação de imagens em bancos de dados multimídia, incluindo também informações visuais das imagens que podem ser obtidas através de um processo automático. A essa abordagem dá-se o nome de "Recuperação de Imagens Baseada em Conteúdo" (ContentBased Image Retrieval - CBIR). 
Vale mencionar, que imagens digitais constituem um tipo de dado não-estruturado. São, basicamente, vetores com intensidades de pixel sem nenhum significado inerente. O objetivo principal da abordagem de recuperação de imagens baseada em conteúdo consiste em extrair informações das imagens que possam caracterizar adequadamente o seu conteúdo.

Assim, dados complexos tais como dados multimídia devem ser comparados usando-se uma medida de similaridade, pois não há sentido serem comparados por desigualdades, como dados em domínios com relação de ordem total ou por operações espaciais, como dados multidimensionais. Assim, dados complexos são naturalmente representados em um espaço métrico, desde que seja definida uma função de distância métrica. Note-se que dados multidimensionais e adimensionais também podem ser representados em um espaço métrico, desde que uma função de distância métrica seja definida também.

Conceitualmente, uma função de distância métrica recebe como parâmetro dois objetos e retorna um valor positivo que determina o grau de similaridade entre os objetos. Outros parâmetros podem ser adicionalmente usados pela função de distância, como no caso das funções de distância quadráticas, definidas na subseção 2.3. Contudo, a maioria das funções de distância recebem como parâmetro características de objetos, extraídas em primeiro lugar por um extrator de característica. Estas características representam os objetos mediante algum atributo escolhido a priori pelo extrator, e são usadas pelos métodos de acesso métricos (MAM) para uma recuperação otimizada.

Vários MAM têm sido desenvolvidos para suportar consultas por similaridade de modo cada vez mais eficiente, e muitos deles diferem pela estrutura que os forma ou pelas políticas adotadas junto às operações de inclusão e busca.

Uma abordagem mais geral para o desenvolvimento de estruturas métricas para consultas por similaridade teve início em 1991 por Uhlmann [81]. A estrutura básica das árvores métricas leva a particionar o espaço de dados em regiões usando objetos representantes aos quais os objetos em cada partição serão associados. Cada partição tem um raio de cobertura e somente objetos dentro deste raio são associados ao representante. Enquanto outros métodos de acesso multidimensionais preocupam-se apenas em minimizar o número de acesso a disco, as árvores métricas têm o intuito de reduzir também o número de cálculos de distância necessários para a execução de uma consulta, pois os objetos indexados são complexos e as comparações entre eles tendem a ser custosas.

Durante a construção de árvores métricas, são calculadas as distâncias entre vários objetos a serem inseridos na estrutura, onde essas distâncias são basicamente a única informação que a árvore necessita dos objetos. A partir daí, forma-se uma hierarquia de objetos representantes para guiar os operadores de busca a uma resposta mais rápida, sem precisar que se avaliem todos objetos indexados.

As distâncias calculadas, seja durante a construção da árvore ou quando da inserção de um novo elemento, podem ser armazenadas na estrutura. Assim, com estas distâncias pré-calculadas, pode-se estimar outras através da propriedade de desigualdade triangular 
da função de distância métrica.

O uso desta propriedade, estimando-se algumas distâncias, evita que cálculos de distância desnecessários sejam realizados, portanto agilizando os operadores de busca. Essa forma de se evitar o cálculo de distâncias é chamada "poda".A poda por desigualdade triangular é pormenorizada em [15] e é explanada a seguir.

Formalmente: Dado um domínio de objetos $\mathbb{S}$, uma função de distância $d: \mathbb{S} \times \mathbb{S} \rightarrow \Re^{+}$ e objetos $s_{1}, s_{2}, s_{3} \in \mathbb{S}$, temos a inequação da desigualdade triangular:

$$
d\left(s_{1}, s_{2}\right) \leq d\left(s_{1}, s_{3}\right)+d\left(s_{3}, s_{2}\right)
$$

Esta equação permite inferir os limites superior e inferior de uma das distâncias conhecendo apenas os valores das outras duas distâncias.

Suponha que as distâncias entre $s_{1}$ e $s_{3}\left(d\left(s_{1}, s_{3}\right)\right)$ e entre $s_{2}$ e $s_{3}\left(d\left(s_{2}, s_{3}\right)\right)$ são conhecidas e deseja-se inferir o valor de a distância entre $s_{1}$ e $s_{2}\left(d\left(s_{1}, s_{2}\right)\right)$, que será denotada por $x$ para facilitar a compreensão. Usando a Equação 3.1 temos:

$$
\begin{gathered}
x \leq d\left(s_{1}, s_{3}\right)+d\left(s_{3}, s_{2}\right) \\
d\left(s_{1}, s_{3}\right) \leq x+d\left(s_{3}, s_{2}\right) \Rightarrow x \geq d\left(s_{1}, s_{3}\right)-d\left(s_{3}, s_{2}\right) \\
d\left(s_{3}, s_{2}\right) \leq d\left(s_{1}, s_{3}\right)+x \Rightarrow x \geq d\left(s_{3}, s_{2}\right)-d\left(s_{1}, s_{3}\right)
\end{gathered}
$$

Sabendo que $x \geq 0$, as Equações 3.3 e 3.4 podem ser combinadas, formando:

$$
x \geq\left|d\left(s_{1}, s_{3}\right)-d\left(s_{3}, s_{2}\right)\right|
$$

pois se $d\left(s_{1}, s_{3}\right)>d\left(s_{3}, s_{2}\right)$, o limite inferior será a equação 3.4 . caso contrário, será a Equação 3.3 .

Combinando as Equações 3.2 e 3.5, temos:

$$
\left|d\left(s_{1}, s_{3}\right)-d\left(s_{3}, s_{2}\right)\right| \leq x \leq d\left(s_{1}, s_{3}\right)+d\left(s_{3}, s_{2}\right)
$$

ou seja, $\left|d\left(s_{1}, s_{3}\right)-d\left(s_{3}, s_{2}\right)\right| \leq d\left(s_{1}, s_{2}\right) \leq d\left(s_{1}, s_{3}\right)+d\left(s_{3}, s_{2}\right)$.

Agora considere um espaço métrico $\mathbb{M}=<\mathbb{S}, d()>$, um conjunto de objetos $S \subseteq \mathbb{S}$, o objeto de consulta $s_{q} \subseteq S$, um raio de consulta $r_{q}$ e um objeto representante $s_{p}$. Uma consulta por similaridade visita os nós da árvore, a partir da raiz, descendo em ramos conforme o raio de consulta intercepte as regiões do espaço métrico, podendo descer em mais de um ramo por nível, uma vez que há intersecções entre as regiões.

Considerando essa consulta como na Figura 3.1. uma consulta por abrangência com centro $s_{q}$ e raio $r_{q}$ pode interceptar regiões do espaço métrico, onde a bola em $r_{q}$ centrada 
em $s_{q}$ intercepta a região representada por $s_{p}$. Então, para saber se a região representada por $s_{x}$ contém parte da resposta, basta saber se a condição (4) é satisfeita. Após o cálculo de distância ser efetuado e verificada a inequação, conclui-se que a região não contém parte da resposta.

Porém, o cálculo de distância (4) indicado na Figura 3.1 pode ser suprimido através da desigualdade triangular indicada na condição (1), tal como todo objeto do nó em questão. Assim, se as condições (2) ou (3) forem satisfeitas, podemos descartar a região representada por $s_{x}$, caso contrário, aplica-se a condição (4) pois pelo menos parte da região de $s_{x}$ estaria na região hachurada, ou seja, na região entre as linhas pontilhadas. Note-se que $d\left(s_{p}, s_{x}\right)$ já foi previamente calculada e armazenada na construção/inserção na árvore. Note que o mesmo conceito por ser aplicado nos nós folhas, sendo que a única diferença é que o raio de cobertura de $s_{x}$ será zero. Esse conceito é o principal meio de poda empregado nos MAM.

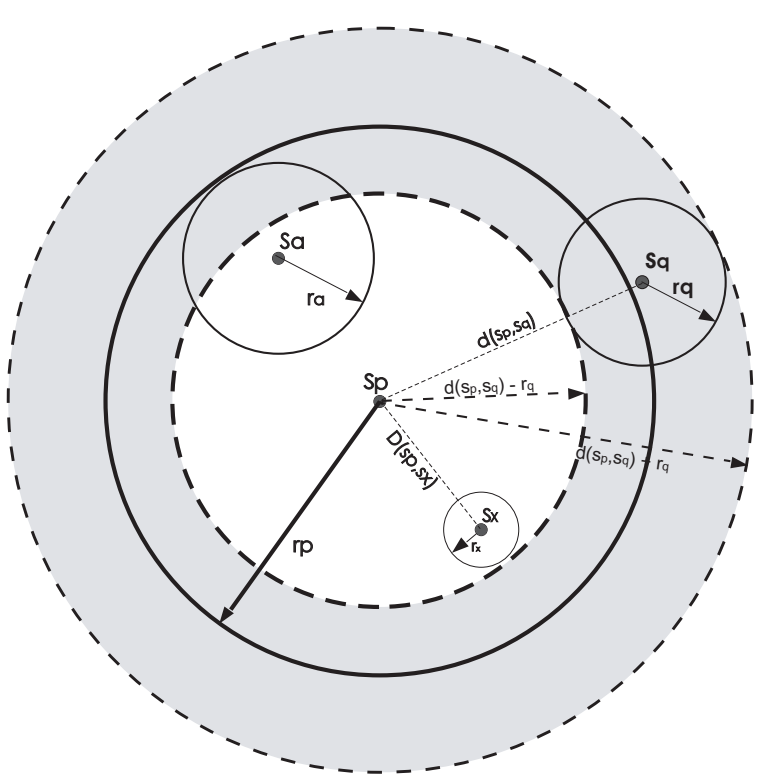

(1) $d(s q, s x) \leq d(s q, s p)+d(s p, s x)$

(2) $d(s p, s x)+r x<d(s p, s q)-r q$

(3) $d(s p, s x)-r x>d(s p, s q)+r q$

(4) $d(s q, s x) \leq r q+r x$

Figura 3.1: Utilização da desigualdade triangular para podar cálculos de distância.

As subseções seguintes resumem alguns extratores de características e detalha e os principais métodos de acesso métricos encontrados até então na literatura, explorando principalmente a estrutura idealizada para cada método e as contribuições dadas pelos mesmos.

\subsection{Extratores de Características}

Existem diferentes formas de se analisar a similaridade entre duas imagens. Dependendo da categoria de recuperação (nível de abstração) desejada, a extração de características pode tomar um rumo bem distinto. Tais categorias referem-se a quais atributos que são de relevância ao usuário em questão, onde estes podem se referir a: atributos visuais, como cor, forma, textura ou até mesmo uma combinação destes; atributos lógicos, como a identificação de objetos (p. ex. selecione as imagens que contém carros); atributos 
semânticos, como a identificação de emoções humanas (selecione imagens que expressem alegria). Nesta seção serão mostradas algumas técnicas de extração com base nos atributos visuais de imagens.

\subsubsection{Atributos visuais}

Atributos visuais tais como: cor, forma e textura são naturalmente candidatos a serem utilizados para extração de características. Várias técnicas foram propostas para extrair características sobre cada tipo de atributo visual, sendo que muitas delas são especializadas para determinados domínios de imagens, onde a especificidade das operações de comparação aumenta.

\section{Análise por cor}

Na literatura são encontrados diversos métodos de recuperação de imagens baseados na similaridade de cor, sendo que quase todos eles compartilham a mesma idéia. Para cada imagem contida na base de dados é calculado o seu histograma de cores. Na ocasião de uma consulta, o usuário pode tanto especificar a proporção desejada de cada cor (em porcentagem, por exemplo), ou submeter uma imagem exemplo para a qual também será calculado o histograma. Para ambos os casos serão retornadas as imagens da base que cujo histograma em cores mais se aproxime daquele dado (ou calculado) para a pesquisa. A técnica de comparação de histograma mais utilizada é conhecida como "intersecção de histogramas" e foi desenvolvida em 1991 por Swain e Ballard [75]. Alguns métodos propostos apresentam melhorias para esta técnica. Dentre eles encontram-se: o uso de histograma de cores acumulativo [73]; o uso de análise por cor baseada em região [18] e o uso de histogramas métricos [78, 77, 17].

As cores podem ser representadas por vários modelos, como o RGB (red, green, blue), que é o modelo mais simples, pois realiza o mapeamento direto das características do dispositivo de exibição, ou por modelos mais complexos como o HSI (hue, saturation, intensity) que se aproxima mais do modo de percepção de cores dos humanos.

Um modelo de cor é basicamente composto de um sistema de coordenadas de três dimensões e um subespaço contido neste sistema, no qual cada cor pode ser representada por um ponto. Os modelos de cores foram propostos para padronizar a representação de cores. No modelo RGB, as cores são representadas por uma mistura de quantidades específicas de vermelho, verde e azul. Utilizando-se 24 bits ( 8 bits para $R, 8$ para G e 8 para B) para a representação de 1 pixel em RGB, representa-se aproximadamente 16,7 milhões de cores diferentes.

A identificação de uma imagem através da característica cor é realizada geralmente pela construção de um histograma em que são calculados para cada cor o número de pixels da imagem com tal cor. Um tipo de medida é a análise dos tons de cinza, muito utilizada para imagens médicas, onde a imagem em tons de cinza é analisada e seu histograma de tons de cinza (conhecido como gray level histogram ou como brightness histogram) é gerado 
e utilizado para comparação nas buscas. Logo, para comparar computacionalmente duas imagens, utilizam-se os histogramas das imagens e a comparação usualmente é realizada mediante alguma norma $L_{P}$, em geral $L_{1}$.

Este processo baseado em cor é computacionalmente simples e linear e pouco sensível a pequenas alterações na imagem (movimentações. No entanto, apresenta alguns pontos a ser considerados. O fato é que duas imagens bem distintas podem possuir histogramas de cores muito semelhantes, uma vez que o método é estatístico. Outro ponto é que freqüentemente o número de cores pode ultrapassar 100 níveis, gerando vetores de características de dimensão alta, o que se torna um grave problema às estruturas de indexação ("maldição da alta dimensionalidade" [42, 3]) porém pouco custosa aos MAM, pois mesmo que a função de distância se torne mais custosa, as podas pela inequação triangular minimizam o número de cálculos de distância.

Devido à pouca capacidade de discriminar imagens distintas que possuem uma densidade de cor semelhante, os histogramas devem ser utilizados em conjunto com outras técnicas de extração de características. Por outro lado, com o uso de histogramas é simples e relativamente pouco custoso, é comum que se empreguem histogramas como um primeiro passo de filtragem, que pode eliminar muitas imagens de um processamento posterior, reduzindo a quantidade daquelas que devem ser submetidas a operação de comparação mais elaboradas e custosas. Neste trabalho destacamos também o fato de que qualquer imagem pode ter seu histograma calculado por uma operação simples, o que o torna um meio de comparação que pode ser aplicada a qualquer par de imagens.

\section{Análise por Textura}

A capacidade de lidar com texturas pode ser útil para distinguir regiões de cores similares (por exemplo, o mar e o céu, ou folhagem e grama), indentificando um padrão de ocorrência dessas cores. Várias técnicas podem ser encontradas na literatura para se extrair das imagens informações de textura. A mais conhecida e difundida delas analisa conjuntos de pares de pixels para cada imagem e monta estruturas com informações estatísticas, a partir das quais são extraídas as características como periodicidade, nível de contraste, rispidez, direcionalidade, regularidade, entre outras. Como exemplo, duas estruturas tradicionalmente utilizadas em análise por textura são as "Matrizes de coocorrência" (Coocurrence Matrices) e as "Matrizes Run-Lengths" [69]. Alguns métodos alternativos de análise incluem o uso de "filtros de Gabor" [61] e fractais [48]. Pesquisas de imagem por textura são formuladas de maneira similar àquelas baseadas em cor, selecionando-se exemplos de texturas a serem procuradas ou fornecendo uma imagem exemplo para consulta. O sistema então deve procurar por imagens cujos atributos de textura sejam mais similares àqueles apresentados para consulta.

Outra técnica utilizada é a análise estrutural. Aplica-se às texturas que possuem elementos que siguam alguma organização espacial bem comportada e previsível. Assim, dos elementos da textura da imagem são extraídos seus formatos e estimam-se regras de 


\begin{tabular}{|l|l|l|l|}
\hline 0 & 0 & 1 & 1 \\
\hline 0 & 0 & 1 & 1 \\
\hline 0 & 2 & 2 & 2 \\
\hline 2 & 2 & 3 & 3 \\
\hline
\end{tabular}

(a)

$$
P_{1,0^{\circ}}=\left[\begin{array}{cccc}
4 & 2 & 1 & 0 \\
2 & 4 & 0 & 0 \\
1 & 0 & 6 & 1 \\
0 & 0 & 1 & 2
\end{array}\right]
$$

(b)
$P_{1,135^{\circ}}=\left[\begin{array}{cccc}2 & 1 & 3 & 0 \\ 1 & 2 & 1 & 0 \\ 3 & 1 & 0 & 2 \\ 0 & 0 & 2 & 0\end{array}\right]$

(c)

Figura 3.2: Exemplo de matrizes de co-ocorrência. (a) imagem em tons de cinza; (b) matriz de co-ocorrência para ângulo 0 e $d=1$; (c) matriz de co-ocorrência para ângulo $135^{\circ}$ e $d=1$.

posicionamento. Tais regras descrevem os elementos em relação aos demais, indicando vizinhanças (conectividade dos elementos), densidade (número de elementos por unidade espacial) e sua homogeneidade ou regularidade.

Um exemplo de utilização de textura para a recuperação de imagens pode ser encontrado em Felipe [33] onde, baseando-se em matrizes de co-ocorrência, define-se um novo descritor chamado gradiente e indica uma combinação ótima de três descritores (gradiente, homogeneidade, entropia) para recuperar imagens por similaridade com alta precisão.

Como este trabalho utiliza, em seus experimentos, no processo de extração de características, matrizes de co-corrência, é importante elucidar tal técnica. As matrizes de co-ocorrência, também denominadas matrizes SGLD (Spatial Gray Level Dependence) [41], são uma das mais conhecidas técnicas de extração de características baseadas em textura para imagens [69].

Sua construção é feita pelo seguinte processo: Dada uma imagem $f$ com um conjunto discreto de tons de cinza I, define-se a matriz de co-ocorrência $P_{d, \phi}(i, j)$, onde cada elemento $(i, j)$ corresponde a um número inteiro que indica quantas vezes um pixel $p_{1}$ de nível de cinza $i$ aparece distante de um pixel $p_{2}$ de intensidade $j$ por uma distância $d$ e um ângulo $\phi$ (verificando-se os dois sentidos, horário e anti-horário). Formalmente, cada elemento $(i, j)$ de $P_{d, \phi}(i, j)$ indica quantas vezes ocorre $p_{1}=p_{2}+(d \cos \phi, d \sin \phi)$, onde $f\left(p_{1}\right)=i$ e $f\left(p_{2}\right)=j$. A Figura 3.2 ilustra um exemplo de duas matrizes de co-ocorrência (b) e (c) calculadas para uma imagem com pixels de até 4 tons de cinza representados em (a). As matrizes de co-ocorrência são matrizes quadradas e simétricas em relação à diagonal principal, ou seja, $P_{d, \phi}(i, j)=P_{d, \phi}(j, i)$.

\begin{tabular}{|c|c|}
\hline Energia & $\sum_{i, j} P_{d, \phi}^{2}(i, j)$ \\
\hline Entropia & $-\sum_{i, j} P_{d, \phi}(i, j) \log \left(P_{d, \phi}(i, j)\right)$ \\
\hline Contraste & $\sum_{i, j}(i-j)^{2} P_{d, \phi}(i, j)$ \\
\hline Homogeneidade & $\sum_{i, j} \frac{P_{d, \phi}(i, j)}{1+(i-j)^{2}}$ \\
\hline
\end{tabular}

Tabela 3.1: Principais descritores utilizados em matrizes de co-ocorrência

Diversas medidas podem ser extraídas de uma matriz de co-ocorrência. Haralick 41] propõe 14 e as mais comuns e utilizadas na literatura são listadas na tabela 3.1. As duas primeiras medidas (energia e entropia) dão uma indicação do comportamento da textura em relação à sua uniformidade e periodicidade. A medida de contraste analisa os valores 
da matriz com ênfase nos elementos mais distantes da diagonal, ou seja, os pontos cujos níveis de cinza possuem maior distinção entre si, o que vale, de fato, como um indicador do nível de contraste da textura. A homogeneidade possui a mesma tendência, porém, com sentido inverso.

A dimensão da matriz $P_{d, \phi}$ é estritamente definida pelo número de tons de cinza distintos na imagem. Deste modo, uma prática comum consiste na utilização de algoritmos de quantização sobre a imagem que se está trabalhando para se reduzir a quantidade de tons de cinza, proporcionando assim a obtenção de matrizes de dimensões reduzidas.

Para se obter um conjunto de medidas que apresente maior poder de caracterização, é necessário computar um número razoável de matrizes para diferentes ângulos $\phi$ e distâncias $d$. Caso exista informações a priori das texturas a serem caracterizadas é possível tirar proveito disto. Por exemplo, para texturas mais refinadas é melhor que sejam computadas matrizes com parâmetros $d$ de pequenos valores, geralmente 1 ou 2. Por outro lado, para texturas mais grosseiras é aconselhável a utilização de valores maiores para $d$.

Procura-se também a utilização de ângulos múltiplos de $\pi / 4$, já que a natureza espacial da imagem induz ao cálculo mais simplificado nas direções vertical, horizontal e nas diagonais. Vale notar que a seguinte relação é válida: $P_{d, \phi}=P_{d, \phi+\pi}$.

A grande desvantagem da utilização das matrizes de co-ocorrência na extração de características da textura está relacionada com seu alto custo computacional. Computar várias matrizes de grandes dimensões nem sempre é uma alternativa factível. Também, a escolha adequada dos parâmetros $d$ e $\phi$ depende muitas vezes de um conhecimento prévio acerca da qualidade das imagens ou seu domínio, o que nem sempre é possível, ou desejável, em determinadas aplicações.

\section{Análise por Forma}

Muitos estudos afirmam que objetos reais são identificados pelo sistema de visão humana primordialmente pela forma [10, 57, 60], justificando a pesquisa em novas técnicas de extração de características baseadas neste atributo.

Nesta abordagem, uma série de características de forma são calculadas e armazenadas para cada objeto encontrado em uma imagem, para cada imagem da base de dados. As consultas são realizadas computando-se o mesmo conjunto de características para a imagem exemplo e retornando aquelas da base com características mais parecidas. Uma propriedade desejável do conjunto de características utilizado é que ele se mostre indiferente para objetos de mesma natureza que estejam em posição, rotação e escala diferentes (invariância às transformações geométricas), e, além disso que possam descrever adequadamente a forma do objeto mesmo quando a imagem contém ruídos. Quanto à classificação dos métodos de extração de características de forma, a mais comum e geral delas leva em consideração se o método analisa apenas os contornos dos objetos ou analisa o objeto como um todo, levando em consideração também os pontos de seu interior. Sendo 
assim, desta classificação são derivadas duas classes de métodos: os métodos baseados em contornos e os baseados em região.

A representação do atributo forma para os objetos presentes nas imagens é dada por vetores de características que podem possuir dimensões distintas. Assim, definida uma função de distância métrica, um MAM pode ser usado para indexar imagens com estas características. Long [54] descreve um sistema que utiliza a recuperação baseada em conteúdo segundo a característica forma. Nesse sistema, o usuário pode entrar com um esboço da forma procurada ou com uma imagem de exemplo, e o sistema retorna as imagens mais similares.

\subsection{Métodos de Acesso Métricos}

Métodos de acesso métricos visam particionar o espaço de dados em regiões escolhendo elementos representantes e agrupando os elementos restantes em sua volta. Podem ser classificados em duas categorias principais [25]: aqueles baseados em funções de distância discretas e aqueles que lidam com distâncias contínuas. MAM também podem ser classificados como estáticos ou dinâmicos, de acordo com seu suporte a inserções/remoções, após a criação da estrutura.

Aqui serão detalhados alguns dos $M A M$ mais relevantes ao trabalho proposto, inspecionando sua estrutura, além de vantagens e desvantagens. Para os métodos a seguir, seja o espaço métrico $\mathbb{M}=<\mathbb{S}, d()>$ e o conjunto de objetos $S \subseteq \mathbb{S}$. Muitos trabalhos já foram propostos para desenvolverem técnicas para responder a consultas por similaridade, e o primeiro trabalho encontrado na literatura, que envolve indexação no espaço métrico, é o trabalho de [15]. Neste, são propostas três técnicas que particionam o espaço métrico hierarquicamente gerando árvores métricas. Porém, estas estruturas se aplicam quando as distâncias entre os elementos do domínio são discretas (números inteiros).

A primeira técnica proposta constrói uma estrutura hierárquica da seguinte maneira: Escolha $s_{r}$ aleatoriamente de $S$, divida $S-\left\{s_{r}\right\}$ em $m+1$ subconjuntos $\left(S^{0}, S^{1}, S^{2}, \ldots, S^{m}\right)$, sendo que todo $s_{j} \in S^{k}$ se e somente se $d\left(s_{j}, s_{r}\right)=k$, onde $k=0,1,2, \ldots, m$. A hierarquia é evidente quando a mesma técnica é aplicada recursivamente em cada subconjunto, criando uma árvore. Esta técnica é eficaz somente quando a distribuição de objetos é uniforme nos intervalos de distâncias, o que é difícil de impor em domínios de dados reais.

A segunda técnica é uma evolução da primeira, só que agora cada subconjunto tem associado um objeto representante com um raio de cobertura, sendo este a maior distância entre o representante e os restantes do mesmo subgrupo. Formalmente, a construção se dá da seguinte maneira: Divida $S$ em $m$ subconjuntos $\left(S^{1}, S^{2}, \ldots, S^{m}\right)$ tais que, para cada subconjunto $S^{i}$, existe um objeto representante $s r_{i}$ onde para todo $x \in S^{i}, d\left(x, s r_{i}\right) \leq r^{i}$, onde $r^{i}$ é o raio de cobertura daquela região. A estrutura hierárquica se forma a medida que a mesma técnica é aplicada aos objetos representantes obtidos em cada nível. Em seu trabalho, Burkhard [15] não detalha como dividir o conjunto de objetos nem como eleger 
os objetos representantes de cada subconjunto.

A terceira técnica é similar à anterior, com o requisito adicional de que o diâmetro (distância máxima entre quaisquer dois objetos em um mesmo conjunto) de qualquer subgrupo seja menor que uma dada constante $C$, cujo valor é diferente para cada nível da estrutura. O conjunto satisfazendo esse critério é chamado de clique. A escolha do valor de $C$ tem que garantir que todos os objetos do espaço estejam em pelo menos um dos cliques. Assim, forma-se a estrutura escolhendo o conjunto de cliques máximos, ou seja, cliques cujo diâmetro seja o maior possível, porém menor que $C$. Em seguida, um objeto de cada clique é escolhido aleatoriamente como representante daquele clique, para guiar ou podar pesquisas.

A primeira abordagem a armazenar distâncias pré-computadas, a fim de que a desigualdade triangular possa ser utilizada como mecanismo de poda, foi o trabalho de [72]. O propósito é evitar cálculos de distância ao máximo, pois são custosos computacionalmente para objetos complexos. A técnica utilizada recai no uso de uma matriz quadrada de ordem $n$ (onde $n$ é o número de objetos indexados) que armazena as distâncias précomputadas na construção da árvore. Esta abordagem é boa para domínios de baixa cardinalidade, mas quando o número de objetos é grande, fica inviável manter uma matriz de tal tamanho.

A seguir são mostrados alguns dos principais métodos de acesso métrico, evoluindo dos estáticos aos dinâmicos, inclusive em sua complexidade e eficiência. Para métodos dinâmicos, usualmente são utilizadas técnicas de particionamento de regiões, quando da inserção de novos objetos, gerando novos nós na árvore, deixando-a balanceada. Assim, um algoritmo de particionamento é dito ideal se a distribuição dos objetos formam regiões nas quais o "volume" de cada uma é o menor possível e a intersecção entre ambas regiões também é a menor possível. O primeiro critério (menor volume) visa reduzir o espaço onde nenhum objeto está presente porém é indexado (dead space) e o segundo critério visa diminuir a intersecção entre as regiões, reduzindo o número de nós visitados por nível em consultas por similaridade.

\subsubsection{GH-tree}

A GH-tree [81], abreviação de generalized hyperplane tree, foi um dos primeiros trabalhos a sugerir uma construção de um MAM. Esta árvore tende a dividir o espaço métrico em hiperplanos generalizados. A definição sobre tais hiperplanos é a seguinte:

Definição: Sejam dois pontos $P_{1}$ e $P_{2}, P_{1} \neq P_{2}$. Um hiperplano generalizado é o conjunto de pontos $Q$ que satisfazem $d\left(Q_{i}, P_{1}\right)=d\left(Q_{i}, P_{2}\right)$. Assim, um ponto $x$ é dito pertencer à partição de $P_{1}$ se $d\left(x, P_{1}\right)<d\left(x, P_{2}\right)$.

Em termos estruturais, cada nó define dois ramos que representarão os subespaços partidos pelo hiperplano. Construindo-se na abordagem top down, a mesma política é 


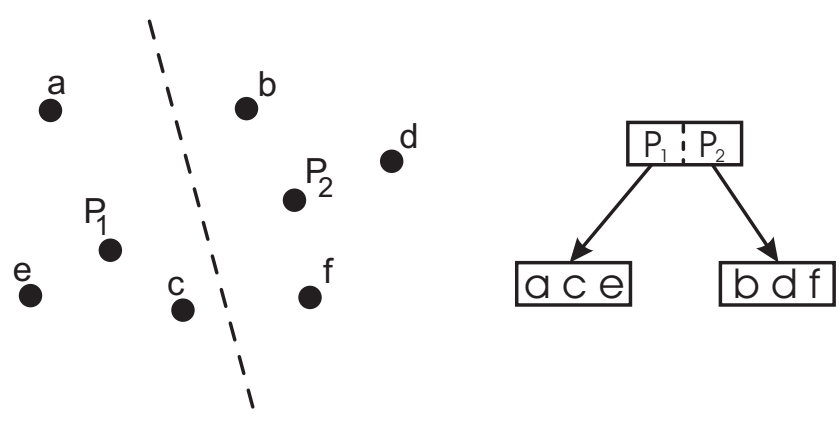

Figura 3.3: Decomposição do espaço na GH-tree

aplicada em cada subpartição.

Para exemplificar esta partição do espaço na GH-tree, a Figura 3.3 mostra a representação desta partição num espaço euclidiano bidimensional. Nota-se que $P_{1}$ e $P_{2}$ delimitam dois subespaços, divididos pelo hiperplano generalizado. Assim, todos os objetos $q$ tal que $d\left(q, P_{1}\right) \leq d\left(q, P_{2}\right)$ pertencem à região de $P_{1}$, caso contrário pertencem à região de $P_{2}$.

A partir de um conjunto de objetos, a GH-tree é construída da seguinte maneira: Escolha dois objetos aleatoriamente como representantes e divida os objetos restantes associando-os aos representantes mais próximos. Em seguida, aplique este processo em ambos subespaços, recursivamente.

Esta estrutura suporta dinamicidade, ou seja, inserções individuais, seguindo a mesma política de escolha acima. A dinamicidade vem do fato de que a estrutura não controla o balanceamento, então a inserção de um novo objeto não quebra nenhuma propriedade da estrutura.

Uma das desvantagens da GH-tree é que somente consultas pontuais podem ser feitas, uma vez que somente pontos podem ser comparados às partições. Outras desvantagem são que dois cálculos de distância por nó precisam ser feitos durante consultas e que a cardinalidade dos nós é limitada a dois, o que inviabiliza seu uso para armazenagem em disco.

\section{Variações da GH-tree}

Uma variação melhorada da GH-tree foi proposta por [14], chamada de $M B T$ (monotonous bisector tree), para trabalhar estritamente com texto. Entretanto, nada no método impediria que o método fosse usado para lidar com espaços métricos em geral, pois a principal diferença proposta é que a $M B T$ seleciona apenas um objeto para cada novo nó. Isto é conseguido reusando-se o objeto "pai" hierarquicamente acima. A vantagem vem na redução do número de cálculos de distância para se realizarem consultas, uma vez que um cálculo já foi feito no nó superior (exceto quando na raiz). 


\subsubsection{VP-tree}

A VP-tree, abreviação de vantage point tree, teve sua idéia previamente esboçada em [81], com o nome de ball decomposition. Foi implementada por Yianilos em [85] com algumas melhorias e variações, visando uma estrutura para responder a consultas por abrangência e por vizinhos mais próximos, com o objetivo de minimizar cálculos de distância.

A VP-tree binária divide o espaço em cortes esféricos, a partir de um ponto de vantagem. Este ponto de vantagem (vantage point, de onde se origina VP-tree) pode ser chamado de objeto representante. Sua política de construção a torna a princípio uma estrutura estática, ou seja, novas inserção não são possíveis.

A política de construção da árvore é a seguinte: A partir de um conjunto de objetos, escolhe-se um objeto representante e calculam-se as distâncias dos objetos restantes a este objeto. Encontra-se um raio que seja a mediana, ou seja, divide o espaço de maneira que metade dos objetos fique dentro do raio de cobertura e a outra metade fora. O mesmo princípio é realizado em ambas as partes recursivamente, formando uma hierarquia.

Foi demonstrado em [85] que, intuitivamente, a política de escolha do objeto representante deve escolher dentre objetos na extremidade do espaço, ou seja, objetos mais remotos, distantes. Mas em seus experimentos Yianilos considera válida a política de escolhe os objetos de modo aleatório, pela rapidez alcançada na construção da estrutura.

Para exemplificar os cortes esféricos e a escolha dos representantes, a Figura 3.4, retirada de [85], mostra uma representação no plano de como dividir o espaço usando tais cortes associados aos representantes situados nas extremidades dos espaço.

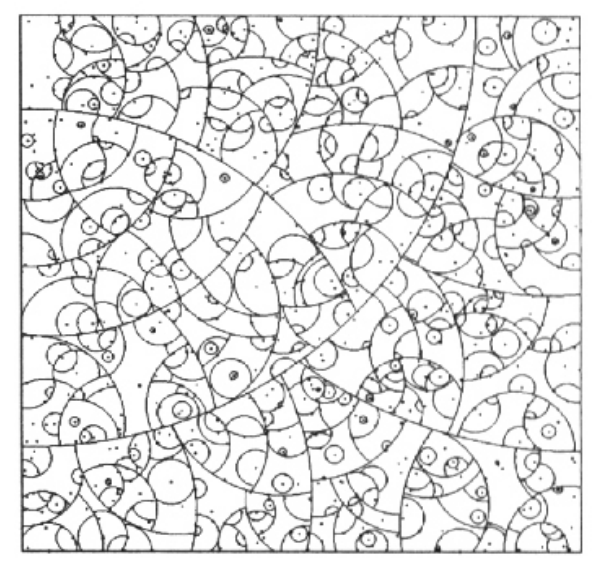

Figura 3.4: Decomposição do espaço na VP-tree.

A seleção da mediana para o raio do corte pode ser feita da seguinte maneira: Após calcular as distâncias de todos objetos ao representante escolhido, ordenam-se tais objetos pela distância a este, e seleciona-se a primeira metade da lista para um ramo e a outra metade para outro ramo.

Note que a VP-tree tem sua construção e pesquisa análoga à ordenação e busca binária em uma dimensão tanto por causa de sua estratégia quanto por sua complexidade. Muitas 
variações foram sugeridas para melhorar a performance da estrutura ou mesmo para permitir dinamicidade. Algumas dessas variações serão explicitadas a seguir.

\section{Variações da VP-tree}

Algumas extensões foram propostas em [85]. A primeira delas, a $v p^{s}$-tree, mantém em adicional a cada nó, um histórico das distâncias dos objetos representantes ancestrais até a raiz, sendo que tais distâncias são calculadas durante a construção da árvore. Nesta construção, cada nó da árvore terá, além de seu identificador, uma lista de limites de distâncias, superior e inferior, denotando o subespaço visto por cada ancestral.

Tal melhoria diminui o número de nós visitados durante as consultas do tipo "vizinhos mais próximos", pois ajudam a escolher a ordem adequada nos quais os ramos são visitados, chegando a uma resposta mais rápida. Esta técnica tem ordem de complexidade de espaço grande para bases com muitos objetos e sofre se a dimensionalidade dos objetos for muito alta. A segunda extensão, a $v p^{s b}$-tree, é uma modificação da primeira, onde os nós folhas formam buckets, armazenando mais objetos, economizando espaço quando armazenados, resultando também em menos acessos a disco para consultas.

Em [12] é citado como generalizar vp-trees binárias em vp-trees de ordem $m$, também chamadas de m-ary vp-trees ou também de multi-way vp-trees. A construção destas árvores é muito parecida, mas nesta extensão, ao invés de escolher a mediana das distâncias entre o objeto representante (ponto de vantagem) e os objetos restantes, os objetos são ordenados pela distância ao objeto representante e são divididos em $m$ grupos de igual cardinalidade. Assim, as m-1 distâncias que delimitam cada grupo são armazenadas junto ao objeto representante no nó. Tal processo diminui a altura da árvore, na tentativa de diminuir cálculos de distância em consultas.

Em [23] foram propostas algumas melhorias na estrutura para permitir inserções de novos objetos, depois que a estrutura já tenha sido criada. Porém, mesmo assim, a estrutura resultante pode degenerar, tornando a estrutura não balanceada.

\subsubsection{MVP-tree}

A MVP-tree, abreviação de multiple vantage points tree, foi introduzida em [12], e republicada em [13] com mais detalhes, com o intuito de otimizar a utilização dos "pontos de vantagem" da vp-tree. Assim como na vp-tree, o espaço métrico na MVP-tree também é particionado em cortes esféricos a partir de pontos de vantagem (tratados aqui como objetos representantes). Entretanto, esta estrutura cria partições a partir de dois objetos representantes por nó e mantém informações extras nos nós folhas (inclusive objetos representantes) para posterior filtragem de cálculos de distância, utilizando-se da desigualdade triangular para tal.

Sua estrutura surgiu de algumas alterações de como utilizar os objetos representantes e seus cortes. Precisamente duas motivações para tais alterações estimularam seu desenvolvimento. A primeira motivação vem do fato de que é possível particionar uma região 
sem que o objeto representante esteja contido na mesma. Isto significa que um mesmo objeto representante pode particionar diferentes regiões associadas a nós em um mesmo nível. Isto se aplica ao objeto representante adicional em cada nó, quando comparada à VP-tree.

A segunda motivação recai na possibilidade de manter informações extras nos nós folhas, ou seja, manter para cada objeto armazenado no nó folha, as distâncias aos objetos representantes no caminho da raiz até o nó folha onde cada objeto reside. Tais distâncias podem ser aplicadas posteriormente em consultas através da desigualdade triangular para evitar cálculos de distâncias desnecessários. A desvantagem está no espaço gasto para manter tais distâncias. Amenizando isto, pode-se manter apenas as $p$ primeiras distâncias da raiz até o nó folha para cada objeto no nó folha.

A construção da $M V P$-tree leva em consideração três parâmetros:

- O número de partições $m$ criadas por cada objeto representante;

- O número máximo $k$ de objetos nos nós folhas;

- O número de distâncias $p$ pré-calculadas a serem armazenadas para cada objeto em nós folhas.

Uma vez definido o parâmetro $m$, o grau de um nó intermediário nesta árvore é definido por $m^{2}$. Por exemplo, em uma MVP-tree binária $(m=2)$, o primeiro objeto representante divide o espaço em duas partes e o segundo divide cada uma dessas partes em outras duas, obtendo um grau $2^{2}=4$ regiões disjuntas. Genericamente, o primeiro representante divide o espaço em $m$ partes e o segundo divide cada uma destas partes em outras $m$ partes, ou seja $m * m=m^{2}$.

Cada nó interno de uma mvp-tree binária é formado pelos seguintes atributos: $\left[O_{p_{1}}, r_{1}, O_{p_{2}}, r_{21}, r_{22}\right]$, onde $O_{p_{1}}$ é o primeiro representante, $r_{1}$ é o seu raio de cobertura, $O_{p_{2}}$ é o segundo representante e $\left\{r_{21}, r_{22}\right\}$ são seus dois raios de cobertura. Cada nó folha também armazena dois representantes, $k$ objetos $\left\{P_{1}, P_{2}, \ldots, P_{k}\right\}$, suas distâncias $\mathrm{D}_{1}[\mathrm{i}]$ e $\mathrm{D}_{2}[\mathrm{i}]$ aos representantes, e uma lista $P_{k}$.PATH das distâncias aos $p$ ancestrais para cada objeto $P_{i}$. A Figura 3.5 mostra um exemplo da divisão do espaço em uma mvp-tree binária que usando uma função de distância euclidiana $L_{2}$. Essa estrutura torna a mvp-tree viável para armazenar em disco.

Durante a construção da mvp-tree binária, o primeiro objeto representante $O_{p_{1}}$ é escolhido arbitrariamente, e o segundo objeto representante $O_{p_{2}}$ é escolhido como sendo o objeto mais distante de $O_{p_{1}}$. A construção de uma $M V P$-tree genérica tem ordem de complexidade $O\left(n \log _{m} n\right)$. Apesar de ser um método estático, é eficiente, superando as árvores $M$-tree e $V P$-tree em consultas por similaridade.

\subsubsection{MM-tree}

A MM-tree (Metric Memory tree) é uma estrutura dinâmica de indexação métrica, mantida em memória principal. Sua estrutura é definida da seguinte maneira: Todos os nós da 


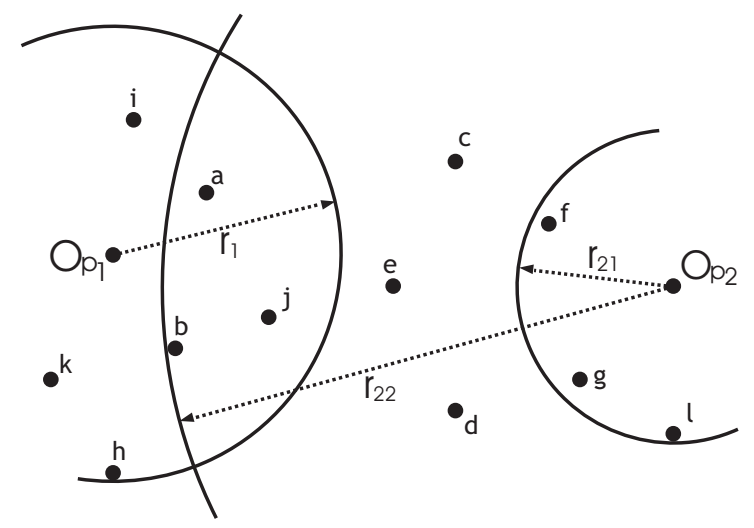

Figura 3.5: Exemplo de uma mvp-tree binária em $\left(\mathbf{R}^{2}, L_{2}\right)$.

árvore têm a mesma estrutura, portanto não existe distinção entre nós folha e não-folha. Cada nó da árvore tem no mínimo um e no máximo dois objetos, a distância entre eles e quatro ponteiros para quatro subárvores que denotam quatro regiões disjuntas no espaço métrico. Em um nó intermediário, cada objeto representante tem como raio a distância ao outro objeto representante. As regiões geradas em cada nó intermediário podem ser melhor visualizadas na Figura 3.6.

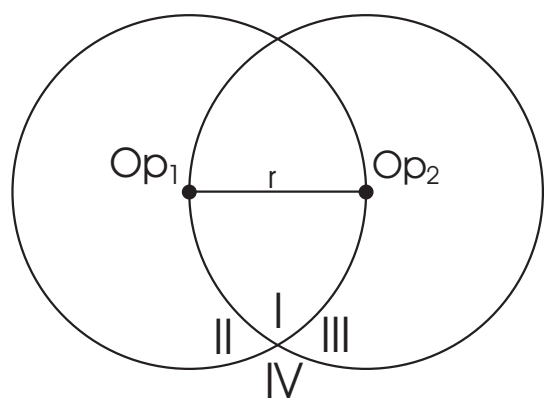

Figura 3.6: Exemplo de um nó em $\left(\mathbf{R}^{2}, L_{2}\right)$ da $M M$-tree

Pela Figura 3.6, podem ser visualizadas quatro regiões, I, II, III e IV. Cada objeto representante tem um raio $r$ que é a distância ao outro objeto representante. A numeração das regiões se dá pelas comparações feitas quando se tenta inserir um novo objeto $O_{n}$, de acordo com a tabela 3.2 .

\begin{tabular}{|c|c|c|c|}
\hline $\mathbf{d}\left(\mathbf{O}_{\mathbf{n}}, \mathbf{O}_{\mathbf{p}_{\mathbf{1}}}\right) \theta \mathbf{r}$ & $\mathbf{d}\left(\mathbf{O}_{\mathbf{n}}, \mathbf{O}_{\mathbf{p}_{\mathbf{2}}}\right) \theta \mathbf{r}$ & Binário & Região Adequada \\
\hline$<$ & $<$ & 00 & I \\
\hline$<$ & $\geq$ & 01 & II \\
\hline$\geq$ & $<$ & 10 & III \\
\hline$\geq$ & $\geq$ & 11 & IV \\
\hline
\end{tabular}

Tabela 3.2: Tomadas de decisão na MM-tree

Pela tabela 3.2 , o código binário diz respeito apenas à numeração (ordem, referência) 
atribuídas aos filhos, fazendo com a árvore seja ordenada (existe uma determinação de quais são os filhos correspondentes às regiões I, II, III e IV).

A inserção nesta estrutura é feita da seguinte maneira: Parte-se da raiz até encontrar um nó que possa conter o objeto a ser inserido, de acordo com as comparações mostradas na tabela 3.2. Se o nó encontrado contiver apenas um objeto, insere-se o novo objeto neste nó. Senão, cria-se um novo nó, insere-se o novo objeto neste e associa-se este novo nó à região correta do nó anterior, novamente de acordo com a tabela 3.2. Essa estrutura tende a se degenerar quando a seqüencia de inserção dos objetos segue um padrão tal que a distância entre objetos contíguos na seqüencia é muito pequena. Isto gera uma árvore muito alta, no pior caso tendendo a uma lista. Um algoritmo que tenta minimizar este problema é mostrado a seguir.

\begin{tabular}{|l|lll|}
\hline Região I & $\left(d\left(s_{q}, O_{p_{2}}\right)<r_{q}+r\right)$ & $\& \&$ & $\left(d\left(s_{q}, O_{p_{1}}\right)<r_{q}+r\right)$ \\
\hline Região II & $\left(d\left(s_{q}, O_{p_{2}}\right)+r_{q} \geq r\right)$ & $\& \&$ & $\left(d\left(s_{q}, O_{p_{1}}\right)<r_{q}+r\right)$ \\
\hline Região III & $\left(d\left(s_{q}, O_{p_{2}}\right)<r_{q}+r\right)$ & $\& \&$ & $\left(d\left(s_{q}, O_{p_{1}}\right)+r_{q} \geq r\right)$ \\
\hline Região IV & $\left(d\left(s_{q}, O_{p_{2}}\right)+r_{q} \geq r\right)$ & $\& \&$ & $\left(d\left(s_{q}, O_{p_{1}}\right)+r_{q} \geq r\right)$ \\
\hline
\end{tabular}

Tabela 3.3: Comparações necessárias para detectar se há intersecção da pesquisa com cada região do nó na $M M$-tree.

Consultas nesta estrutura necessitam de comparações aos representantes para saber quais regiões o objeto de consulta intercepta. Por exemplo, considere a consulta mostrada na Figura 3.7, onde um objeto de consulta $s_{q}$ de raio $r_{q}$ é indicado. Para saber quais regiões a consulta intercepta, a tabela 3.3 rege as condições, onde cada condição satisfeita indica que a consulta intercepta aquela região e o nó terá que ser visitado. Uma vantagem da $M M$-tree é tal que as regiões formadas pelos representantes são disjuntas, sendo que uma busca pontual na estrutura compara apenas um nó por nível, sendo o pior caso a altura máxima de cada subárvore escolhida.

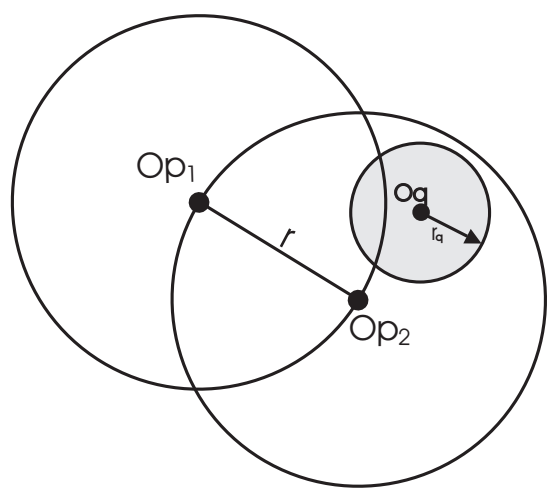

Figura 3.7: Exemplo de consulta na MM-tree 


\section{Algoritmo de Semibalanceamento}

Como já dito, a $M M$-tree tende a se degenerar quando a seqüencia de inserção dos objetos segue um padrão tal que a distância entre objetos contíguos na seqüência é muito pequena. Neste caso a estrutura pode se tornar uma lista encadeada. Para amenizar tal situação, ou seja, para tornar a estrutura menos sensível aos objetos de entrada e sua ordem, um algoritmo de semibalanceamento foi desenvolvido, numa tentativa de redistribuir os objetos nos nós.

O algoritmo deve ser ativado durante a inserção e somente quando o objeto inserido faz com que a subárvore alvo de inserção cresça em nível. O algoritmo somente é aplicado quando o número de objetos naquele nível é menor que oito e maior que dois.

Considere a Figura 3.8. Em (a), temos que a situação em que a inserção de um novo objeto indicado por $h$ faz com que o sub-ramo ao qual foi inserido cresça um nível, mesmo existindo espaço em outras regiões. O algoritmo proposto, aplicado na situação mostrada em (a), inicialmente organiza os objetos a, b , c, d, e, f, g, h em uma lista e cria uma matriz de distâncias para os objetos. Note que esta matriz nunca será maior que 8x8. Em seguida, o algoritmo elege cada par de objetos como representantes, verificando se é possível organizar todos os demais em apenas um nível, basendo-se na tabela 3.2. O algoritmo pára quando encontra o primeiro par de objetos representantes com a condição desejada ou quando se esgotam todas as combinações possíveis. A matriz de distâncias foi criada para evitar que se repitam cálculos de distâncias. Em (b) é mostrada a árvore depois da aplicação do algoritmo, que encontrou uma melhor distribuição de objetos mudandose os objetos representantes $(\mathrm{a}, \mathrm{b})$ por $(\mathrm{d}, \mathrm{e})$. É importante notar que o algoritmo tenta balancear apenas nós folhas, pois senão seria necessário reorganizar toda uma subárvore, o que seria custoso. Resultados mostram que a altura máxima da árvore diminui em $50 \%$ com a aplicação desse algoritmo, levando a árvores mais baixas.

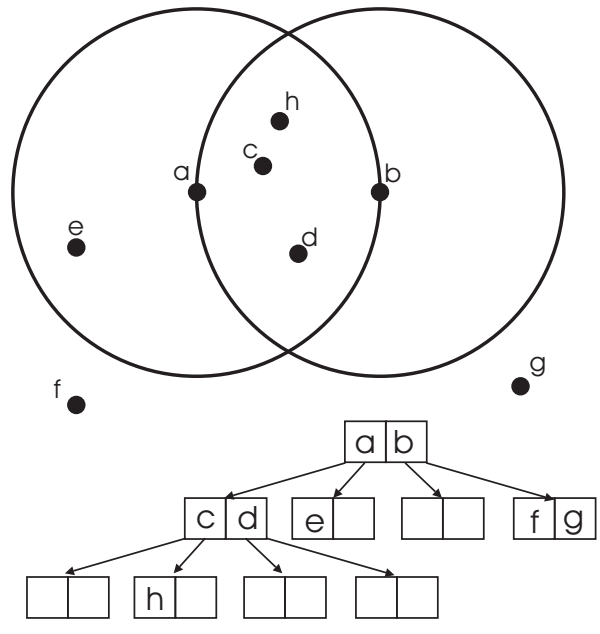

(a)

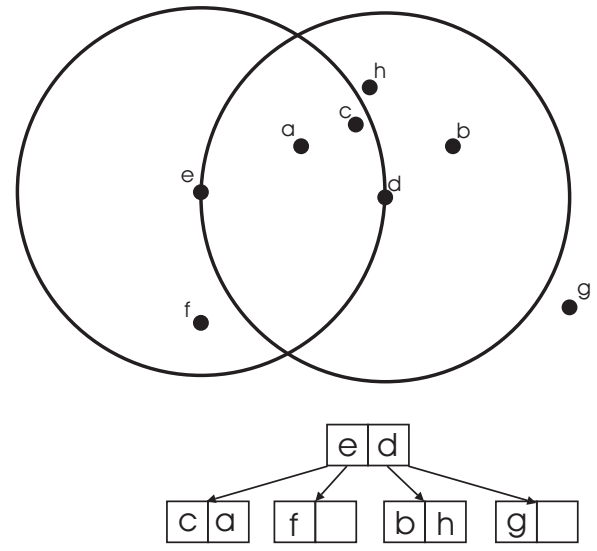

(b)

Figura 3.8: Balanceamento exaustivo na MM-tree. 
Este algoritmo torna a inserção um pouco mais custosa (acrescenta $8^{3}$ comparações, ou seja, ordem de complexidade constante) mas como a altura da árvore tende a diminuir, as pesquisas podem ser mais rápidas. Testes apontam que numa base com 21473 palavras da língua portuguesa, usando a métrica $L_{E d i t}$, utilizando-se este algoritmo, conseguiu-se diminuir a altura da árvore em quase a metade (de 41 para 21 níveis).

\subsubsection{M-tree}

Primeiro MAM dinâmico para disco balanceado a surgir na literatura, a $M$-tree foi apresentada em [28]. Ao contrário dos outros métodos citados, ela permite a inserção de objetos após a construção da árvore, a qualquer momento, fazendo deste um método dinâmico que não exige (porém não impede) reestruturações periódicas. Além disto, tem sua construção segundo a abordagem bottom-up, garantindo o balanceamento da estrutura.

Os nós folhas da $M$-tree armazenam todos os objetos indexados, representados por suas chaves ou valores característicos, enquanto os nós internos da árvore armazenam os objetos representantes. Todos os objetos têm armazenadas suas distâncias ao representante do nó onde ele está, para, em futuras consultas, podarem-se subárvores utilizando-se a desigualdade triangular.

Todos os objetos são armazenados nas folhas e a intersecção das regiões do espaço métrico, abrangidas por duas subárvores de um mesmo nó, pode não ser vazia. Ela armazena um dado conjunto de objetos $\left\{s_{1}, \ldots, s_{n}\right\}$ em nós folhas de tamanho fixo, que correspondem às regiões do espaço métrico.

Cada entrada $s_{r}$ do nó interno reúne os seguintes atributos: $\left[s_{r}, \operatorname{ptr}\left(\mathrm{T}\left(s_{r}\right)\right), \mathrm{r}\left(s_{r}\right)\right.$, $\left.\mathrm{d}\left(s_{r}, \mathrm{P}\left(s_{r}\right)\right)\right]$, onde $\operatorname{ptr}\left(T\left(s_{r}\right)\right)$ é um ponteiro para a subárvore (nó filho), $s_{r}$ é o objeto representante, $d\left(s_{r}, P\left(s_{r}\right)\right)$ é a distância ao objeto representante pai (exceto quando na raiz) e $r\left(s_{r}\right)$ é o raio da região que cobre todos os objetos que estão a uma distância menor ou igual ao representante (chamado de raio de cobertura).

Cada entrada $s_{j}$ do nó folha reúne os seguintes atributos: $\left[s_{j}, \operatorname{oid}\left(s_{j}\right), \mathrm{d}\left(s_{j}, \mathrm{P}\left(O_{j}\right)\right)\right]$, onde $s_{j}$ é o objeto indexado, oid $\left(s_{j}\right)$ é o identificador do objeto indexado e $\mathrm{d}\left(s_{j}, \mathrm{P}\left(s_{j}\right)\right)$ é a distância do objeto ao representante daquele nó.

Nas consultas, os objetos são descartados pelo uso do raio de cobertura e das distâncias dos objetos a seus objetos representantes, através da desigualdade triangular, podendo assim evitar que cálculos de distância desnecessários sejam feitos.

\section{Políticas de Particionamento}

Os nós na M-tree são de tamanho fixo, então, caso a inserção de um novo objeto $O_{n}$ seja requisitada, um algoritmo escolherá um nó que possa acomodar o novo objeto, escolhendo o nó no qual o objeto representante $O_{r}$ tem a menor distância, d $\left(O_{n}, O_{r}\right)$, de $O_{n}$. Se o nó escolhido já atingiu sua capacidade máxima permitida, um novo nó é instanciado no 
mesmo nível e então, um reparticionamento é executado entre os objetos do nó selecionado e o objeto a ser inserido.

Na Figura 3.9(a), como exemplo, é mostrado um nó com capacidade excedida. Então devemos particioná-lo em duas regiões para acomodar todos os objetos. Assim, um novo nó é alocado no mesmo nível e os objetos são realocados de acordo com sua distância ao objeto representante, este promovido por um dos algoritmos descritos a seguir. O processo de particionamento se resume da seguinte forma: Aplica-se um algoritmo de promoção no conjunto de objetos, selecionando-se dois objetos representantes $\left(O_{p_{1}}\right.$ e $O_{p_{2}}$ na Figura $3.9(\mathrm{~b}))$. Então os objetos restantes são redistribuídos de acordo com sua proximidade (distância) aos objetos representantes, ou seja, são associados aos representantes mais próximos, sendo que, em caso de empate, são associados à partição de menor tamanho (menor número de objetos). Estes objetos representantes são copiados para o nó pai, formando uma hierarquia. Se o nó pai exceder sua capacidade, o algoritmo é realizado novamente sobre ele, e assim por diante.

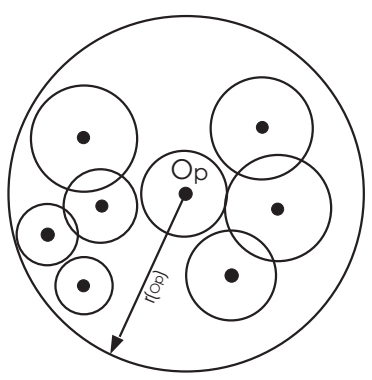

(a)

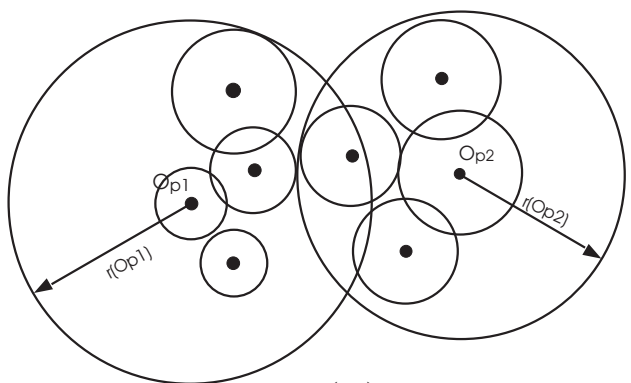

(b)

Figura 3.9: Particionamento em $\left(\mathbf{R}^{2}, L_{2}\right)$ de um nó na M-tree. Figura tirada de [28]

Antes que a redistribuição ocorra, um algoritmo de promoção deve ser executado. Este algoritmo de promoção determina dois objetos a serem promovidos. Existem várias políticas para esta tarefa, dentre elas: m_RAD, mM_RAD, M_LB_DIST, RANDOM, SAMPLING. A seguir segue uma descrição de cada política de promoção.

- m_RAD: "A menor soma dos raios". Este algoritmo é o mais complexo em termos de cálculos de distância. Ele considera todos os pares possíveis de objetos como representantes, e depois de simular a redistribuição dos objetos entre os representantes, promove o par de objetos no qual a soma dos raios de cobertura é a mínima.

- $m M_{-} R A D$ : Este algoritmo é similar ao $m_{-} R A D$, porém ele minimiza o máximo que cada um dos raios de cobertura atinge para ser escolhido como o melhor par.

- M_LB_DIST: Abreviação de Maximun Lower Bound on DISTance, esta política difere das anteriores no fato de que esta utiliza apenas as distâncias pré-computadas armazenadas na estrutura. O algoritmo, que deve escolher dois novos representantes 
$O_{p_{1}}$ e $O_{p_{2}}$, considera que $O_{p_{1}} \equiv O_{p}$, e determina $O_{p_{2}}$ como o objetos mais distante de $O_{p}$, que é determinado por

$$
d\left(O_{p_{2}}, O_{p}\right)=\max _{j}\left\{d\left(O_{j}, O_{p}\right)\right\}
$$

- RANDOM: Este algoritmo seleciona de uma maneira aleatória os objetos represetativos. Embora não seja um algoritmo inteligente, é rápido e seus resultados podem ser utilizados como base de comparação para outras políticas.

- SAMPLING: Esta é a política RANDOM aplicada no conjunto de objetos a ser redistribuído, gerando uma amostra (subconjunto) de objetos. Para cada par desta amostra os objetos são redistribuídos e o raio de cobertura de ambos representantes é estimado, sendo escolhido o par cuja soma dos raios é a mínima. Em [28] utiliza-se o tamanho da amostra como sendo um décimo da capacidade nodal.

\section{Distribuição das entradas}

Após a execução do algoritmo de promoção, dois objetos representantes foram promovidos. Agora, deve-se distribuir as entradas de acordo com a distância delas aos novos representantes. Considerando um conjunto $C$ de $n$ entradas a ser redistribuído (associado) entre os objetos representantes $O_{p_{1}}$ e $O_{p_{2}}$ já promovidos, existem duas abordagens para realizar esta tarefa, variando apenas o modo com que as entradas são distribuídas: o método Balanceado e o método do Hiperplano Generalizado.

- Hiperplano Generalizado: Este método associa cada objeto de $C$ ao objeto representante $\left(O_{p_{1}}\right.$ ou $\left.O_{p_{2}}\right)$ mais próximo. Note-se que esta técnica é utilizada em [81] na GH-tree como política de construção da árvore.

- Balanceado: Este método tem o objetivo de balancear as partições criadas, e é baseado no seguinte algoritmo:

Enquanto $C$ não for vazio faça

início

associe a $O_{p_{1}}$ o vizinho mais próximo em $C$;

associe a $O_{p_{2}}$ o vizinho mais próximo em $C$;

fim.

O método balanceado, associa para cada objeto representante o objeto mais próximo dele, alternativamente, forçando assim que ambos representantes cubram o mesmo número de objetos, um a mais ou um a menos, dependendo se o número de objetos a serem redistribuídos for par ou ímpar. Já o método do hiperplano generalizado foca a distribuição direto nos objetos não representantes, escolhendo o representante mais próximo deles e 
associando-os a esse. Note-se que este último método pode fazer com que a capacidade mínima de um dos nós não seja atendida.

Dependendo da distribuição dos dados, uma estratégia não balanceada pode levar a dados mais bem distribuídos na árvore, no entanto leva a nós pouco utilizados. O método balanceado pode, em alguns casos, aumentar a sobreposição entre as regiões do espaço métrico, porém aumenta a utilização do espaço nodal e pode reduzir a altura da árvore ao longo das inserções quando comparado ao outro método.

Uma alternativa é combinar estes dois métodos, da seguinte maneira: Seja $m$ o número mínimo de objetos por nó e $N$ o número total de objetos a redistribuir, aplique o método balanceado pode ser aplicado nos primeiros $2 * m$ objetos, para garantir a distribuição mínima nos nós. Nos $N-2 m$ objetos restantes o método do hiperplano generalizado pode ser aplicado.

\section{Considerações sobre a M-tree}

A M-tree é um método de acesso dinâmico para disco que provê uma boa performance para consultas por similaridade de objetos. Resultados de experimentos com bases de dados reais e sintéticas compararam as estruturas $R^{*}$-tree e a $M$-tree e concluem que esta última supera em todos os casos de teste com uma melhoria de mais de 100\%. As desvantagens desse método é o fato de que ele não possui nenhum mecanismo de manutenção, para diminuir as sobreposições entre as regiões, além do fato de seus algoritmos de particionamento serem muito custosos.

\subsubsection{Slim-tree}

A Slim-tree [80] pode ser vista como uma evolução da $M$-tree, também dinâmica, com algumas melhorias quanto às inserções e às políticas de particionamento. A Slim-tree é o primeiro método de acesso dinâmico que tenta resolver o problema da sobreposição entre regiões do espaço métrico (nós), propondo uma técnica para minimizá-lo, o Slim-Down [80] [16].

Este método de acesso também usa a desigualdade triangular, explicitada na seção 3.1. para evitar cálculos de distância desnecessários em consultas por similaridade.

Da mesma maneira que a $M$-tree, a Slim-tree armazena os objetos indexados em seus nós folhas, criando uma hierarquia de objetos representantes até o topo da árvore (raiz). Cada nó (partição) contém um raio de cobertura, e somente os objetos dentro deste raio de cobertura são associados ao objeto representante desta partição.

As inovações na Slim-tree são as seguintes.

- Um algoritmo diferente guia a inserção de novos objetos na subárvore apropriada;

- É definido um novo algoritmo de particionamento, baseado no Mininum Spanning tree (Árvore Geradora Mínima); 
- Um algoritmo de reestruturação da árvore, o Slim-Down, que tenta reduzir a sobreposição nodal da estrutura, além do fat-factor, um mecanismo que mede o fator de sobreposição nodal.

Em termos estruturais, a Slim-tree é semelhante à $M$-tree, com pequenas modificações. O objeto representante agora possui um atributo a mais, NEntries, que armazena o número de entradas na sua subárvore. Este atributo é usado pelo algoritmo de inserção proposto. Este algoritmo leva a uma árvore com alta utilização do espaço nos nós e o número de nós diminuirá, reduzindo assim o tamanho do índice em disco, aumentando a performance pois menos acessos a disco serão feitos.

A figura 3.10 mostra um exemplo desta estrutura indexando sete palavras, utilizando uma função de distância $L_{E d i t}$.

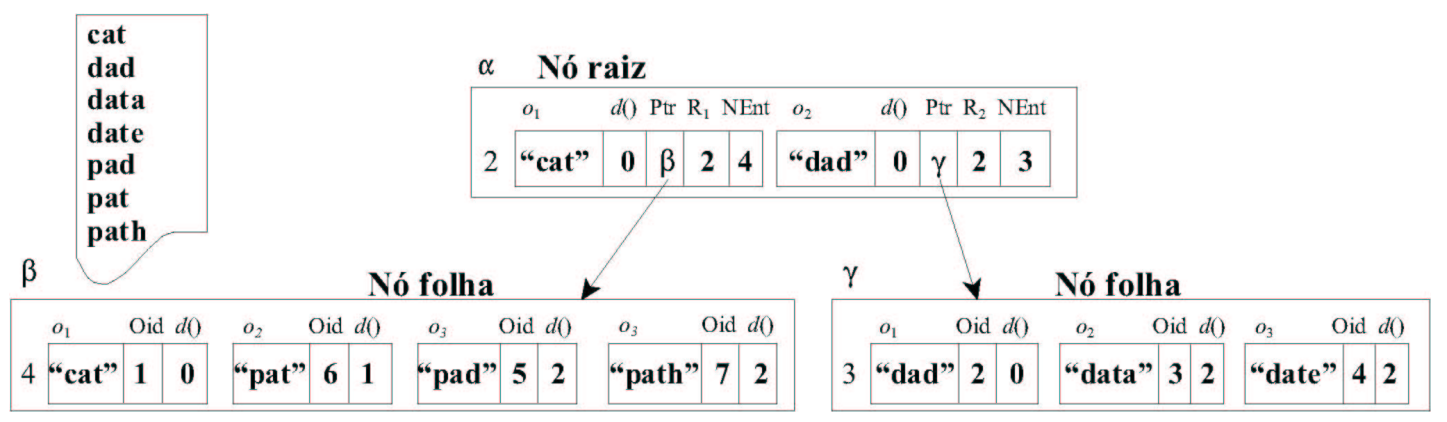

Figura 3.10: Exemplo estrutural da Slim-tree indexando palavras usando uma métrica $L_{\text {Edit }}$

A política de inserção proposta é definida da seguinte maneira: Na inserção de um novo objeto $O_{n}$, caso nenhum nó esteja qualificado para armazená-lo, ou seja, se não existe $O_{r}$ na raiz tal que $d\left(O_{r}, O_{n}\right) \leq r\left(O_{r}\right)$, então é escolhido o nó que tenha a distância mínima entre $O_{n}$ e o objeto representante deste nó e a seguir o raio de cobertura do nó é aumentado para conter $O_{n}$. Caso haja empate nessa escolha (mais de uma região cobre $O_{n}$ ), é aplicado um algoritmo que escolhe o nó que irá conter $O_{n}$. Este algoritmo (chamado de choosesubtree) pode ser implementado de três maneiras: Aleatório, onde seleciona aleatoriamente um nó para conter $O_{n}$; Distância Mínima, onde seleciona o nó cujo objeto representante está mais próximo de $O_{n}$; Ocupação Mínima, onde seleciona o nó que tenha ocupação mínima, baseado no atributo NEntries, para armazenar $O_{n}$. Este último é o algoritmo padrão.

A escolha do algoritmo de seleção nodal para inserções influencia diretamente a estrutura formada. O algoritmo de escolha aleatória gera rapidamente árvores usualmente quase tão eficientes quanto as outras duas abordagens, mas não se pode prever ou determinar seu comportamento. O algoritmo de escolha com base na distância mínima tende a gerar árvores com ocupação nodal menor, gerando árvores altas, enquanto o algoritmo baseado na ocupação mínima tende a gerar árvores mais baixas com utilização nodal maior. O ponto é que o resultado da aplicação dos algoritmos descritos na estrutura variam dependendo do conjunto de dados aplicado. 


\section{Políticas de Particionamento}

Apesar de recomendar o algoritmo MST (Minimum Spanning Tree), são dispostos três algoritmos para o particionamento dos objetos:

- RANDOM - Os dois novos centros representantes são arbitrariamente selecionados e os objetos restantes são distribuídos entre eles. Cada objeto é armazenado no nó cujo representante esteja mais próximo.

- MinMax - Este é o algoritmo $M \_R A D$ na $M$-tree, sendo considerado o mais promissor algoritmo de particionamento levando em consideração a performance da busca.

- MST - É gerada a árvore de cobertura mínima dos objetos e uma das maiores arestas, representando a maior distância, é excluída. Os dois subgrafos conexos resultantes são as partições criadas.

Um exemplo do algoritmo $M S T$ sobre um conjunto de objetos é mostrado na figura 3.11. Em (a) temos o nó a ser particionado. Após construir a árvore geradora mínima mostrada em (b), a maior aresta será excluída. Em (c) temos as novas regiões após o particionamento com os objetos representantes já promovidos. O MST tem menor ordem de complexidade que o MinMax, $O\left(n^{2} \log n\right)$ contra $O\left(n^{3}\right)$, e chega a resultados próximos deste, deixando pouco a desejar em consultas. Existem vários algoritmos que constroem um MST. Um algoritmo de ordem de complexidade $O($ eloge) foi proposto [53], onde ' $e$ ' é o número de arestas. O algoritmo proposto por Prim [66] resolve em ordem de complexidade $O\left(n^{2}\right)$.

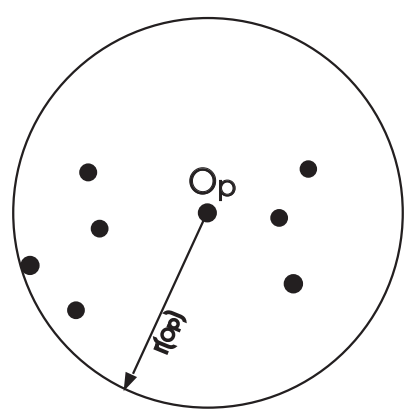

(a)

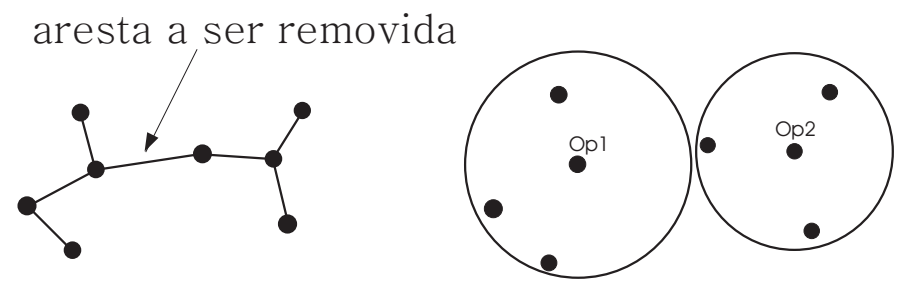

(b) (c)

Figura 3.11: Exemplo de particionamento na Slim-tree usando o algoritmo MST

\section{Otimização das Sobreposições}

Idealmente, uma árvore métrica ótima não possui sobreposições nodais, porém não existiam mecanismos para medir o nível de sobreposições. Assim, um procedimento chamado 
absolute fat-factor foi proposto como sendo um modo de quantificar a sobreposição nodal, dando possibilidade de estimar o quanto a estrutura pode ser melhorada.

A definição do absolute fat-factor considera apenas consultas por abrangência para estimar a árvore, uma vez que consultas por vizinhos mais próximos (nearest neighbors) podem ser vistas como um caso especial de consultas por abrangência [6].

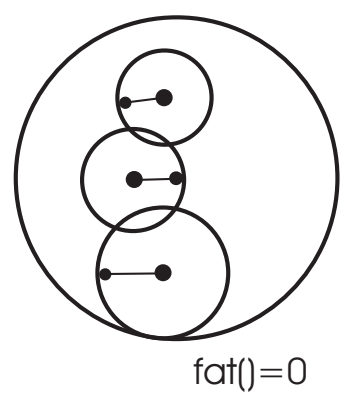

(a)

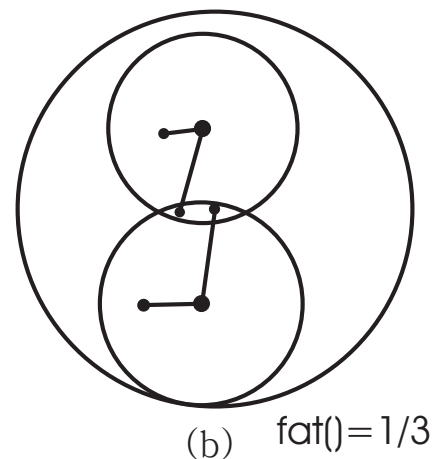

(b) $\quad \operatorname{fat}()=1 / 3$

Figura 3.12: Exemplo de duas árvores indexando o mesmo conjunto de dados, com diferente número de nós e absolute fat-factors

Assim, para uma árvore métrica ideal, uma consulta pontual deve visitar apenas um nó por nível, então o absolute fat-factor deve ser zero. No pior caso, onde todos os nós da árvore devem ser visitados, o absolute fat-factor deve ser um. Formalmente, considere $T$ uma árvore métrica com altura $H$ e $M$ nós, e $N$ o número de objetos indexados. A sobreposição de regiões numa árvore métrica pode ser medida como o número de objetos que são cobertos por ambas regiões, dividido pelo número de objetos em ambas. Então, o absolute fat-factor pode ser definido como:

$$
f a t(T)=\frac{\left(I_{c}-H N\right)}{N} \frac{1}{(M-H)}
$$

onde $I_{c}$ é o número total de acessos a nós necessários para responder uma consulta pontual para cada um dos $N$ objetos indexados na árvore. Um exemplo de utilização deste método é mostrado na figura 3.12 .

A partir dessa medida, pode-se avaliar o nível de sobreposição na árvore. Se este é muito alto, a árvore tem sua performance prejudicada, necessitando de um ajuste para reorganizar sua estrutura. O algoritmo Slim-down tem por objetivo reorganizar uma árvore para que ela seja mais magra (menor sobreposição entre nós do mesmo nível), para deixá-la mais rápida nas pesquisas, minimizando as sobreposições nos nós intermediários.

O algoritmo Slim-down segue o seguinte procedimento:

1. Para cada nó $i$ no nível $h$ da árvore, encontre o objeto $c$ mais distante de seu representante $b$.

2. Procure um nó $j$, irmão de $i$, tal que o objeto $c$ também esteja coberto por $j$. Se o 
nó $j$ existe e este não tem sua capacidade alcançada, remova $c$ do nó $i$ e o insira no nó $j$.

3. Se o nó $i$ não está vazio, corrija seu raio de cobertura, senão o exclua.

No algoritmo acima, os passos de 1 a 3 devem ser aplicados em todos os nós de um dado nível da árvore. Se após uma volta completa pelos nós, um ou mais objetos moveram-se de nó, todo o processo deve ser repetido até que nenhum objeto mova-se de nó. Um exemplo deste algoritmo pode ser visto na figura 3.13 . Nessa figura, o objeto $s$ originalmente armazenado no nó $B$ também é coberto pelo nó $A$. Como $s$ é o objeto mais distante do representante do nó $B$, ele é transferido para o nó $A$, sem causar aumento do raio do nó $A$. Isso permite reduzir o raio do nó $B$, reduzindo a sobreposição, que nesse exemplo cai de $\frac{1}{9}$ para zero.

Este algoritmo pode não ter fim, caso exista um movimento cíclico de objetos sem a diminuição de raios de cobertura. Então limita-se a quantidade de vezes que o passo 3 é realizado por nível. O número três foi suposto um bom número nos experimentos realizados.

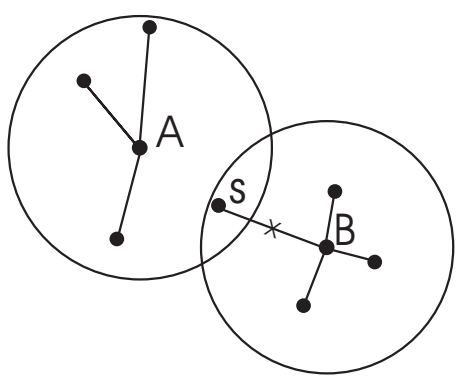

(a)

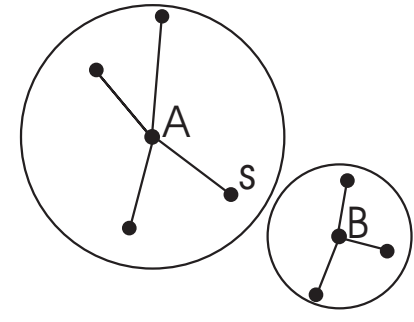

(b)

Figura 3.13: Exemplo de aplicação do algoritmo Slim-down

Note que, na figura 3.13(a), existem dois nós no mesmo nível, os quais compartilham um objeto (na intersecção). Embora este objeto esteja fisicamente em apenas um deles, quando o algoritmo de consulta pelo objeto na intersecção for acionado, ele terá que visitar as duas regiões, afetando a performance da consulta. Após o algoritmo Slim-down ser aplicado, resultam os nós mostrados em (b), os quais não compartilham nenhum objeto. O algoritmo Slim-down não garante excluir todos as sobreposições, mas sim reduzi-las.

\section{Considerações sobre Slim-tree}

A Slim-tree é uma estrutura de acesso dinâmica que indexa objetos em espaços métricos, assim como a M-tree, mas com algumas melhorias em sua performance, quando comparada à $M$-tree, que chega a atingir $200 \%$ de redução em acessos a disco quando em consultas por abrangência, e os algoritmos de inserção e particionamento MST garantem inserções 
40 vezes mais rápidas. E foi observado que o algoritmo Slim-down agiliza em até $35 \%$ as consultas por abrangência, após ser aplicado na estrutura [16].

\subsubsection{Família $O M N I$}

Múltiplos objetos representantes globais foram propostos em [70] definindo o conceito OMNI. Este conceito pode ser ser utilizado como um método de acesso métrico (omniseqüencial, uma busca seqüencial melhorada) ou aplicado junto a $M A M$ já existentes, diminuindo acessos a nós e, consequentemente cálculos de distância em consultas.

O conceito se resume a escolher estrategicamente um certo número de objetos representantes e fazê-los globais a todos os objetos em qualquer região do espaço ocupada por um conjunto de dados. Ao conjunto de representantes globais é dado o nome de OMNI-foci, e cada representante é chamado individualmente de um focus. Quando o conceito OMNI é aplicado junto a um método de acesso já existente, é gerado um MAM pertencente a uma nova família de métodos de acesso - a família $\boldsymbol{O M N I}$.

Quando um objeto é inserido na base de dados, as suas coordenadas $O M N I C_{i}$ são calculadas e armazenadas. A coordenada $C_{i}$ de um objeto $s_{i}$ é o conjunto das distâncias entre $s_{i}$ para cada focus existente. Desta maneira, as coordenadas OMNI são utilizadas durante as consultas para reduzir cálculos de distância através da desigualdade triangular. O custo computacional desta abordagem está relacionado ao tempo desprendido para calcular as coordenadas $O M N I$ para cada objeto do conjunto de dados e o espaço em memória para armazenar as coordenadas obtidas. Assumindo que poucos foci são necessários, ambos os custos devem ser pequenos.

Intuitivamente, quanto mais foci, maior o poder de poda, mas a posição relativa dos foci é um fator importante estrategicamente para um maior poder de poda. Além disso, a escolha da cardinalidade do conjunto e quais são os foci estão estreitamente relacionados. Em [70], define-se que a escolha dessa cardinalidade deve ser $\left\lceil D_{2}\right\rceil+1$, onde $D_{2}$ é a dimensão de correlação fractal como uma aproximação da dimensão intrínseca do conjunto de dados [5] [46]. Por exemplo, dois foci são escolhidos para conjuntos de dados com dimensão intrínseca um ou menos, e assim por diante.

A posição dos focus é importante para reduzir a quantidade de falsos positivos durante a consulta, pois cada falso positivo terá que ser avaliado para ser excluído da resposta. A figura 3.14 mostra um exemplo de utilização dos representantes globais. Cada focus exclui objetos (região com fundo branco), separando os objetos possíveis resposta (região cinza claro). A intersecção dos arcos de todos focus (região mais escura) conterá a resposta com poucos falsos positivos a serem avaliados posteriormente.

A escolha dos representantes é importante para uma boa redução da região de intersecção, e idealmente estes devem estar na periferia do conjunto (os mais externos possível) e devem estar igualmente distantes entre si. Por exemplo, três foci tenderão a definir um triângulo equilátero, enquanto quatro foci tenderão a um tetraedro. Uma vez que nem sempre é possível sintetizar objetos, deve-se escolher os objetos do conjunto de dados com 
as características mais próximas das requeridas.

Um algoritmo de ordem linear no número de objetos do conjunto de dados é proposto por [70], com a finalidade de escolher os foci dado um conjunto de objetos inicial. Este algoritmo inicia procurando dois objetos na borda do conjunto, classificando-os como foci. Isso é feito da seguinte maneira: Escolha aleatoriamente um objeto $A$. A seguir encontre o objeto $f_{1}$ mais distante de $A$ e classifique-o como foci. Finalmente encontre o objeto $f_{2}$ mais distante de $f_{1}$, classificando-o também como foci.

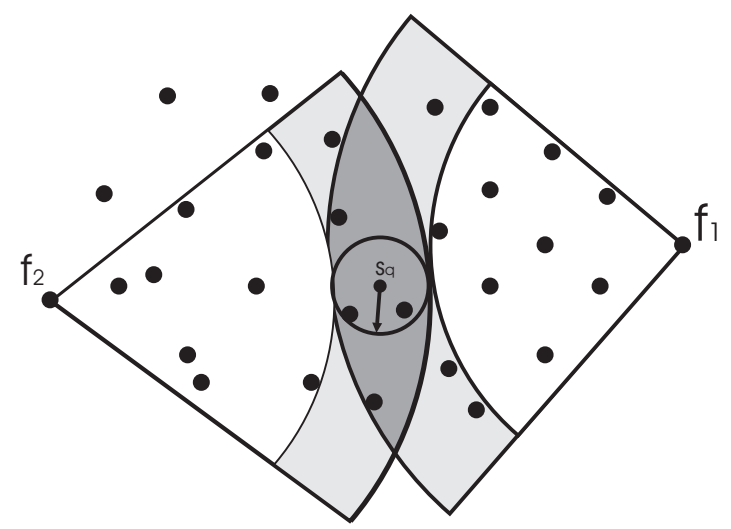

Figura 3.14: Exemplo de utilização de múltiplos representantes globais em consultas.

Se mais de dois foci são necessários, o próximo foci será um objeto que esteja igualmente distante de $O_{f_{1}}$ e $O_{f_{2}}$. A figura 3.15 mostra um exemplo de escolha do terceiro focus, onde nesse caso o objeto mais eqüidistante de $f_{1}$ e $f_{2}$ é o objeto $s_{4}$.

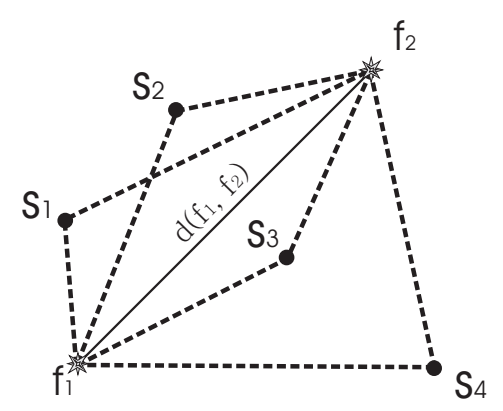

Figura 3.15: Exemplo de escolha dos omni-foci.

De forma genérica, para novos foci utilizando os $k$ foci já escolhidos, o próximo foci é eleito como sendo o objeto no qual minimiza a seguinte expressão:

$$
\operatorname{erro}\left(s_{i}\right)=\sum_{j=1}^{k}\left|d\left(f_{1}, f_{2}\right)-d\left(f_{j}, s_{i}\right)\right|
$$

Assim, o objeto que tiver menor erro será classificado como foci. Este processo é 
refeito até que todos os foci tenham sido obtidos. Apesar de se realizem vários cálculos de distância para se escolherem os foci, tais cálculos já podem ser armazenados como sendo as coordenadas dos objetos não foci. Além disso, o algoritmo não precisa tratar todo o conjunto de dados para escolher bons objetos foci, podendo ser aplicado em amostras (samplings) do conjunto. Objetos foci podem ser adicionados e removidos facilmente, com o custo de atualizar as coordenadas dos objetos já inseridos.

\section{Membros da família $O M N I$}

O conceito OMNI pode ser aplicado junto com métodos de acesso como busca seqüencial, $B$-trees e $R$-trees. As coordenadas $O M N I$ devem ser utilizadas somente para consultas utilizando-se a desigualdade triangular para evitar cálculos de distância. Aplicar o conceito $O M N I$ a estas estruturas requerem a eleição dos foci e a geração das coordenadas de todos os objetos do conjunto, como descritos anteriormente. Para as definições a seguir, considere $s_{q}$ um objeto central de consulta por abrangência com raio $r_{q}$. Aqui é mostrado como utilizar os conceitos $O M N I$ juntos com os métodos busca sequencial, B-trees e R-trees.

- Omni-sequencial: Este método é criado aplicando-se o conceito OMNI à busca seqüencial. Neste método, todos os objetos são consultados seqüencialmente para efetuar-se a pesquisa. Porém, quando uma consulta é realizada, primeiro é calculada a coordenada do objeto de consulta e, então, combinada às coordenadas dos objetos indexados. A propriedade da desigualdade triangular é utilizada para evitar cálculos de distância na consulta. Assim, cada objeto $s_{i}$ indexado pode desconsiderar o cálculo de distância ao objeto de consulta $s_{q}$ se qualquer focus $f_{k}$ satisfazer a expressão $\left|d\left(f_{k}, s_{i}\right)-d\left(f_{k}, s_{q}\right)\right|>r_{q}$.

- OmniB ${ }^{+}$-forest: Os objetos no espaço métrico não possuem relação de ordem e não podem ser indexados por métodos de acesso tais como $B^{+}$-trees. Todavia, as distâncias de um focus $f_{k}$ para cada objeto do conjunto pode ser ordenado e portanto ser indexado por uma $\mathrm{B}^{+}$-tree. Assim, teremos $k B^{+}$-trees, uma para cada focus, formando uma OmniB $B^{+}$-forest. Assim, quando uma consulta é efetuada, cada $\mathrm{B}^{+}$-tree é analisada descartando objetos que não estejam no intervalo $r_{\min }=d\left(f_{k}, s_{q}\right)-r_{q}$ e $r_{\text {max }}=d\left(f_{k}, s_{q}\right)+r_{q}$. A resposta da consulta é obtida realizando-se cálculos diretos de distância somente nos objetos que estão na intersecção dos resultados obtidos das árvores (junção métrica).

- OmniR-tree: As coordenadas de cada objeto podem ser indexadas utilizando-se uma $R$-tree, resultando na OmniR-tree. A vantagem desta estrutura é a possibilidade de indexar dados não-vetoriais numa $R$-tree, além do fato de reduzir a dimensionalidade dos dados indexados, pois o número dos foci é escolhido com base na dimensão intrínseca do conjunto de dados, usualmente menor do que o espaço onde eles estão imersos. 
Ao invés de indexar as coordenadas em outros métodos de acesso, pode-se combinar o conceito OMNI em árvores métricas. A DF-tree é um método de acesso dinâmico proposto por [79], que supera a Slim-tree (seção 3.3.6) quanto ao número de cálculos de distância nas consultas. Ela combina os algoritmos de construção da Slim-tree com o conceito OMNI utilizando representantes globais (foci), escolhidos da maneira mostrada nesta seção, para auxiliar as consultas.
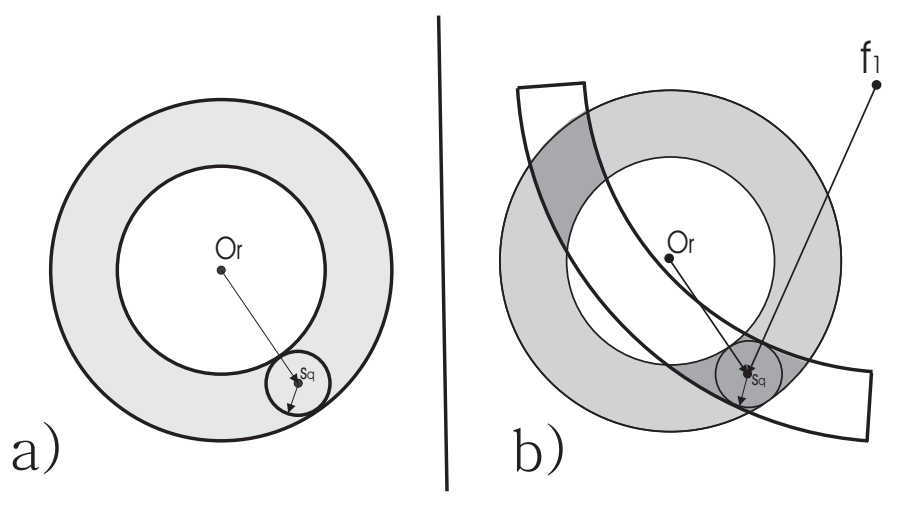

Figura 3.16: Utilização de múltiplos representantes globais com a Slim-tree.

A figura 3.16 mostra como múltiplos representantes globais são utilizados para descartar regiões em consultas. Em (a) temos uma consulta em $s_{q}$ por abrangência com raio indicado e $s_{r}$ o objeto representante da região. Os objetos fora da região sombreada são descartados pela desigualdade triangular, não necessitando cálculos de distância para eles. Em (b) temos um focus $f_{1}$ auxiliando na poda. Note que a região de intersecção, região onde serão consultados os objetos para realizarem cálculos de distância, diminuiu bastante em relação à região sombreada do item (a). Portanto muitos objetos foram descartados com o auxílio de representantes globais junto a representantes locais (nodais).

\subsection{Análise da recuperação de dados}

Em um sistema de recuperação de dados, é comum uma fase de validação de seus métodos de acesso com o propósito de avaliar a performance da recuperação, ou seja, quão precisos estes métodos o são. O tipo de análise feita depende das tarefas e objetivos que o sistema acarretará. No caso da recuperação de dados por conteúdo, esta avaliação é feita estimando-se a proporção de dados relevantes nos quais uma dada consulta retorna, onde através desta análise pode-se inferir o número de falsos positivos que o método retorna, ou a precisão do mesmo. Após esta fase funcional, onde mede-se a "qualidade" do resultado, a próxima etapa é realizada fazendo-se uma análise de performance do sistema, onde esta recae sobre quão eficaz é o método, medindo-se quesitos como velocidade (tempo), cálculos feitos e acessos a disco.

Um método de acesso pode falhar, omitindo resultados que deveriam ser retornados (falsos negativos) ou ser pouco preciso, retornando mais objetos dos que deveria (falsos 
positivos). O ideal é não termos falsos negativos e reduzir a quantidade de falsos positivos.

Dependendo do foco ao que se dá à validação do método, existem diversas maneiras de se analisar a recuperação dos dados [4]. A mais conhecida, Precisão e Revocação (Precision and Recall), é a mais usada para a validação dos métodos de acesso. Existem extensões que combinam a precisão e a revocação como a média harmônica e a Medida E [4]. Na próxima seção ilustraremos como calcular os gráficos de Precision and Recall.

\subsubsection{Precision and Recall}

Um gráfico Precision and Recall ilustra a precisão da resposta dada por um método de acesso baseada na revocação dos documentos relevantes. Podemos entender a precisão (Precision) de uma resposta como sendo a proporção dos documentos retornados que são relevantes sobre o total retornado. A revocação (Recall) define a proporção dos documentos relevantes que foram retornados sobre o número de documentos que deveriam ser recuperados. Note-se que quando um gráfico deste tipo atinge a marca dos 100\%, o método não apresenta falsos negativos, e quanto maior a precisão no gráfico, menor é o número de falsos positivos.

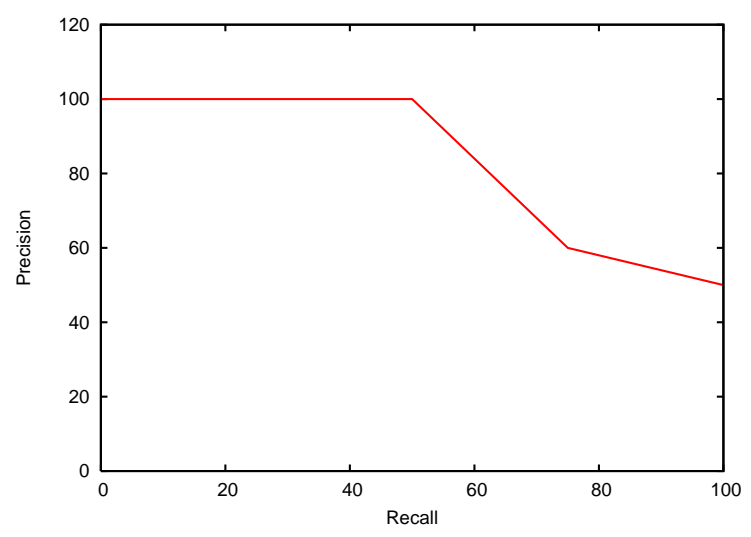

(a)

$$
\begin{aligned}
& \mathrm{I}=\{\mathrm{A}, \mathrm{C}, \mathrm{D}, \mathrm{F}\} \\
& \mathrm{R}=\{\mathrm{A}, \mathrm{C}, \mathrm{B}, \mathrm{E}, \mathrm{D}, \mathrm{H}, \mathrm{L}, \mathrm{F}\}
\end{aligned}
$$

(b)

Figura 3.17: Exemplo de um gráfico Precision and Recall (a), validando um resultado R sobre um resultado exato I. (b)

Formalmente, a técnica é formulada da seguinte maneira, baseando-se na Figura 3.18 . Dada uma consulta, definiremos o conjunto resposta ideal como I. Assuma que um método de acesso retorne um conjunto de resposta definido por $R$. Sejam $|I|$ e $|R|$ como sendo o número de elementos em cada conjunto e $|R I|$ o número de elementos na interseção dos conjuntos. As medidas de precision e recall são as seguintes:

- Recall $=\frac{|R I|}{|I|}$

- Precision $=\frac{|R I|}{|R|}$

Ainda na Figura 3.18, notamos que quanto maior é a intersecção entre os conjuntos relevantes e recuperados, maior será a precisão do método. 


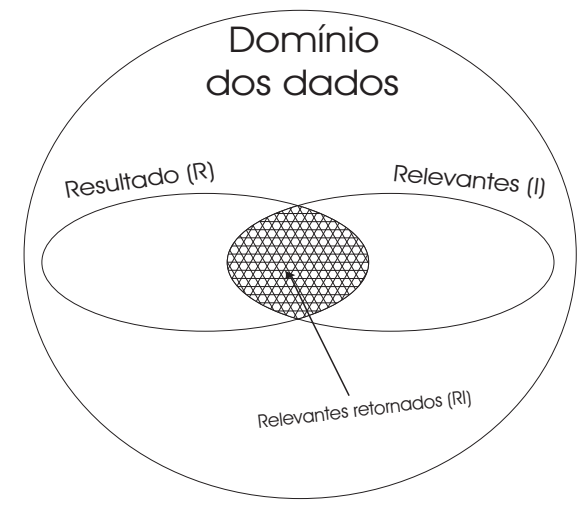

Figura 3.18: Conjuntos de resultados possíveis.

Existem várias formas de se gerar tais gráficos. Uma delas é gerar para cada consulta seu gráfico de Precision and Recall, obtendo o gráfico resultante calculando-se a média das precisões pela fórmula $\bar{P}(r)=\sum_{i=1}^{N_{q}} \frac{P_{i}(r)}{N_{q}}$, ou seja, a precisão $\bar{P}$ num dado nível de revocação $r$ será a média aritmética das precisões $P_{i}$ de cada gráfico daquele nível.

Como exemplo, considere a Figura 3.17. Em (b) temos o resultado $R$ retornado por um método de acesso qualquer e $I$ o resultado ideal, ou seja, os documentos relevantes que deveriam ser recuperados. O método calcula os pontos do gráfico mostrado em (a) da seguinte maneira: Marcam-se os documentos retornados que são relevantes e, para cada um deles, calcula-se o ponto do gráfico. Por exemplo a primeira ocorrência é o documento 'A' com (precision, recall) de $(100 \%, 25 \%)$, ou seja $(1 / 1,1 / 4)$. A segunda ocorrência é o documento 'C' com (100\%, 50\%), o terceiro é o documento 'D' com (60\%, $75 \%$ ) e o último é o documento ' $\mathrm{F}$ ' com $(50 \%, 100 \%)$. Como todos os documentos relevantes foram recuperados, o gráfico atinge a revocação na marca de 100\%, ou seja, não existiram falsos negativos.

Como várias consultas geram gráficos com diferentes coordenadas atribuidas, é necessário realizar-se a interpolação em cada gráfico, onde a precisão interpolada num dado nível de revocamento será $P\left(r_{j}\right)=\max _{r_{j} \leq r \leq r_{j+1}} P(r)$.

\subsection{Conclusão}

Neste capítulo discorreu-se sobre os atributos que formam a base de um método de acesso para recuperação de imagens baseada em conteúdo. Apresentaram-se técnicas de extração de características de imagens baseandas em análise visual, mecanismos para a avaliação da performance da recuperação, onde relevou-se a "qualidade" da resposta, confrontada à "rapidez" da mesma.

Sobre os vários métodos de acesso métricos apresentados, a maioria busca diminuir dois fatores: o número de cálculos de distância e o número de acessos a disco para recuperar os objetos, na tentativa de atingir estruturas mais eficientes para retornar objetos com base 
em seu conteúdo. Ambos fatores podem ser reduzidos reduzindo-se sobreposições nodais na estrutura do índice.

Embora a preocupação esteja em reduzir tais fatores, todos os MAM indexam os objetos com base em apenas um conjunto de característica extraída dos objetos. Mas, em domínios de dados mais complexos, um objeto pode ter mais do que um conjunto de características extraídas, sendo que algumas delas são mais discriminantes que outras em determinadas consultas. Por exemplo, podem existir algoritmos especiais (funções de distância) para um determinado conjunto de de características extraídas, que não existem para todos os objetos do domínio, impossibilitando qualquer estrutura já criada de indexálos por estas características, sendo necessário a criação de uma árvore para cada conjunto de característica extraída, obrigando a serem realizadas junções métricas para responder a essas consultas.

Portanto, uma única estrutura baseada em múltiplas funções de distância que consiga discriminar objetos de acordo com suas características específicas seria mais eficaz, menos propensa a erros e de aplicação imediata em sistemas gerenciadores de bases de dados. E é esta a proposta deste trabalho, detalhada no próximo capítulo. 


\section{Domínio Métrico Generalizável}

\subsection{Introdução}

Pode-se considerar que ambos os operadores de seleção por similaridade, consulta por abrangência e consulta aos vizinhos mais próximos correspondem ao operador de seleção $(\sigma)$ em domínios de dados que suportam relações de ordem total [2], sendo notadas nesta dissertação por $\sigma_{\text {consulta }}$ Conjunto. Ambos os operadores recebem um objeto de consulta mais um fator limitante e retornam um conjunto de objetos resposta [8] [62] [86].

Dessa maneira, cada um desses operadores de seleção por similaridade pode ser visto como uma operação de seleção, onde o critério de seleção (predicado) envolve a similaridade de dados em domínios métricos e podem, portanto, ser incluídos na álgebra relacional, na qual se embasa toda a teoria e técnica de desenvolvimento dos gerenciadores relacionais. Utilizando o símbolo $\sigma_{c} S$ para denotar uma operação de seleção por similaridade através do critério $c$, uma operação de consulta por abrangência centrada no objeto $s_{q}$ que tem como fator limitante o raio $r_{q}$ seria representada como $\sigma_{R Q\left(s_{q}, r_{q}\right)} S$ e uma operação de consulta de vizinhos mais próximos centrada no objeto $s_{q}$ tendo como fator limitante o número de objetos $n_{q}$ seria representada como $\sigma_{K N N Q\left(s_{q}, n_{q}\right)} S$.

Os algoritmos para implementar essas operações e as estruturas de indexação criadas para suportá-las têm sido intensamente estudados nos últimos anos e já estão desenvolvidos a ponto de serem eficientes o suficiente para que possam ser utilizados em ferramentas reais para busca por similaridade, tais como sistemas de consulta a imagens com busca por conteúdo [88] [55] [83] [35] [74].

No entanto, agora que as técnicas de busca por similaridade estão atingindo um grau de maturidade que permite seu uso em sistemas destinados ao usuário final (e não em apenas em protótipos para pesquisa como até bem recentemente), vários outros requisitos vêm sendo colocados por uma quantidade apreciável de aplicações [58] [67]. Um dos problemas decorre de como é definida a função de distância nesses domínios de dados. Como mesmo 
a noção de similaridade é difícil de ser definida na maioria dos domínios mais complexos, tais como em coleções de imagens, a técnica normalmente adotada consiste em extrair de cada elemento de dado um conjunto pré-determinado de características, criando-se um conjunto de dados denominado vetor de características que deve representar o elemento original de maneira concisa e de maneira o mais discriminante possível. A seguir, o vetor de características é utilizado para a busca e comparação [19] [38] .

\subsection{Motivação}

Normalmente, um exame é realizado por um motivo específico: localizar uma patologia, trauma, má-formação etc., que pode estar em um dos órgãos imageados no exame. Algoritmos específicos para detecção de problemas específicos em uma imagem têm sido amplamente estudados e muitos deles já são de uso freqüente e seguro.

É fato simples de se verificar que na maioria dos domínios de dados, e em particular em aplicações específicas envolvendo imagens, tais como em aplicações de imagens médicas ou imagens de processos de metalurgia, as características com maior poder discriminativo são as que levam em consideração aspectos particulares de uma imagem, que não estão presentes na maior parte das imagens de uma coleção.

Por exemplo, um algoritmo para discriminar imagens de massa óssea em ossos específicos é provavelmente a melhor opção para classificar osteoporose, mas esse algoritmo somente irá fornecer resultados válidos se ele for executado sobre uma imagem que apresenta um osso adequado [44]. Portanto, algoritmos específicos devem ser aplicados a imagens que apresentem condições específicas, tais como a ocorrência do órgão, ângulos corretos para a obtenção da imagem, posição do órgão na imagem, ajustes adequados dos parâmetros de configuração do equipamento de coleta etc.

Dentre as diversas imagens de um único exame de tomografia, poucas imagens podem atender aos requisitos de um determinado algoritmo específico. Se esse exame for indexado em um sistema de armazenagem e busca por conteúdo de imagens, apenas as características que podem ser extraídas de todas as imagens poderão ser utilizadas. Já aquelas poucas imagens de cada exame que podem ter suas características extraídas por um algoritmo mais específico não podem ser indexadas por essas características. Elas deveriam ter estas características específicas extraídas e utilizadas para melhor representar a imagem.

Enquanto o fato descrito acima pode parecer óbvio para o tratamento de uma única imagem, sua solução em um ambiente de bases de dados, onde grandes coleções de imagens estejam armazenadas, não é trivial. A dificuldade decorre do fato que se cada imagem incorporar em seu vetor de características as que lhe são específicas, não existe um meio de criar uma chave de indexação para o conjunto. Assim, até então usa-se apenas um vetor de características que seja universalmente aplicável ao conjunto como um todo, procurando-se outras maneiras de reconquistar um poder discriminativo adequado. 
Um outro ponto a se considerar é que, quando incorporarmos ao vetor de características de cada imagem as características que lhe são específicas, extraídas por extratores adequados, muitas vezes faz-se necessária a associação de uma função de distância adequada àquele tipo de característica. Assim, para cada classe de imagem, associa-se uma métrica, aqui definida como sendo o par (características, função de distância).

A técnica até então utilizada para satisfazer a essas restrições é o uso de múltiplas estruturas de indexação. Mas essa técnica em muitas situações não pode ser empregada. Em primeiro lugar, quando um atributo de uma relação é indexado (ou mesmo simplesmente pesquisado para responder a uma operação de busca), todos os elementos da relação tem que ser indexados. Isso obriga a que as imagens sejam armazenadas cada uma em um atributo separado da relação, o que não é exeqüível, pois cada exame tem um número diferente de "cortes" e em posições que não são padronizadas. Em segundo lugar, usar uma estrutura de indexação para obter parte da resposta e depois usar outra para refinar essa consulta é ao mesmo tempo ineficiente e propenso a erros oriundos de falsos positivos e falsos negativos gerados em buscas nas estruturas. Em terceiro lugar, a escolha de quais são as imagens que atendem aos critérios de cada algoritmo específico dentre todas as imagens de um exame deve ser realizado de maneira automática e independente para cada exame, o que já requer uma análise automática de todos os elementos de um atributo de uma relação por uma álgebra formalizada para domínios de imagens [45].

Assim, a possibilidade de dispor de um método de indexação que permita utilizar mais de uma função de distância para indexar dados que estão em um mesmo atributo de uma relação tem uma aplicação importante e imediata em domínios em que a identificação de classes de imagens seja importante para a continuação de operações de busca já iniciadas.

Neste trabalho exploramos a possibilidade de definir um conceito aplicável a qualquer estrutura de dados concebida dentro dos conceitos de dados em domínios métricos, por meio de uma função de distância adaptável, ou seja, que mude dependendo de algumas características universais, permitindo assim acomodar características que sejam particulares a algumas classes de imagens e não a todo o conjunto delas, escolhendo corretamente a métrica mais adequada a cada consulta dentre as métricas associadas às imagens.

\subsection{O Domínio Métrico Generalizável}

Um domínio de dados pode ter seus dados classificados numa abstração de generalização (ver seção 2.2). A generalização é estruturada de acordo com as características específicas que os dados possuam, que fazem cada elementos pertencer a uma dada classe mais especializada na hierarquia. Quando manipulamos conjuntos diferentes de imagens, podese querer associar um determinado extrator a uma classe específica de imagens, para uma melhor discriminação ou pelo fato daquela classe possuir alguma característica peculiar. Considerando-se a Figura 4.1, como exemplo prático, podemos especializar uma imagem de RM em corte de crânio ou de espinha, e aplicar um extrator específico para cada 
uma delas. Ainda mais, dependendo do corte de cada RM pode-se querer extrair uma característica adicional de algum tipo de orgão imageado e tipo de corte daquela parte do corpo. Essa hierarquia poderia continuar sendo reformada tanto quanto se queira. Por exemplo poder-se-ia buscar imagens de crânio axial que apresente assimetria que revelem alguma má-formação, e assim sucessivamente.

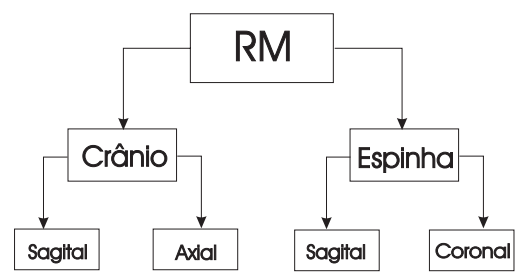

Figura 4.1: Exemplo de generalização em imagens.

Assim, conjuntos de imagens podem ser agrupados hierarquicamente numa abstração de generalização, onde, de acordo com a Figura 4.2, imagens de determinado tipo podem apresentar características particulares que as fazem pertencer a um determinado subtipo, sendo o vetor resultante a união das características na hierarquia. Cada classe também pode ter um algoritmo específico definido para discriminar imagens daquele subtipo. Isso permite reduzir o conjunto de características úteis de cada elemento do conjunto de dados individualmente, baseando-se nos valores obtidos para uma ou algumas poucas características a serem extraídas em primeiro lugar. Baseando-se nesses valores, podese decidir quais outras características são importantes para esse elemento de dado em particular e então acrescentá-las ao seu vetor de características.

À aplicação do conceito de abstração de generalização num espaço métrico, fazendose o uso de múltiplas características e múltiplas funções de distância, chamaremos de Domínio Métrico Generalizável (DMG). Este termo se refere a uma generalização do conceito de domínios métricos, onde mais de uma função de distância está definida, sendo que possivelmente nem todas elas sejam aplicáveis a todos os elementos do conjunto. Cada método de acesso métrico que se baseie neste novo domínio será então chamado de Método de Acesso Métrico Generalizado (GMAM).

Para indexar dados num DMG, existem algumas restrições em relação às características e às funções de distância. As métricas escolhidas devem suprir as propriedades indicadas pelo DMG, para comparar imagens com múltiplas características e diferentes funções de distância associadas. Estas propriedades são descritas a seguir.

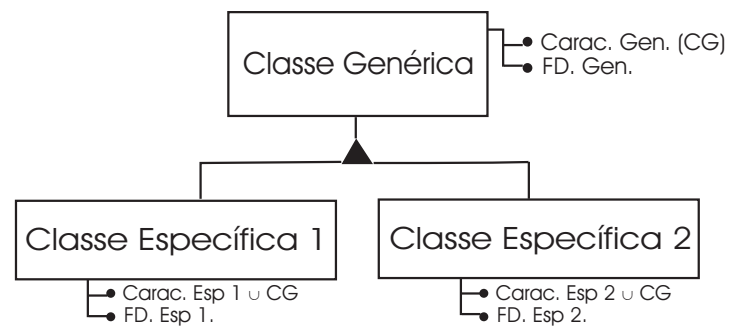

Figura 4.2: Classes e Sub-classes 


\subsubsection{Múltiplas Características}

Foram feitas algumas propostas para indexar dados que possuam mais de uma característica extraída. [26, 20]. A maioria delas visa solucionar pesquisas complexas, termo que se refere a pesquisas por similaridade que envolvem mais de uma característica como condição na seleção. O fato é que todas obrigam os dados a terem a mesma quantidade de características extraídas, o que não é interessante quando se pretende discriminar dados de acordo com uma propriedade peculiar da imagem, ou ainda mais, presente em imagens de uma determinada categoria. Um outro fator importante é que, devido às diferentes escalas que diferentes características possam apresentar, aplicações que lidam com múltiplas características devem manter uma normalização entre as características [68.

Quando manipulam-se múltiplas características e muitos dos objetos indexados não compartilham todas elas, é necessário um mecanismo de comparação entre estes tipos de dados que seja adaptável às características envolvidas.

Assim, definiremos o conceito de projeção de características: Seja o espaço de características $\Phi$, e uma instância $\nu=\left\{c_{1}, c_{2}, c_{3}\right\}, \nu \subset \Phi$, onde $c_{i}$ é uma característica, que pode representar um ou mais valores numéricos ou textuais. Dois objetos que possuam quaisquer $c_{i}$ devem ser projetados no mesmo espaço de características para efetuar-se a comparação entre eles.

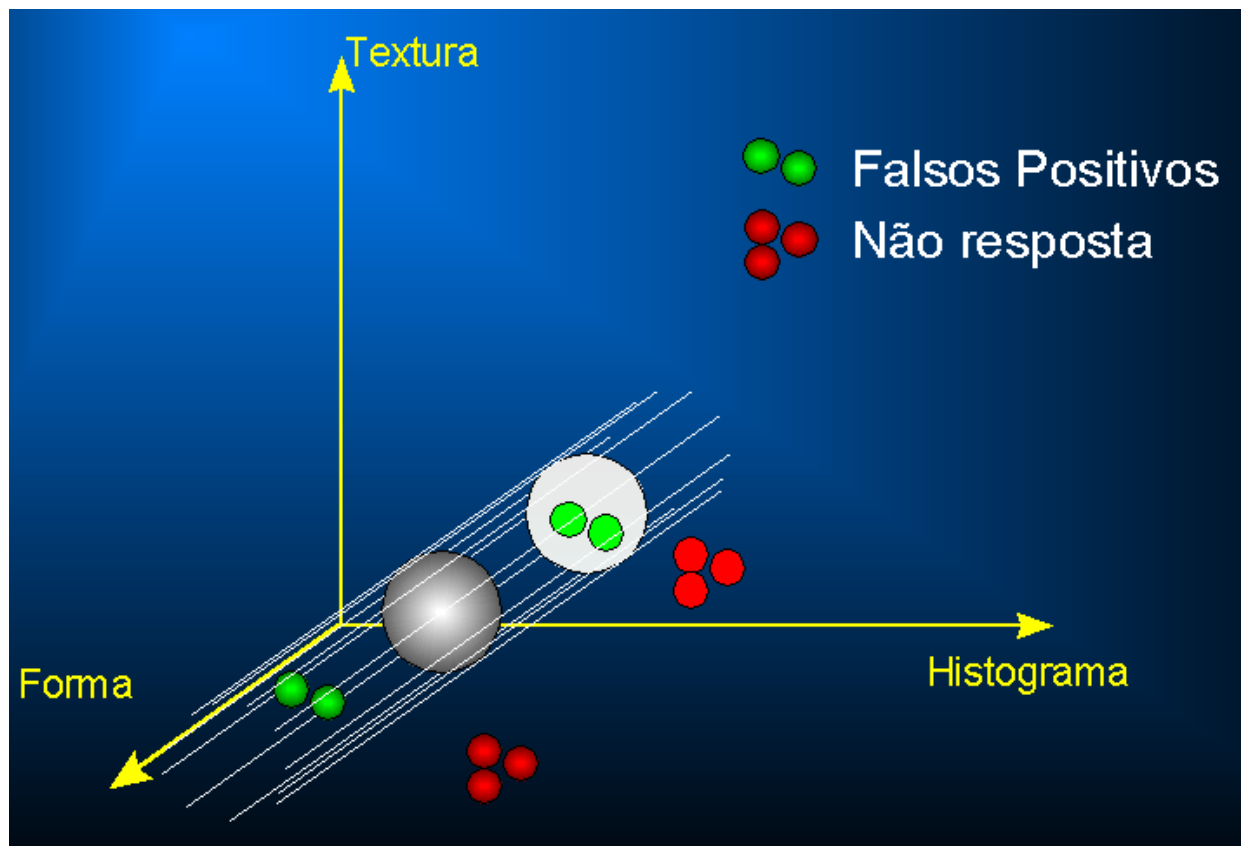

Figura 4.3: Exemplo de projeção de características.

Por exemplo, considere a Figura 4.3. Notam-se três características, histograma, textura e forma, uma em cada dimensão. A esfera cinza representa uma consulta (uma range query) que considera as três características combinadas por uma métrica $L_{2}$ e o círculo branco representa a projeção desta consulta no plano (histograma, textura) desconsiderando-se a característica forma. Note que os objetos de cor verde não fazem parte da resposta quando consideramos as três características, mas o fazem quando pro- 
jetamos em duas características, constituindo-se portanto em falsos positivos. Os objetos em vermelho, que não faziam parte da resposta analisando-se três características, continuam não fazendo parte em duas características, não influenciando na resposta.

Devido à função de distância, é importante reconhecer que não existirão falsos negativos nesta técnica de projeção se esta for aplicada de maneira adequada. Em particular, qualquer função de distância que é limitada inferiormente pela função de distância utilizada para construir a árvore pode ser usada em consultas sem falsos negativos no resultado [27].

Para isto, é definida uma condição necessária e suficiente para garantir a não existência de falsos negativos. Considere $\gg$ o grau de abrangência de uma função de distância, ou seja, se $D_{1} \gg D_{2}$, então significa que $D_{1}$ é mais abrangente que $D_{2}$, no mesmo domínio de dados. É importante ressaltar que quanto mais abrangente a função, menor é o valor de similaridade que ela retorna, ou seja $D_{1} \gg D_{2} \rightarrow D_{1}\left(s_{1}, s_{2}\right)<D_{2}\left(s_{1}, s_{2}\right)$, onde $s_{1}$ e $s_{2}$ são dois objetos quaisquer do domínio.

Seja $D$ uma função de distância qualquer, $L C_{1}$ e $L C_{2}$ as listas das características comparadas, $\left|L C_{i}\right|$ o número de características na lista $i$ e k é um número adicional de características não totalmente correlacionadas. Então a expressão 4.1 implica que para cada função de distância utilizada, a abrangência aumenta conforme diminui o número de características envolvidas, ou seja, a função se torna mais restritiva conforme aumentase o número de características comparadas. Essa é uma propriedade desejável, pois, quanto mais características um objeto possuir, melhor ele é representado, sendo que mais atributos podem ser comparados com outros objetos, aumentando a discriminação.

$$
D\left(L C_{1}\right) \gg D\left(L C_{2}\right),\left|L C_{1}\right|<\left|L C_{2}\right|, L C_{2}=L C_{1}+k, k>0
$$

A proposta deste conceito de projeção visa estabelecer que objetos com características diferentes possam ser comparados, pois fazem parte da mesma hierarquia de subtipos. Então, no mínimo, uma característica será compartilhada por quaisquer pares de objetos, uma vez que o tipo genérico encontra-se na raiz da hierarquia.

Por exemplo, vamos considerar exames de tomografias computadorizadas (TC). Em relação às imagens, existe uma convenção para traduzir os valores de voltagem detectados por um tomógrafo em unidades digitais. Dessa forma, temos valores que variam de -1000 , onde nenhuma voltagem é detectada: o objeto não absorveu praticamente nenhum dos fótons de Rx, e se comporta como o ar; ou um valor muito alto, algo como +1000 ou mais, caso poucos fótons cheguem ao detector: o órgão absorveu quase todos os fótons de Rx. Essa escala onde -1000 é mais escuro, 0 é um cinza médio e +1000 (ou mais) é bem claro. Dessa forma quanto mais Rx o órgão absorver, mais claro ele é na imagem. Outra vantagem é que esses valores são ajustados de acordo com os tecidos biológicos. Uma escala de cinzas foi criada especialmente para a tomografia computadorizada e sua unidade foi chamada de unidade Hounsfield (HU), em homenagem ao cientista que desenvolveu a tomografia computadorizada: 0 HU é água, -1000 HU é ar, 300 a 350 HU é osso, -120 a 
-80 HU é gordura e de 50 a 55 HU é músculo.

Assim, num exame de TC temos que todas as imagens podem ter seu histograma extraído e mapeado para valores HU. Com base nisto, as especializações na hierarquia podem ocorrer quando faz-se um tratamento especial a algum tipo de órgão. Por exemplo, pode-se querer extrair medidas de textura quando a imagem apresentar um osso, ou aplicar um algoritmo específico de extração quando for detectado um músculo.

Quando um objeto com características diferentes das do objeto de consulta faz parte do resultado, pode-se considerar que este objeto é um falso positivo. Porém, este objeto pode ser muito similar ao de consulta nas características que são compartilhadas (que ambos possuam), portanto pode ser viável mantê-lo na resposta, quando se deseja mais abrangência na consulta.

Assim, podemos aumentar o grau de discriminação das consultas, adicionando tantas características forem necessárias, uma vez que a árvore já foi construída com o conceito de projeções de características. A próxima etapa é tratar a comparação de objetos referente às funções de distância diferentes, para garantir que não hajam falsos negativos.

\subsubsection{Múltiplas Funções de Distância}

Após a imagem ter sido processada e suas características extraídas, é necessária uma associação da função de distância ideal para aquele tipo (ou conjunto) de característica(s). Assim, a todo objeto do tipo imagem é associada uma métrica, o que envolve a definição das características extraídas e a função de distância utilizada. Esta associação deve ser feita por um especialista, separadamente da modelagem dos dados.

O fato de cada objeto do conjunto de dados estar associado a uma função de distância implica na manipulação correta de múltiplas funções de distância, quando os objetos são comparados entre si. Embora em muitos trabalhos a possibilidade de lidar com mais de uma função de distância seja possível porém não considerada [26, 20], a preocupação findou-se somente na necessidade de não haver falsos negativos em consultas. Isto pode ser resolvido da seguinte maneira: se um método de acesso do tipo árvore é construído baseado numa função de distância $d$, então qualquer outra função $d_{2}$ diferente de $d$ que seja utilizada para consultas somente estará livre de falsos negativos se $d$ for um limite inferior para $d_{2}$, ou seja, $d_{2}$ deve ser mais abrangente [27].

Assim, isto também valerá quando na construção da árvore lidando-se com múltiplas funções de distância, ou seja, ao comparar dois objetos associados a funções de distância diferentes, basta escolher a função de distância mais restritiva possível dentre as possíveis mais abrangentes, isso garantirá que não haverá falsos negativos em consultas.

Formalmente, considere $D$ uma função de distância qualquer, $L C_{1}$ e $L C_{2}$ as listas das características comparadas. O conjunto de funções de distância deve contemplar a propriedade 4.2 para garantir as condições desejadas anteriormente. Pela restrição, deve existir uma correlação entre as funções de distância, onde cada $D_{i}$ do conjunto de funções de distância deve ter uma correspondente mais restritiva $D_{i+1}$, mantidas iguais as listas 
de características envolvidas $L_{1}$ e $L_{2}$.

$$
\forall i: D_{i}(L C 1) \gg D_{i+1}(L C 2), L C 1=L C 2
$$

Uma classe de funções de distância bem conhecida que satisfaz esta propriedade é a família $L_{P}$ (veja seção 2.3). Pela equação 2.1 apresentada anteriormente, onde quanto maior é o valor inteiro de $p$, mais abrangente é a função.

Um exemplo simples pode ser visto na Figura 4.4, onde a mudança da função de distância ilustra a restritividade da consulta com o mesmo raio de cobertura, centrada no objeto de consulta $Q$. Da figura, nota-se que o objeto $A$ faz parte da resposta somente se utilizarmos a função de distância $L_{\text {inf }}$ ou $L_{2}$, porém não o fará se utilizarmos $L_{1}$. Assim, a família $L_{p}$ ilustra bem este quesito de restritividade/abrangência das funções de distância, contemplando matematicamente a restrição 4.2 mostrada anteriormente.

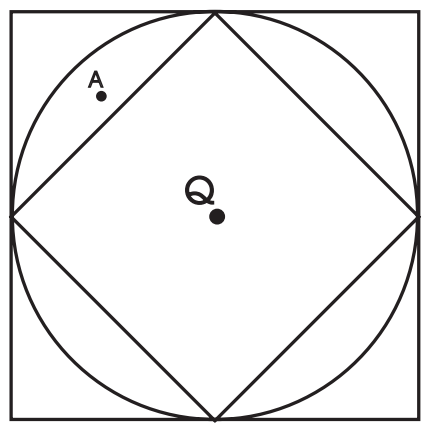

Figura 4.4: Exemplo de abrangência de funções de distância usando a família $L_{p}$.

Uma outra classe de funções de distância que segue as propriedades de abrangência é a família $L_{E d i t}$ (ver seção 2.3), onde a versão com pesos se torna mais restritiva que a versão básica satisfazendo $L E$ dit $\gg W$ Ledit.

\subsubsection{Função de Distância Adaptativa}

Uma Função de Distância Adaptativa (FDA) para dados em um DMG deve selecionar, dentre as combinações de funções de distância e características, uma combinação mais restritiva possível nas características e funções de distância (para aproveitar o poderio discriminativo) para cada comparação efetuada.

A simples troca de função de distância não é suficiente para garantir que não haverá falsos negativos, uma vez que a restritividade também é condicionada pela projeção de características (seção 4.3.1). Isto acontece por causa da combinação das funções de distâncias e das característica envolvidas. Por exemplo, seja $D=\left\{d_{1}, d_{2}\right\}, d_{1} \gg d_{2}$ o conjunto de funções de distância e $C=\left\{c_{1}, c_{2}, c_{3}\right\}$ o conjunto das características, a expressão $d_{1}\left(c_{1} \cup c_{2}\right) \gg d_{2}\left(c_{1} \cup c_{2} \cup c_{3}\right)$ pode ser verdadeira apenas para determinados domínios de dados. Então, é preciso estabelecer a priori as possíveis combinações para cada domínio de dados, formando as condições necessárias para definir uma FDA. 


\section{Família $L_{p}$}

Para ilustrar o conceito formularemos uma aplicação utilizando a família de funções de distância $L_{p}$ e como características as medidas de textura e histograma. Considere as três funções $L_{p}=\left\{L_{1}, L_{2}, L_{i n f}\right\}$, e as características $C=\{h, e, h o\}$, onde $h$ define o histograma dos níveis de cinza, e define a medida de entropia e ho define a medida de homogeneidade, sendo que os valores númericos nas características estão normalizados.

Tendo em mente que $L_{\text {inf }} \gg L_{2} \gg L_{1}$, uma FDA para este domínio deve escolher dentre as características, as que forem resultado de uma projeção das características dos objetos de comparação e associar a função de distância mais restritiva possível. Por exemplo, para métricas formadas por \{Características, função de distância\}, considere os objetos $s_{1}=\left\{h \cup e, L_{1}\right\}$ e $s_{2}=\left\{h \cup e \cup h o, L_{2}\right\}$. Para comparar estes objetos, a escolha da função de distância é feita considerando todas as funções abrangentes. O objeto $s_{2}$ está associado à $L_{2}$, esta pode ser trocada por $L_{\text {inf }}$ e o objeto $s_{1}$ está associado à $L_{1}$ que pode ser trocada por $L_{2}$ e $L_{\text {inf }}$. Assim, temos:

$$
\begin{gathered}
s_{1} \rightarrow L_{1} \mathbf{L}_{2} L_{i n f} \\
s_{2} \rightarrow \mathbf{L}_{2} L_{i n f}
\end{gathered}
$$

Portanto, a função de distância mais restritiva que ambas possam utilizar é a $L_{2}$. Na prática, o resultado é o mesmo se, dadas as funções de distância associadas aos objetos a ser comparados, a função de distância escolhida for a mais abrangente das duas consideradas. As características a serem consideradas neste exemplo se é determinada pela projeção das características explicada na seção 4.3.1. Assim, o conjunto das características consideradas será a projeção de $s_{2}$ em $\{h \cup e\}$, uma vez que apenas estas características são compartilhadas por ambos objetos. Finalmente, a métrica utilizada para comparar $s_{1}$ e $s_{2}$ é definida pelo par $\left\{h \cup e, L_{2}\right\}$.

Mais genericamente, um algoritmo para comparar quaisquer objetos distintos em suas características e funções de distância é mostrado no algoritmo 1 .

\subsection{Conclusão}

Concluímos que a necessidade de um método de acesso dispor de funcionalidade de indexação para objetos com múltiplas características diferentes e múltiplas funções de distância é necessária e aplicável diretamente às aplicações recentes, devido a sua eficiência comparada ao mesmo processo utilizando-se de vários métodos de acesso.

Assim sendo, foi proposto um novo conceito que pode ser aplicado a qualquer método de acesso métrico, o Domínio Métrico Generalizável, que possibilita a manipulação de objetos com múltiplas características, sendo que nem todos objetos compartilham todas as características, associados a funções de distâncias diferentes. Isto possibilitou indexar estes tipos objetos num mesmo método de acesso, classificados em tipos e subtipos 


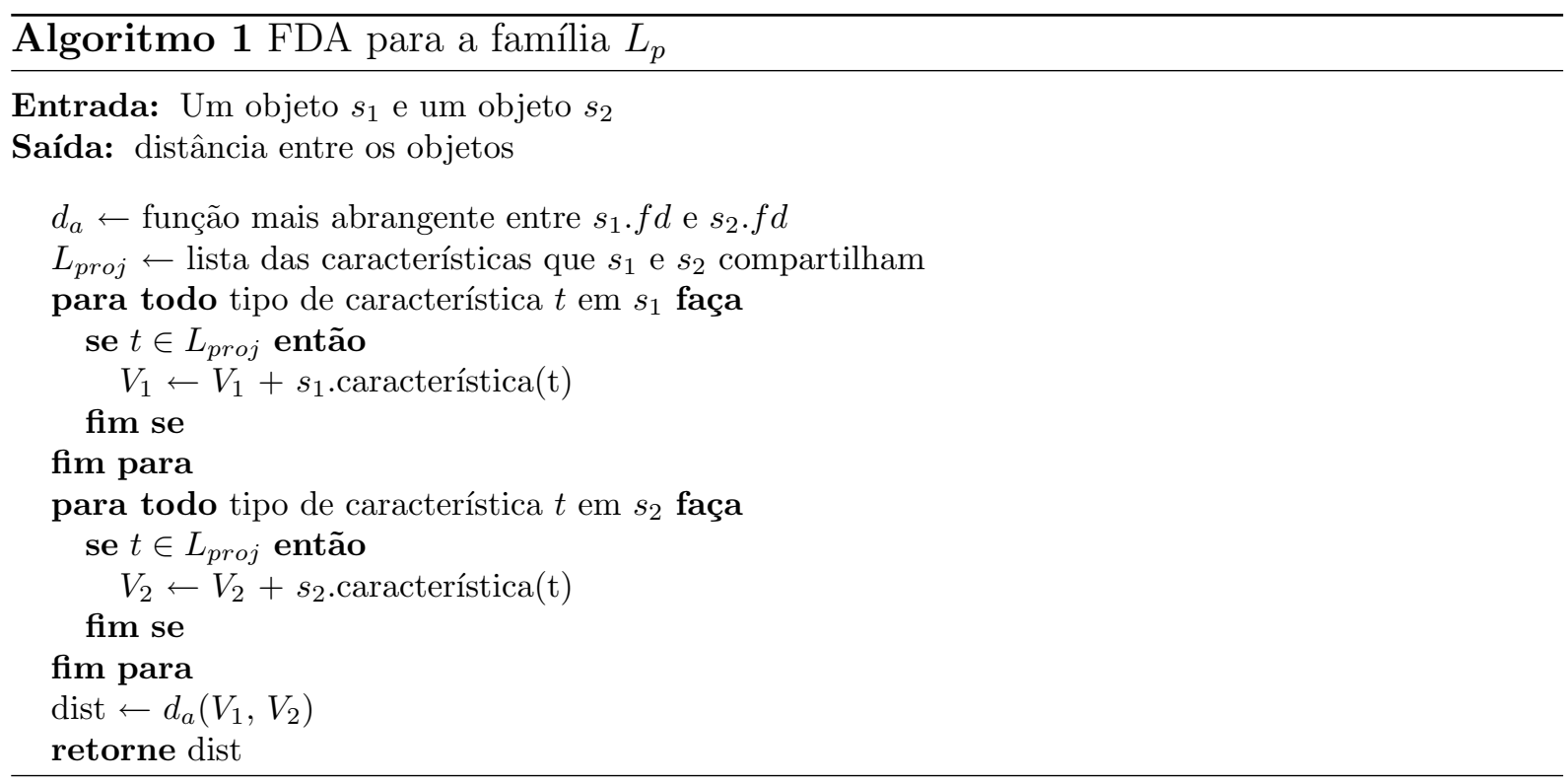

numa abstração de generalização, garantindo que não haja falsos negativos e viabilizando consultas com níveis de restritividade variados. Os métodos de acesso baseados neste novo domínio, são chamados de Método de Acesso Métrico Generalizado.

Finalmente, foram apresentadas as propriedades necessárias para a adequação deste conceito, quanto à projeção correta das características e a escolha correta na combinação destas com as funções de distância envolvidas. Também foi definida como deve ser a função de distância adaptável para este domínio métrico generalizável, ilustrando seu uso num domínio de dados exemplo com imagens associadas a funções de distância pertencentes à família $L_{p}$ através de exemplos de comparações e um algoritmo genérico para tal. 


\section{Capítulo \\ 5 \\ Experimentos e Resultados}

\subsection{Introdução}

Esta seção mostra os experimentos realizados para validar e testar a eficiência da aplicação do conceito proposto neste trabalho. Como não existe na literatura nada comparado a este conceito, os experimentos se direcionam a demonstrar que não existem falsos negativos nas consultas, a restritividade alcançada de acordo com as funções de distância escolhidas. Além disso, os experimentos demonstram o ganho de desempenho quando objetos com múltiplas características são indexados.

\subsection{Base de Dados e Métricas Utilizadas}

A base de dados utilizada nos testes possui 800 imagens do corpo humano, extraídas por ressonância magnética, classificadas conforme seu tipo de corte e a parte do corpo imageado. As imagens foram divididas em 4 classes que são: os cortes axial, coronal e sagital das imagens de crânio e o corte sagital das imagens de espinha. Cada classe de imagem contribui com 200 imagens, e um exemplo de cada classe pode ser vista na Figura 5.1 .

Para aplicar o DMG (Domínio Métrico Generalizável), cada classe de imagem foi associada a uma métrica diferente, onde cada métrica dita o par < Função de distância, Características da imagem $>$. Apesar desta associação ser extremamente condicionada por extratores adequados para cada domínio de imagem, utilizou-se aleatoriamente uma distribuição de características e funções de distância para ilustrar a utilização do método, a fim de validar a teoria proposta anteriormente.

As características utilizadas para os testes foram automaticamente normalizadas pelos extratores que as geraram, de modo que todas estão dentro da faixa de valores $(0,1)$. 


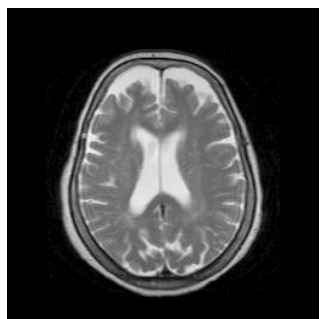

(a) Crânio - Axial

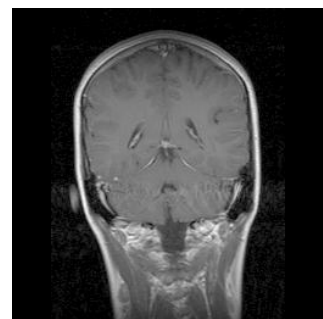

(b) Crânio - Coronal

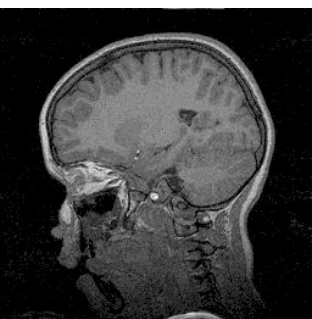

(c) Crânio - Sagital

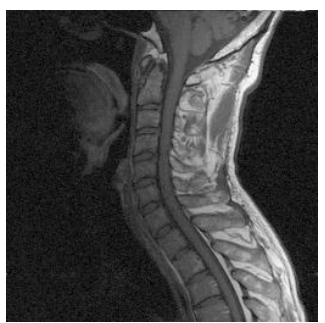

(d) Espinha - Sagital

Figura 5.1: Classificação das imagens utilizadas por cortes e orgãos

As características de textura baseadas em matrizes de co-ocorrência, vistas na seção 3.2.1 são parametrizadas para indicar quantas distâncias e ângulos são calculados. Por exemplo, para quaisquer descritores dos 14 propostos por Haralick [41], se extrairmos características baseando-se em 4 ângulos e 5 distâncias, teremos $5^{*} 4=20$ matrizes de coocorrência, portanto até 20 valores de cada descritor poderão ser extraídos para compor o vetor de característica.

Assim, temos o DMG formado e indicado na Figura 5.2, onde cada classe e subclasse é associada a uma métrica específica. As métricas associadas são mostrada na Tabela 5.1. Note que o vetor de características resultante é a concatenação de outros, extraídos por métodos diferentes. A notação Histograma(256) se refere à extração de um histograma de 256 níveis de cinza da imagem, enquanto as notações $\operatorname{Entropia}(a, d) / \operatorname{Homogeneidade}(a, d)$ referem-se a extrações dos descritores de textura utilizando-se $a$ ângulos e $d$ distâncias para a formação das matrizes de co-ocorrência. As métricas utilizadas na Tabela foram escolhidas aleatoriamente a fim de demonstrar a técnica.

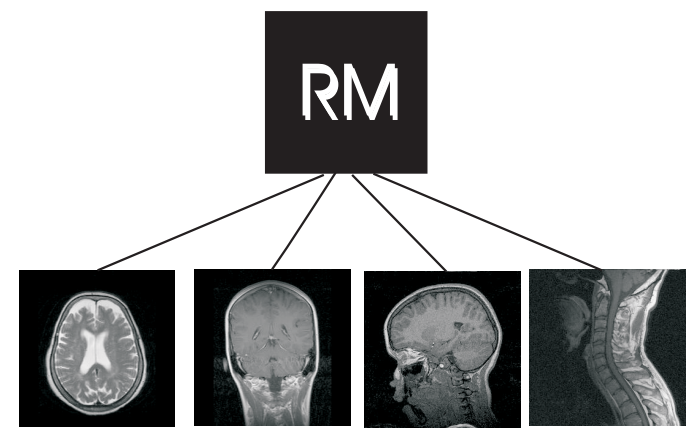

Figura 5.2: hierarquia

\begin{tabular}{|c|c|c|c|}
\hline & Classe & Vetor de características & F.D. \\
\hline 0 & Genéri ca $(\mathrm{RM})$ & Histograma $(256)$ & $L_{1}$ \\
\hline 1 & Espinha - Sagital & Histograma $(256) \cup$ Entropia $(4,5)$ & $L_{1}$ \\
\hline 2 & Crânio - Coronal & Histograma $(256) \cup$ Entropia $(1,3)$ & $L_{i n f}$ \\
\hline 3 & Crânio - Sagital & Histograma $(256) \cup$ homogeneidade $(4,5)$ & $L_{2}$ \\
\hline 4 & Crânio - Axial & Histograma $(256) \cup$ Entropia $(4,5)+$ Homogeneidade $(4,5)$ & $L_{2}$ \\
\hline
\end{tabular}

Tabela 5.1: Associação de uma métrica a cada classe de imagem. 
Nos experimentos foi utilizado um Computador Desktop Athlon XP 3200+ (FSB 333MHz), $1 G b$ RAM DDR-400MHz (dual mode), HD Serial ATA, Motherboard Asus A $7 N 8 X$-deluxe.

Foram utilizados, como estudo de caso, os métodos de acesso Slim-tree e Sequencial Scan (busca sequencial) em um DMG, gerando assim as árvores G-Slim-tree e GSequencial Scan. Nos experimentos de performance, estas foram comparados aos Slim-tree e Sequencial Scan quando estes últimos consideram apenas uma característica aplicável ao conjunto todo (histograma de níveis de cinza). A idéia é mostrar que a GMAM G-Slimtree é mais eficiente que a MAM Slim-tree, e a GMAM G-Sequencial Scan é mais eficiente que a Sequencial Scan, e que as podas realizadas pelas árvores não provocam falsos negativos. A configuração das árvores é a padrão definida por seus autores e o tamanho da página no disco utilizado pelas estruturas foi de $32 \mathrm{~Kb}$. A biblioteca de MAM Arboretum foi utilizada para a realização de todos testes/implementações. Toda a documentação e o código da Arboretum pode ser encontrada em http://gbdi.icmc.usp.br/arboretum.

\subsection{Gráficos Precision and Recall}

Um gráfico Precision e Recall (PR), como visto na seção 3.4.1, é uma técnica de medição que mostra a precisão na recuperação dos dados por um dado método de acesso. Para os experimentos em questão, foram construídas para cada classe de imagens descritos, uma vez que cada classe de imagem está associada a diferentes métricas e a precisão alcançada pode variar de acordo com estas associações. O objetivo destes gráficos é mostrar que o conceito proposto neste trabalho funciona bem (recupera imagens com boa precisão) com diferentes associações de métricas, além de garantir que não existam falsos negativos, garantidos pela análise do gráfico PR gerado pela metodologia mostrada na seção 3.4.1.

Para a realização destes gráficos, é necessário definir, para cada consulta, o conjunto de imagens retornadas que é o conjunto resposta correto $C$. Como na hierarquia das imagens foi realizada uma classificação pré-definida, assumimos que a resposta ideal para uma dada consulta é aquela que retorna as imagens da mesma classe na hierarquia.

Para cada gráfico PR, foram realizadas várias consultas, o equivalente a $10 \%$ do conjunto total, sendo que $10 \%$ dos objetos de cada classe (Tabela 5.1) foram aleatoriamente escolhidos e inclusos como objetos centrais de consultas, para garantir que todos os tipos de objetos fossem testados. Cada gráfico resultante é a média aritmética de cada gráfico intermediário gerado para cada classe.

É importante dosar se um algoritmo muito discriminativo é o ideal para a aplicação. As vezes é interessante manter no resultado uma gama maior de objetos que são similares ao de consulta, mesmo que sejam de outras classes, pois estas podem estar relacionadas de alguma maneira. Assim, um algoritmo muito discriminativo pode ser bom quando se quer restringir uma consulta, e um algoritmo pouco discriminativo pode ser bom quando se deseja realizar uma consulta mais abrangente. 


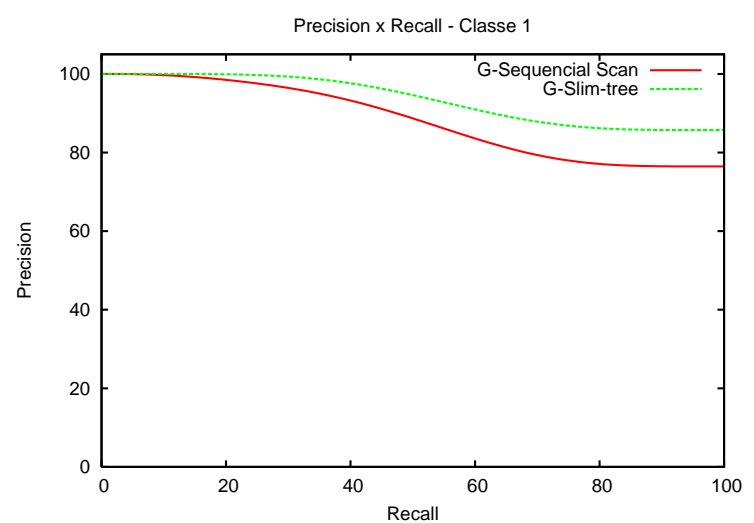

(a)

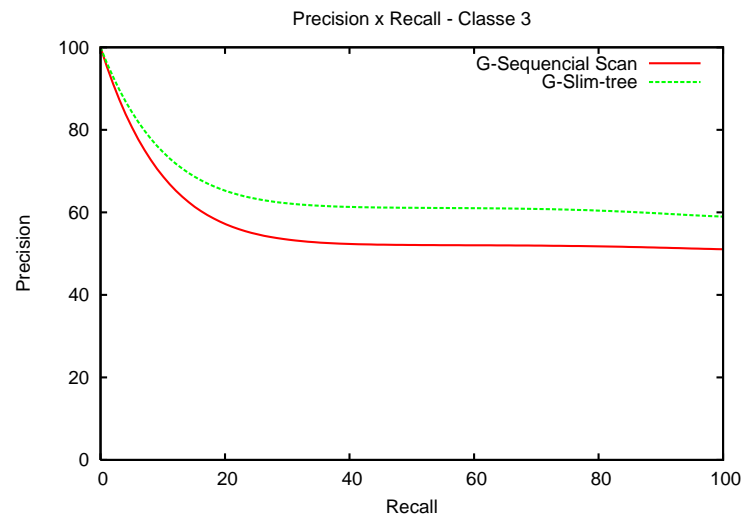

(c)

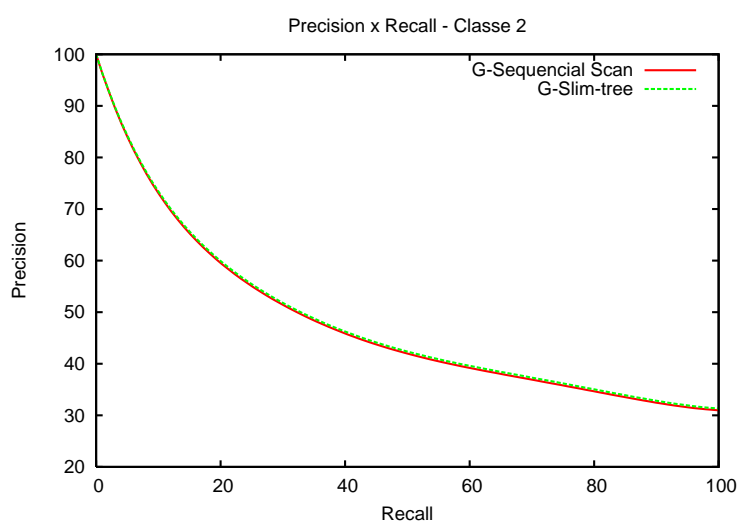

(b)

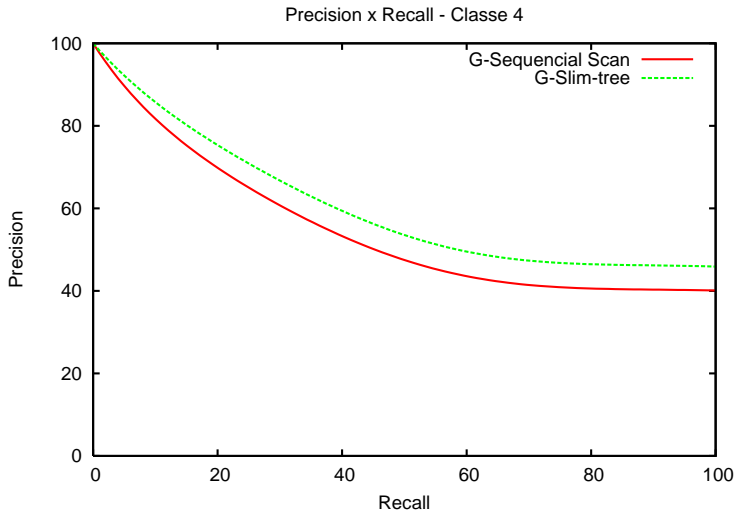

(d)

Figura 5.3: Gráficos Precision and Recall para as diferentes classes de imagens. 
A Figura 5.3 mostra os gráficos Precision and Recall construídos para os conjuntos de imagens descritos. Baseando-se na Tabela 5.1, pode-se notar como a função de distância escolhida pode influenciar na precisão. O gráfico 5.3(a) mostra uma recuperação bastante discriminativa, uma vez tendo usado $L_{1}$ (a mais restritiva das funções $L_{p}$ ), recuperando em sua maioria objetos da mesma classe do objeto de consulta. Os gráficos 5.3 (c) e 5.3 (d) mostraram um comportamento similar, tendo a função de distância escolhida $L_{2}$, o que levou a uma recuperação de discriminação média. O gráfico 5.3(b) mostra que a recuperação foi mais abrangente, uma vez que a função de distância escolhida é a mais ampla possível na família $L_{p}$, a $L_{\text {inf }}$.

Nota-se que em todos os gráficos, o MAM Slim-tree se mostrou mais eficiente que o MAM Sequencial Scan, reduzindo o número de falsos positivos no resultado das consultas. Este ganho comprova que as GMAM mantém seu comportamento ao indexar dados num Domínio Métrico Generalizável. Um outro fato que pode ser analisado nos gráficos da figura é a ausência de falsos negativos, uma vez que todos os gráficos atingiram recall de $100 \%$.

Assim, com os gráficos Precision and Recall mostramos que a performance do resultado das consultas é boa e as árvores quando em DMG retornam bons resultados. A próxima análise a ser feita é medir o desempenho das consultas, ou seja, o quão rápido elas o são e a escalabilidade das árvores quando aumenta-se o número de imagens indexadas.

\subsection{Medidas de Desempenho e Escalabilidade}

As medidas de desempenho mostram a performance dos MAM nas consultas. As medidas feitas consideraram o tempo de processamento, número de cálculos de distância realizados ou número de acessos a disco realizados. Para os experimentos, foram realizadas consultas por vizinhos mais próximos e por raio de cobertura. A quantidade de consultas é novamente proporcional a $10 \%$ do total de imagens indexadas e distribuiu-se as consultas sobre as 4 classes categorizadas na Tabela 5.1 .

Nos gráficos de RQ, o raio de cobertura varia entre 0 e 0.1 , retornando na marca 0.1 os objetos mais semelhantes em até $10 \%$ do objeto central de consulta. O raio de cobertura real utilizado para RQ é formado pelo raio porcentagem multiplicado por um fator de conversão. Este fator de conversão varia de um conjunto de dados para outro e pode ser calculado medindo-se a maior distância entre os elementos do conjunto.

A Figura 5.4 mostra os resultados obtidos para as consultas KNNQ e RQ realizadas.

No gráfico 5.4 (a) medimos o número médio de acessos a disco numa consulta do tipo KNNQ. Pode-se notar que a G-Sequencial Scan perde para a Sequencial Scan, isto já era esperado, pois o tamanho dos vetores de características nas GMAM é maior que nas MAM consideradas. Assim, as árvores GMAM têm mais nós que as MAM, portanto num acesso sequencial, todos estes adicionais serão acessados. Ainda nesta figura, temos que a G-Simtree ganha da Slim-tree convencional, pois as podas de subárvores foram condicionadas 


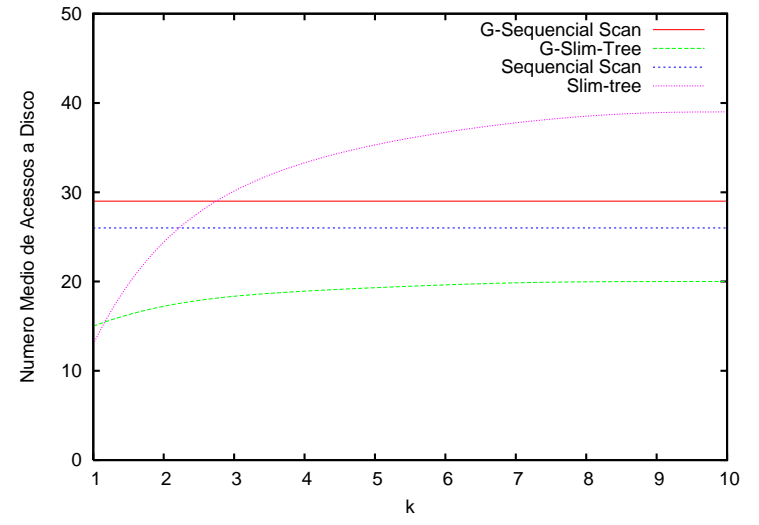

(a)

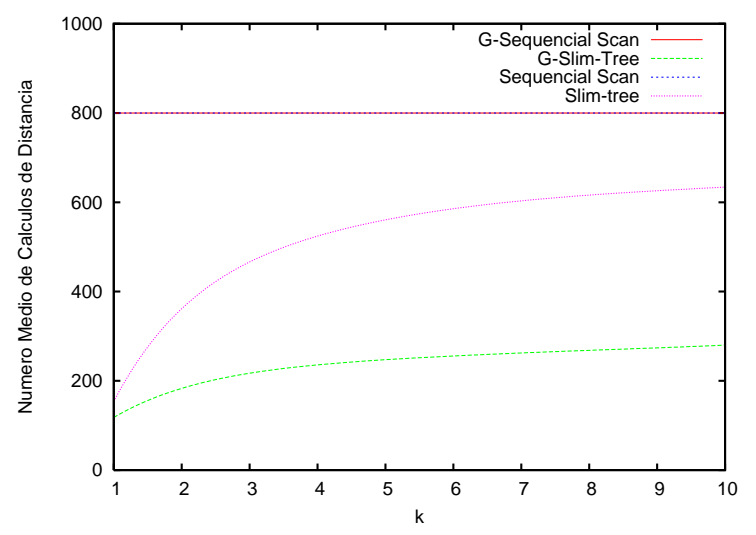

(c)

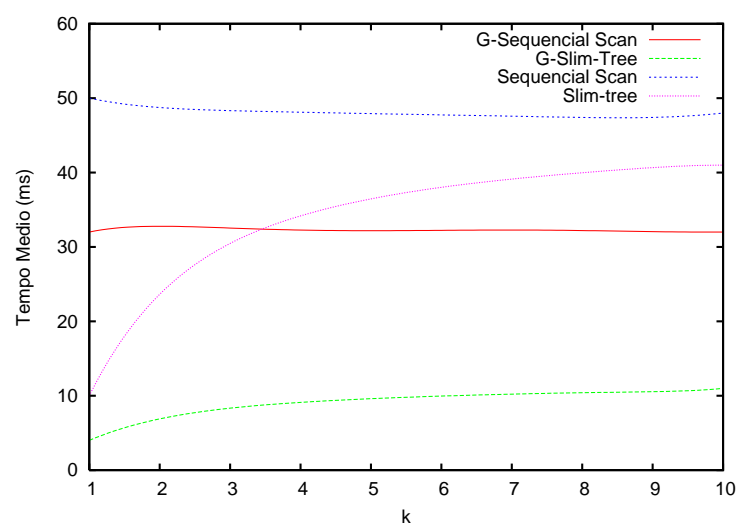

(e)

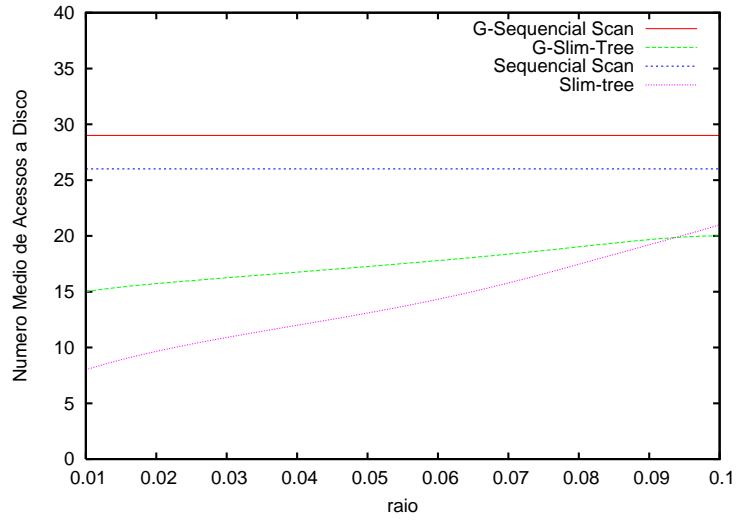

(b)

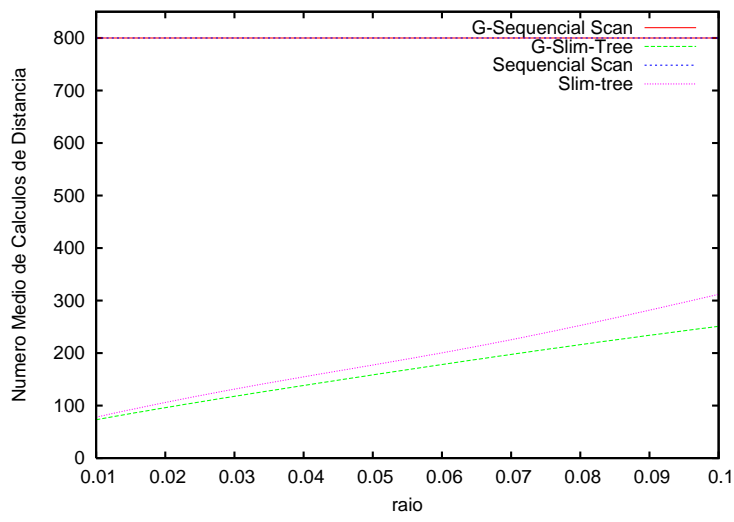

(d)

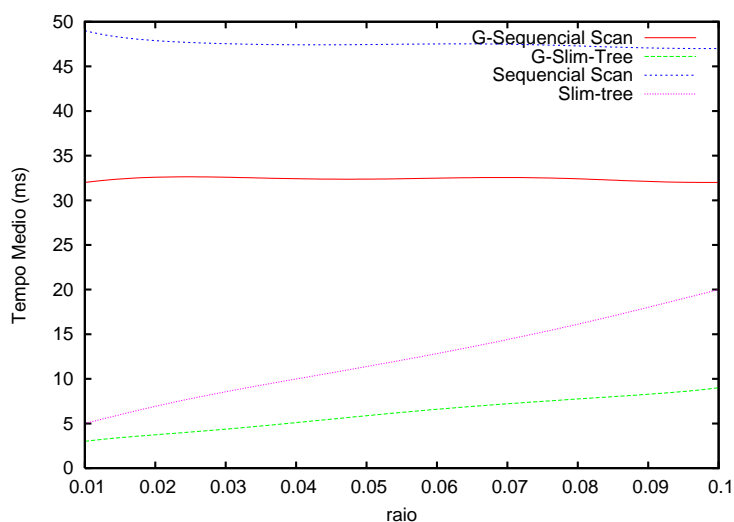

(f)

Figura 5.4: Gráficos de desempenho para consultas do tipo KNNQ(a,c,e) e RQ(b,d,f).

pelas características mais específicas dos objetos, causando uma maior restritividade.

No gráfico 5.4(b) medimos o número médio de acessos a disco numa consulta do tipo RQ. Aqui, temos que as GMAM perdem em acesso a disco para as MAM. A GSequencial Scan perde pelo mesmo motivo do tamanho do vetor de características citado anteriormente, já as podas da G-Slim-tree não conseguiu diminuir o número de acessos a disco feita pela Slim-tree.

Nos gráficos 5.4(c) e 5.4(d) medimos o número médio de cálculos de distância consulta 
do tipo KNNQ. Como esperado, as árvores G-Sequencial Scan e Sequencial Scan empatam, pois como o acesso é sequencial, todos elementos são comparados. A G-Slim-tree conseguiu ótimo desempenho em relação à Slim-tree em consultas do tipo KNNQ e um leve ganho em consultas do tipo RQ. Aqui, as podas pela maior restritividade das características possibilitou um melhor desempenho.

Os gráficos 5.4(e) e 5.4(f) mostram o tempo de consulta das árvores. Notamos que as árvores GMAM são mais rápidas que as MAM. A G-Slim-tree conseguiu realizar menos cálculos de distância que a Slim-tree, em alguns casos menos acessos a disco, influindo no tempo. Fatores diversos influenciam como: funções de distância diferentes nas GMAM, distribuição das distâncias diferentes entre G-Sequencial Scan e Sequencial Scan, pois a Sequencial Scan considera em sua resposta mais objetos que a G-Sequencial Scan, por causa da projeção detalhada na seção 4.3.1, que restringe menos a consulta.

A próxima etapa é analisar o desempenho das estruturas de maneira assintótica. O objetivo dos gráficos de escalabilidade é mostrar como as estruturas se comportam nas consultas a medida que a massa de dados cresce. Foram feitas consultas com vários objetos (10\% distribuídos entre as classes) e os gráficos mostrados são resultantes da média dos gráficos intermediários. Para as consultas do tipo RQ, foi utilizado raio 0.2 (recupera os objetos similares em até $20 \%$ ) e para as consultas do tipo KNNQ foi passado como parâmetro $k$ o valor 5 (cinco vizinhos mais próximos).

A Figura 5.5 mostra os gráficos de escalabilidade construídos pelos experimentos. Como idealizada, a os gráficos de escalabilidade mantiveram o comportamento dos gráficos de performance, só que agora o tamanho do conjunto indexado varia. Como esperado, o comportamento das GMAM G-Sequencial Scan e Sequencial Scan são lineares. Já o GMAM G-Slim-tree se mostra bem escalável, mantendo um comportamento sobrelinear, porém mais eficiente que a MAM Slim-tree em cálculos de distância, mas mantém sua ineficiência para acessos a disco em RQ.

\subsection{Conclusão}

Neste capítulo foi descrita a base de dados utilizada para os experimentos, assim como a etapa de extração de características para compor os vetores de características dos objetos pertencentes a cada classe de imagem.

Os experimentos realizados analisaram como a precisão das consultas é flexível ao usuário conforme escolhem-se as funções de distância para cada classe de imagem ou a cada consulta, em tempo de execução. Além disto, mostrou-se como a G-Slim-tree se mostrou mais precisa que a G-Sequencial Scan, diminuindo assim o número de falsos positivos retornados na mesma consulta.

Uma análise de desempenho mostrou que o comportamento das árvores em um DMG é bom, ou seja, a G-Slim-tree se mostrou mais eficiente quanto ao número de cálculos de distância que a Slim-tree, perdendo em acessos a disco em RQ, e a G-Sequencial Scan 


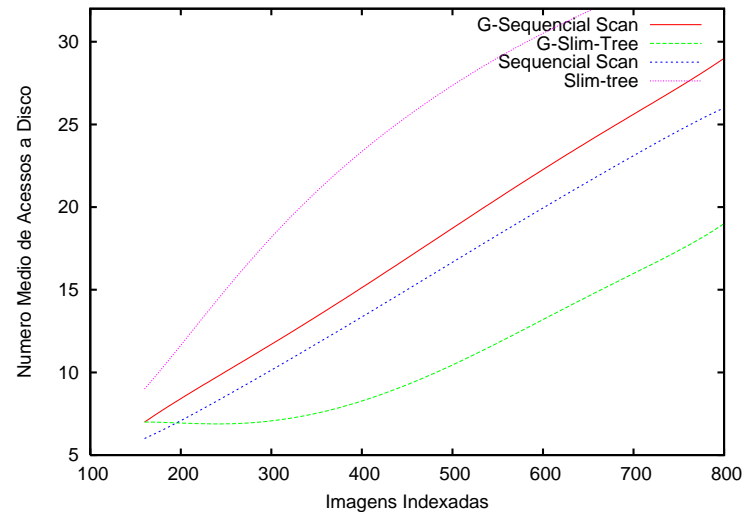

(a)

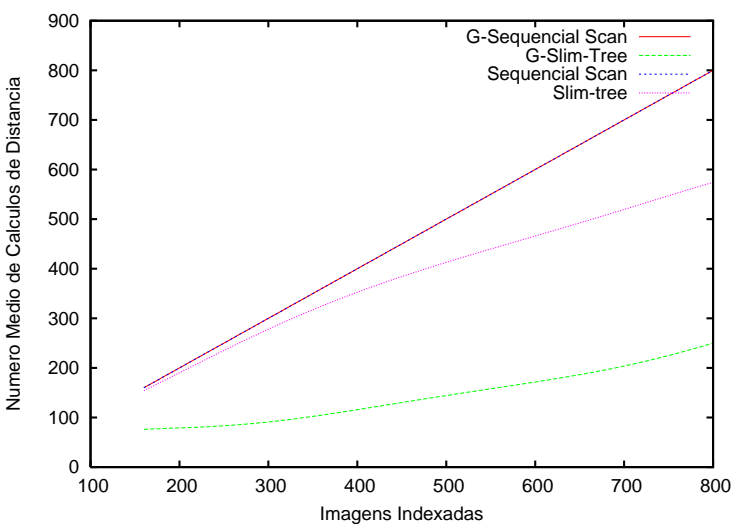

(c)

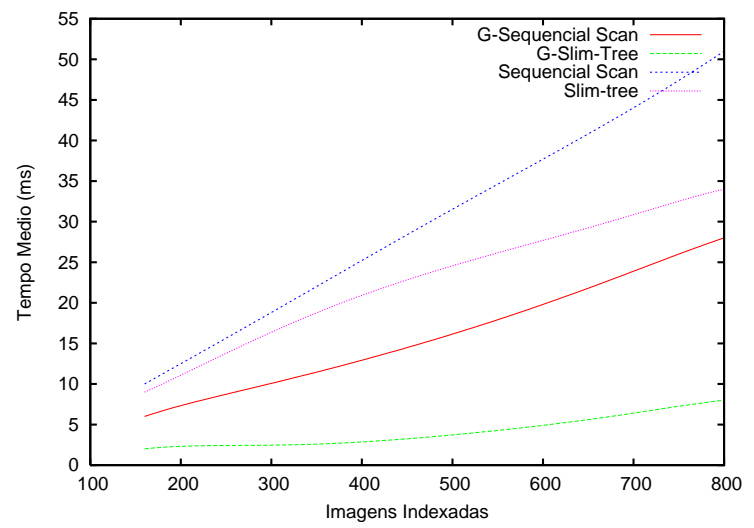

(e)

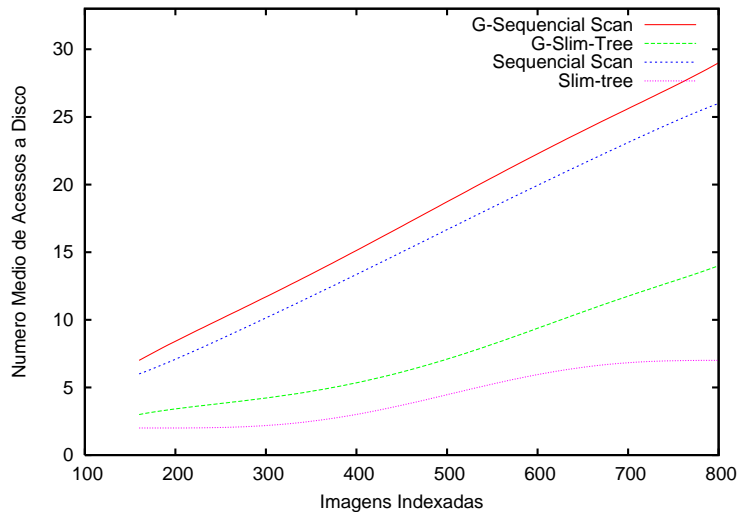

(b)

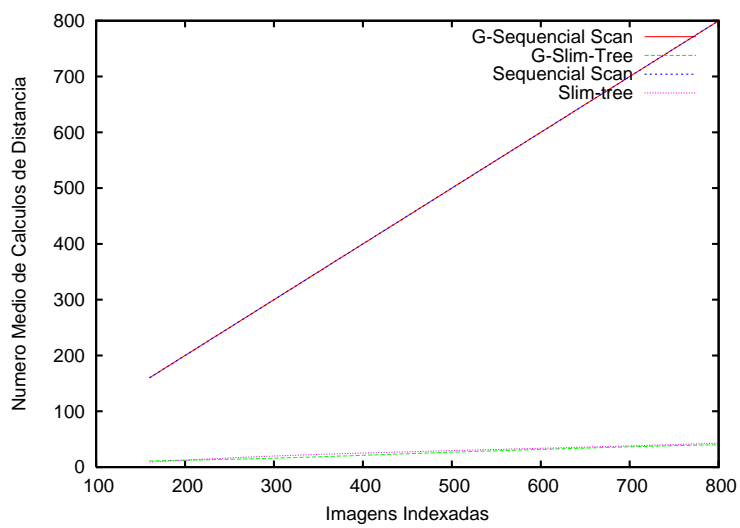

(d)

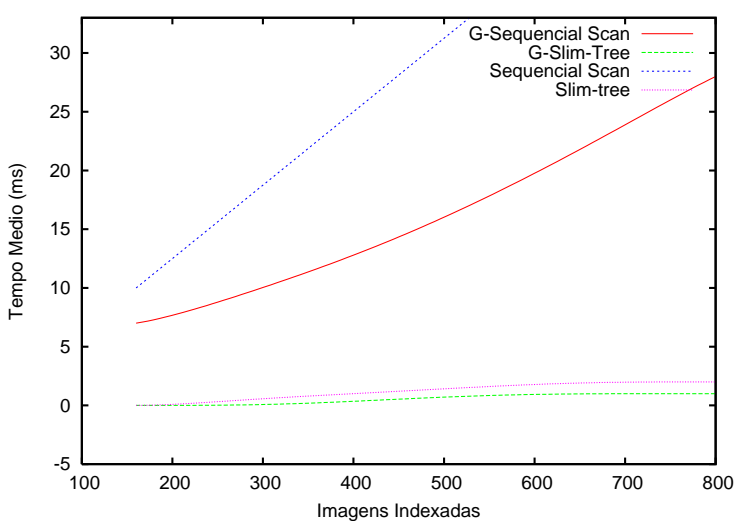

(f)

Figura 5.5: Gráficos de escalabilidade para consultas do tipo $\operatorname{KNNQ}(\mathrm{a}, \mathrm{c}, \mathrm{e})$ e RQ(b,d,f).

perdeu em alguns quesitos para a Sequencial Scan convencional, mas se mostra mais rápida pela melhor distribuição dos dados referente tamanho maior do vetor de características, mais restritivo que a projeção realizada ao utilizar-se a Sequencial Scan convencional.

Por fim foi feita uma análise sobre o impacto na escalabilidade das estruturas, causado pela inserção de diferentes tamanhos de conjuntos de dados e analisando-se o desempenho em cada tamanho de conjunto.

Assim, vê-se pelo que precede que os experimentos demonstram na prática os resul- 
tados idealizados a priori na teoria dos Domínios Métricos Generalizáveis, viabilizando o uso de MAM neste domínio, quando se faz necessário um tratamento especial para classes específicas de objetos dentro do conjuntos de dados armazenado. 


\section{Capítulo \\ 6}

\section{Conclusão}

Mais importante que resolver problemas específicos, é primordial que a solução encontrada para um dado problema seja genérica o suficiente para ser aplicada em outros problemas da área.

Este trabalho contribuiu com um conceito inédito na área de indexação de dados em espaços métricos, propondo um Domínio Métrico Generalizável, uma generalização do conceito de domínios métricos, onde mais de uma função de distância está definida, sendo que possivelmente nem todas elas sejam aplicáveis a todos os elementos do conjunto. Imagens neste domínio podem ser agrupadas hierarquicamente, e características específicas destas podem ser adicionadas em seu vetor de características, ainda que outras não as tenham. Assim, temos um único índice para objetos associados a diferentes funções de distâncias e diferentes vetores de características.

Ao acomodar características que sejam particulares a algumas classes de imagens, e não de todo o conjunto delas, permitiu reduzir o conjunto de características úteis de cada elemento do conjunto de dados individualmente, baseando-se nos valores obtidos para uma ou algumas poucas características a serem extraídas em primeiro lugar. A partir desses valores, pode-se então decidir quais outras características são importantes para esse elemento de dado em particular.

Com isso, tornou-se possível trabalhar com uma estrutura de dados concebida dentro dos conceitos de dados em domínios métricos, que admita o uso de uma função de distância adaptável, ou seja, que mude para determinados grupos de objetos, dependendo de algumas características universais. E, através dos resultados expostos no capítulo 5 , pode-se concluir que este trabalho cumpriu o objetivo proposto, flexibilizando consultas em nova maneira de indexar dados com diferentes MAM, agora num Domínio Métrico Generalizável.

A fase de testes mostrou que quando se indexa imagens neste domínio, a precisão das consultas é flexível de acordo com a escolha das funções de distância associadas a cada 
classe. Os experimentos feitos também demonstram o bom desempenho da estrutura Slim-tree sobre a Sequencial Scan, indexando imagens neste domínio.

\subsection{Propostas de Trabalhos Futuros}

Este trabalho teve em seu âmbito explorar propriedades aplicadas em espaços métricos para solucionar o problema de indexar de dados organizados numa hierarquia de tipos e subtipos.

Muitos outros problemas estão sendo atacados na literatura. Como é o caso de consultas complexas que podem envolver predicados onde as condições de seleção envolvem consultas por similaridade baseados em múltiplos objetos e múltiplas características [2]. Assim, é possível que o conteúdo deste trabalho possa dar suporte a estas consultas, uma vez que ele possui uma flexibilidade maior para indexar objetos com múltiplas características e múltiplas funções de distância.

Uma outra linha de pesquisa é estudar as propriedades já formuladas em teorias dos espaços métricos, e determinar se algumas delas podem ser utilizadas dentro da área de indexação de dados métricos. O uso destas propriedades pode aumentar a eficiência dos MAM já existentes ou podem viabilizar que novas aplicações possam utilizar MAM, limitadas em primeiro momento pelas poucas propriedades até então aplicadas. 


\section{Referências Bibliográficas}

[1] Charu C. Aggarwal. Re-designing distance functions and distance-based applications for high dimensional data. SIGMOD Record, 30(1):13-18, 2001. 3

[2] Adriano S. Arantes, Marcos R. Vieira, Jr. Traina, Caetano, and Agma Juci Machado Traina. Operadores de seleção por similaridade para sistemas de gerenciamento de bases de dados relacionais. In a ser publicado nos Anais do XVIII Simpósio Brasileiro de Banco de Dados, Manaus, Brasil, 2003. 48, 68

[3] C. Faloutsos B. U. Pagel, F. Korn. Deflating the dimensionality curse using multiple fractal dimensions. In 16th International Conference on Data Engineering - ICDE, pages 589-598, San Diego, CA, 2000. IEEE Computer Society. 3, 21

[4] Berthier Baeza-Yates, Ricardo / Ribeiro-Neto. Modern Information Retrieval. Pearson, 1999. 45

[5] Alberto Belussi and Christos Faloutsos. Estimating the selectivity of spatial queries using the 'correlation' fractal dimension. In Umeshwar Dayal, Peter M. D. Gray, and Shojiro Nishio, editors, Proc. 21st Int. Conf. Very Large Data Bases, VLDB, pages 299-310. Morgan Kaufmann, 11-15 1995. 41.

[6] S. Berchtold, C. Böhm, A. Keim, and H. P. Kriegel. A cost model for similarity queries in metric spaces. In ACM Symp. on Principles of Database Systems (PODS), pages 78-86, Tucson-AZ, 1997. ACM Press. 39

[7] Stefan Berchtold, Daniel A. Keim, and Hans-Peter Kriegel. The x-tree: An index structure for high-dimensional data. In Intl. Conf. on Very Large Databases (VLDB), pages 28-39, Bombay, India, 1996. 3

[8] Kevin S. Beyer, Jonathan Goldstein, Raghu Ramakrishnan, and Uri Shaft. When is "nearest neighbor" meaningful? In ICDT '99: Proceeding of the 7th International Conference on Database Theory, pages 217-235. Springer-Verlag, 1999. 48

[9] Mauro Biajiz and Caetano Traina Jr. Representação de modelos de dados orientados a objetos através de parametrizações de abstrações. PhD thesis, IFSC - USP, September 1996. 9 
[10] I. Biederman. Recognition-by-components: a theory of human image understanding. Psychological Review, 94(2):115-147, 1987. 23

[11] Alberto Del Bimbo. Visual Information Retrieval. Morgan Kaufmann, San Francisco, Califórnia, 1999. 16

[12] Tolga Bozkaya and Meral Ozsoyoglu. Distance-based indexing for high-dimensional metric spaces. In SIGMOD '97: Proceedings of the 1997 ACM SIGMOD international conference on Management of data, pages 357-368. ACM Press, 1997. 28

[13] Tolga Bozkaya and Meral Ozsoyoglu. Indexing large metric spaces for similarity search queries. ACM Transactions on Database Systems, 24(3):361-404, 1999. 28

[14] E. Bugnion, S. Fei, T. Roos, P. Widmayer, and F. Widmer. A spatial index for approximate multiple string matching. In First South American Workshop on String Processing, pages 43-53, Belo Horizonte, Brazil, 1993. 26

[15] W. A. Burkhard and R. M. Keller. Some approaches to best-match file searching. Communications of the ACM, 16(4):230-236, 1973. 18, 24

[16] Jr. C. Traina, A. Traina, C. Faloutsos, and B. Seeger. Fast indexing and visualization of metric data sets using slim-trees. IEEE Transactions on Knowledge and Data Engineering, 14(2):244-260, 2002. 36, 41

[17] Camilo Yamauchi Campo and Agma Juci Machado Traina. Uma abordagem eficiente para recuperação de imagens médicas. In Káthia Marçal de Oliveira and Álvaro Rabelo Jr., editors, $3^{\circ}$ Workshop de Informática Médica - WIM'2003 - in CD-ROM, pages in CD-ROM, Fortaleza, CE, 2003. 20

[18] Chad Carson, Serge Belongie, Hayit Greenspan, and Jitendra Malik. Region-based image querying. In Proceedings of IEEE Workshop on Content-Based Access of Image and Video Libraries, pages 42-49, San Juan, Puerto Rico, 1997. 20

[19] Chad Carson and Virginia E. Ogle. Storage and retrieval of feature data for a very large online image collection. Bulletin of the Technical Committee on Data Engineering, 19(4), 1996. 49

[20] Guang-Ho Cha. Bitmap indexing method for complex similarity queries with relevance feedback. In $M M D B$ '03: Proceedings of the 1st ACM international workshop on Multimedia databases, pages 55-62. ACM Press, 2003. 52, 54

[21] Kaushik Chakrabarti and Sharad Mehrotra. The hybrid tree: An index structure for high dimensional feature spaces. In Proceedings of the 15th International Conference on Data Engineering, 23-26 March 1999, Sydney, Austrialia, pages 440-447. IEEE Computer Society, 1999. 3 
[22] Kaushik Chakrabarti and Sharad Mehrotra. Local dimensionality reduction: A new approach to indexing high dimensional spaces. In Amr El Abbadi, Michael L. Brodie, Sharma Chakravarthy, Umeshwar Dayal, Nabil Kamel, Gunter Schlageter, and KyuYoung Whang, editors, VLDB 2000, Proceedings of 26th International Conference on Very Large Data Bases, September 10-14, 2000, Cairo, Egypt, pages 89-100. Morgan Kaufmann, 2000. 3

[23] Ada Wai chee Fu, Polly Mei shuen Chan, Yin-Ling Cheung, and Yiu Sang Moon. Dynamic vp-tree indexing for n-nearest neighbor search given pair-wise distances. The VLDB Journal, 9(2):154-173, 2000. 28

[24] Tzi-cker Chiueh. Content-Based Image Indexing. In Proceedings of the Twentieth International Conference on Very Large Databases, pages 582-593, Santiago, Chile, 1994. 14

[25] Edgar Chávez, Gonzalo Navarro, Ricardo A. Baeza-Yates, and José Luis Marroquín. Searching in metric spaces. ACM Computing Surveys, 33(3):273-321, 2001. 24

[26] Paolo Ciaccia and Marco Patella. The m2-tree: Processing complex multi-feature queries with just one index. In DELOS Workshop: Information Seeking, Searching and Querying in Digital Libraries, 2000. 52, 54

[27] Paolo Ciaccia and Marco Patella. Searching in metric spaces with user-defined and approximate distances. ACM Trans. Database Syst., 27(4):398-437, 2002. 53, 54

[28] Paolo Ciaccia, Marco Patella, and Pavel Zezula. M-tree: An efficient access method for similarity search in metric spaces. In Matthias Jarke, editor, Intl. Conf. on Very Large Databases (VLDB), pages 426-435, Athens, Greece, 1997. iii, 33, 34, 35

[29] Douglas Comer. Ubiquitous b-tree. ACM Comput. Surv., 11(2):121-137, 1979. 1

[30] Christos Faloutsos. Searching Multimedia Databases by Content. Kluwer Academic Publishers, Boston, MA, 1996. 8, 14

[31] Christos Faloutsos. Indexing of multimedia data. In Multimedia Databases in Perspective, pages 219-245. Springer Verlag, 1997. 14

[32] Christos Faloutsos, Ron Barber, Myron Flickner, Jim Hafner, Wayne Niblack, Dragutin Petkovic, and William Equitz. Efficient and effective querying by image content. Journal of Intelligent Information Systems, 3(3/4):231-262, 1994. 14

[33] J. C. Felipe, A. J. M. Traina, and C. Traina Jr. Retrieval by content of medical images using texture for tissue identification. In 16th IEEE Symposium on Computer-Based Medical Systems (CBMS'03), pages 175-180. IEEE Computer Society, 2003. 22 
[34] Joaquim C. Felipe and Agma J. M. Traina. Warp metric distance: Aprimorando o uso de histogramas de intensidade para busca por similaridade em imagens médicas. In X Congresso Brasileiro de Informática em Saúde- CBIS'2004, Ribeirão Preto, SP-Brazil, 2004. 15

[35] Dagan Feng, Weidong Cai, Jinman Kim, and Yu Suk Lim. Medical image data retrieval and manipulation through the WWW. In Intl. Symposium on Intelligent Multimedia, Video and Speech Processing, pages 381 -384. IEEE Society, 2001. 48

[36] Volker Gaede and Oliver Günther. Multidimensional access methods. ACM Computing Surveys, 30(2):170-231, 1998. 3

[37] Larissa Pinca Sarro Gomes and Caetano Traina Jr. Método para projeto de aplicativos centrados em bdoo utilizando abstração de generalização. MSc Diss., ICMC USP, August 1999. 9

[38] Ulrich Guntzer, Wolf-Tilo Balke, and Werner Kiesling. Optimizing multi-feature queries for image databases. In The VLDB Journal, pages 419-428, 2000. 49

[39] A. Guttman. R-tree : A dynamic index structure for spatial searching. In $A C M$ Int'l Conference on Data Management (SIGMOD), pages 47-57, Boston, MA, 1984. ACM PRess. 3

[40] J. Hafner, H. S. Sawhney, W. Equitz, M. Flickner, and W. Niblack. Efficient color histogram indexing for quadratic form distance functions. IEEE Transactions on Pattern Analysis and Machine Intelligence, 17(7):729-736, 1995. 10

[41] Robert M. Haralick, K. Shanmugam, and Its'Hak Dinstein. Textural features for image classification. IEEE Transactions on Systems, Man, and Cybernetics, 3(6):610621, November 1973. 22, 59

[42] Alexander Hinneburg and Daniel A. Keim. Optimal grid-clustering: Towards breaking the curse of dimensionality in high-dimensional clustering. In Malcolm P. Atkinson, Maria E. Orlowska, Patrick Valduriez, Stanley B. Zdonik, and Michael L. Brodie, editors, VLDB'99, Proceedings of 25th International Conference on Very Large Data Bases, September 7-10, 1999, Edinburgh, Scotland, UK, pages 506-517. Morgan Kaufmann, 1999. 21

[43] E. Hunt, M. P. Atkinson, and R. W. Irving. A database index to large biological sequences. In Peter M. G. Apers, Paolo Atzeni, Stefano Ceri, Stefano Paraboschi, Kotagiri Ramamohanarao, and Richard T. Snodgrass, editors, 27th International Conference on Very Large Data Bases, pages 139-148, Roma, Italy, 2001. Morgan Kaufmann. 14 
[44] M.A. Belmonte J. M. Sotoca, J. M. Iñesta. Hand bone segmentation in radioabsorptiometry images for computerised bone mass assessment. Computerized Medical Imaging and Graphics, 27:459-467, 2003. 49

[45] Caetano Traina Jr., Josiel M. Figueiredo, and Agma J. M. Traina. Image domain formalization for content-based image retrieval. In Proceedings of the 20th Annual ACM Symposium on Applied Computing (SAC), Santa Fe, New Mexico, USA, March 13-17 2005. 50

[46] Caetano Traina Jr., Agma J. M. Traina, and Christos Faloutsos. Distance exponent: A new concept for selectivity estimation in metric trees. In International Conference on Data Engineering - ICDE, page 195, San Diego - CA, 2000. IEEE Computer Society. 41

[47] Tamer Kahveci and Ambuj K. Singh. Efficient index structures for string databases. In The VLDB Journal, pages 351-360, 2001. 11, 14

[48] Lance M. Kaplan, Romain Murenzi, and Kameswara R. Namuduri. Fast fractal feature extraction for texture segmentation using wavelets. In I. K. Sethi and R. C. Jain, editors, Storage and Retrieval for Image and Video Databases VI, pages 162173, 1998. 21

[49] Norio Katayama and Shin'ichi Satoh. The sr-tree: an index structure for highdimensional nearest neighbor queries. In SIGMOD '97: Proceedings of the 1997 ACM SIGMOD international conference on Management of data, pages 369-380. ACM Press, 1997. 3

[50] E. Keogh. Exact indexing of dynamic time warping, 2002. 15

[51] Eamonn Keogh, Kaushik Chakrabarti, Michael Pazzani, and Sharad Mehrotra. Dimensionality reduction for fast similarity search in large time series databases. Knowledge and Information Systems, 3(3):263-286, Aug 2001. 3, 15

[52] Flip Korn, Bernd-Uwe Pagel, and Christos Faloutsos. On the 'dimensionality curse' and the 'self-similarity blessing'. IEEE Transactions on Knowledge and Data Engineering, 13(1):96-111, 2001. Elaine Josiel. 3

[53] J. B. Kruskal, jr. On the shortest spanning subtree of a graph and the traveling salesman problem. In Proc. Amer. Math. Soc., volume 7, pages 48-50, 1956. 38

[54] G. R. Thoma L. R. Long, S. K. Antani. A prototype content-based image retrieval system for spine x-rays. In 16th IEEE Symposium on Computer-Based Medical Systems (CBMS'03), pages 156-162. IEEE Computer Society, 2003. 24 
[55] Thomas M. Lehmann, Berthold Wein, Daniel Keysers, Jörg Bredno, Mark Oliver Güld, Henning Schubert, and Michael Kohnen. Image retrieval in medical applications - the irma-approach, 2001. 48

[56] V. I. Levenshtein. Binary codes capable of correcting deletions, insertions, and reversals. Cybernetics and Control Theory, 10(8):707-710, 1966. 10

[57] Dennis M. Levi and Stanley A. Klein. Seeing circles: what limits shape perception? Vision Research, 40(17):2329-2339, August 2000. 23

[58] Yoo National Library. Toward validation databases for medical imaging: Engineering a scientific rendezvous, 2001. 48

[59] King-Ip Lin, H. V. Jagadish, and Christos Faloutsos. The tv-tree: An index structure for high-dimensional data. $V L D B$ J., 3(4):517-542, 1994. 3

[60] Gunter Loffler, Hugh R. Wilson, and Frances Wilkinson. Local and global contributions to shape discrimination. Vision Research, 43(5):519-530, March 2003. 23

[61] B. S. Manjunath and W. Y. Ma. Texture features for browsing and retrieval of large image data. IEEE Transactions on Pattern Analysis and Machine Intelligence, 18(8):837-842, 1996. 21

[62] Apostol Natsev, Rajeev Rastogi, and Kyuseok Shim. Walrus: A similarity retrieval algorithm for image databases. IEEE Transactions on Knowledge and Data Engineering, 16(3):301-316, 2004. 48

[63] N. Papamarkos, A. Atsalakis, and C. Strouthopoulos. Adaptive color reduction, 2002. 3

[64] Mira Park, Jesse S. Jin, and Laurence S. Wilson. Fast content-based image retrieval using quasi-gabor filter and reduction of image feature dimension. In SSIAI '02: Proceedings of the Fifth IEEE Southwest Symposium on Image Analysis and Interpretation, page 178. IEEE Computer Society, 2002. 3

[65] M. Patella. Similarity Search in Multimedia Databases. PhD thesis, Università a degli Studi di Bologna, Italy, 1999. 14

[66] C. R. Prim. Shortest connection matrix network and some generalizations. Bell System Technical Journal, 36:1389-1401, 1957. 38

[67] Seppo Puuronen, Alexey Tsymbal, and Iryna Skrypnyk. Advanced local feature selection in medical diagnostics. In CBMS '00: Proceedings of the 13th IEEE Symposium on Computer-Based Medical Systems (CBMS'00), pages 25-30. IEEE Computer Society, 2000. 48 
[68] Gang Qian, Shamik Sural, Yuelong Gu, and Sakti Pramanik. Similarity between euclidean and cosine angle distance for nearest neighbor queries. In Proceedings of the 2004 ACM symposium on Applied computing, pages 1232-1237. ACM Press, 2004. 52

[69] Todd R. Reed and J. M. Hans Du Buf. A review of recent texture segmentation and feature extraction techniques. Image Understanding, 57(3):359-372, 1993. 21,22

[70] Filho Santos, Roberto Figueira, Agma Juci Machado Traina, Jr. Traina, Caetano, and Christos Faloutsos. Similarity search without tears: The OMNI family of allpurpose access methods. In Intl. Conf. on Data Engineering (ICDE), pages 623-630, Heidelberg, Germany, 2001. IEEE Computer Society. 41, 42

[71] Timos K. Sellis, Nick Roussopoulos, and Christos Faloutsos. The r+-tree: A dynamic index for multi-dimensional objects. In Intl. Conf. on Very Large Databases (VLDB), pages 507-518, Brighton, England, 1987. Morgan Kaufmann. 3

[72] D. Shasha and T. L. Wang. New techniques for best-match retrieval. ACM Transactions on Information Systems (TOIS), 8(2):140-158, 1990. 25

[73] M. Stricker and M. Orengo. Similarity of color images. In W. R. Niblack and R. C. Jain, editors, Storage and Retrieval for Image and Video Databases III, Proc SPIE 2420), pages 381-392, 1995. 20

[74] Mee Young Sung, Moon Suck Kim, Myung-Whun Sung, Eom Joon Kim, and Jae Hong Yoo. Comed: A real-time collaborative medicine system. In CBMS '00: Proceedings of the 13th IEEE Symposium on Computer-Based Medical Systems (CBMS'00), page 215. IEEE Computer Society, 2000. 48

[75] M. J. Swain and D. H. Ballard. Color indexing. IJCV: International Journal of Computer Vision, 7(2):11-32, 1991. 20

[76] Agma J. M. Traina and Caetano Traina Jr. Similarity search in multimedia databases. Handbook of Video Databases - Design and Applications, 1:711-738, 2003. 2

[77] Agma Juci Machado Traina, Jr. Traina, Caetano, Josiane Maria Bueno, Fábio Jun Takada Chino, and Paulo M. de Azevedo-Marques. Efficient content-based image retrieval through metric histograms. World Wide Web Journal, Kluwer Academic Publishing Co., 6(2):157-185, 2003. 20

[78] Agma Juci Machado Traina, Jr. Traina, Caetano, Josiane Maria Bueno, and Paulo Mazzoncini de Azevedo Marques. The metric histogram: A new and efficient approach for content-based image retrieval. In Xiaofang Zhou and Pearl Pu, editors, Sixth IFIP Working Conference on Visual Database Systems, volume 216 of IFIP Conference Proceedings, pages 297-311, Brisbane, Australia, 2002. Kluwer Academic Publishers. 20 
[79] Jr. Traina, Caetano, Agma Juci Machado Traina, Christos Faloutsos, and Bernhard Seeger. Fast indexing and visualization of metric datasets using slim-trees. IEEE Transactions on Knowledge and Data Engineering, 14(2):244-260, 2002. 44

[80] Jr. Traina, Caetano, Agma Juci Machado Traina, Bernhard Seeger, and Christos Faloutsos. Slim-trees: High performance metric trees minimizing overlap between nodes. In Carlo Zaniolo, Peter C. Lockemann, Marc H. Scholl, and Torsten Grust, editors, Intl. Conf. on Extending Database Technology, volume 1777 of Lecture Notes in Computer Science, pages 51-65, Konstanz, Germany, 2000. Springer. 36

[81] Jeffrey K. Uhlmann. Satisfying general proximity/similarity queries with metric trees. Information Processing Letter, 40(4):175-179, 1991. 17, 25, 27, 35

[82] Aditya Vailaya, Mário A. T. Figueiredo, Anil K. Jain, and Hong-Jiang Zhang. Image classification for content-based indexing. IEEE Transactions on Image Processing, 10(1):117-30, 2001. 3

[83] Bram van Ginneken. Towards a clinical chest workstation, 2001. 48

[84] D. Randall Wilson and Tony R. Martinez. Improved heterogeneous distance functions. Journal of Artificial Intelligence Research, 6:1-34, 1997. 11

[85] Peter N. Yianilos. Data structures and algorithms for nearest neighbor search in general metric spaces. In Fourth Annual ACM/SIGACT-SIAM Symposium on Discrete Algorithms - SODA, pages 311-321, Austin, TX, 1993. 27, 28

[86] Atsuo Yoshitaka and Tadao Ichikawa. A survey on content-based retrieval for multimedia databases. IEEE Transactions on Knowledge and Data Engineering, 11(1):8193, 1999. 48

[87] D. Zhang. Image Retrieval Based on Shape. PhD thesis, Monash University, March 2002. 16

[88] Tatjana Zrimec. A medical image information system. In Arnold W. M. Smeulders and Sennay Ghebreab, editors, VISIM Workshop: Information Retrieval and Exploration in Large Collections of Medical Images, page 5, Utrecht, Netherland, 2001. 48 